

\section{DISCLAIMER}

This report was prepared as an account of work sponsored by an agency of the United States Government. Neither the United States Government nor any agency Thereof, nor any of their employees, makes any warranty, express or implied, or assumes any legal liability or responsibility for the accuracy, completeness, or usefulness of any information, apparatus, product, or process disclosed, or represents that its use would not infringe privately owned rights. Reference herein to any specific commercial product, process, or service by trade name, trademark, manufacturer, or otherwise does not necessarily constitute or imply its endorsement, recommendation, or favoring by the United States Government or any agency thereof. The views and opinions of authors expressed herein do not necessarily state or reflect those of the United States Government or any agency thereof. 


\section{DISCLAIMER}

Portions of this document may be illegible in electronic image products. Images are produced from the best available original document. 


\section{Printed in the United States of America. Available from National Technical Information Service \\ U.S. Department of Commerce 5285 Port Royal Road, Springfield, Virginia 22161 NTIS price codes-Printed Copy: A07 Microfiche A01}

This report was prepared as an account of work sponsored by an agency of the United States Government. Neither the United States Government nor any agency thereof, nor any of their employees, makes any warranty, express or implied, or assumes any legal liability or responsibility for the accuracy, completeness, or usefulness of any information, apparatus, product, or process disclosed, or represents that its use would not infringe privately owned rights. Reference herein to any specific commercial product, process, or service by trade name, trademark, manufacturer, or otherwise, does not necessarily constitute or imply its endorsement, recommendation, or favoring by the United States Government or any agency thereof. The views and opinions of authors expressed herein do not necessarily state or reflect those of the United States Government or any agency thereof. 
ORNL/TM-7078

Contract No. W-7405-eng-26

Energy Division

REVIEW OF LEGAL AND INSTITUTIONAL ISSUES IN THE USE OF DECENTRALIZED SOLAR ENERGY SYSTEMS

Martin Schweitzer

Date Published: April 1980

OAK RIDGE NATIONAL LABORATORY

Oak Ridge, Tennessee 37830

operated by

UNION CARBIDE CORPORATION

for the

DEPARTMENT OF ENERGY 
THIS PAGE

\section{WAS INTENTIONALLY LEFT BLANK}


CONTENTS

Page

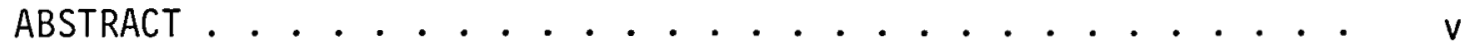

ACKNOWLEDGEMENTS ............................... vii

1. INTRODUCTION .......................... 1

1.1 Purpose of This Study ........... 3

1.2 Research Methodology ........... 3

1.3 Major Issues ............... . . . 4

1.3.1 Prohibitions on the use of solar equipment ............ . . 4

1.3.2 Regulation of production and placement of solar equipment .......... 5

1.3 .3 Access to sunlight ........... 8

1.3.4 Financial incentives and impediments to the use of solar technologies ........ 11

1.3.5 Public utility-solar user interface..... 13

1.4 Plan of the Report ............. 14

2. PROHIBITIONS ON THE USE OF SOLAR TECHNOLOGIES ..... 16

2.1 Public Statutes .............. 16

2.1 .1 Zoning ............. 16

2.1 .2 Aesthetic controls ........... . 20

2.1 .3 Building codes ............. 21

2.2 Private Agreements . . . . . . . . . . 23

3. REGULATION OF PRODUCTION AND PLACEMENT OF SOLAR

EQUIPMENT . . . . . . . . . . . . . . 25

3.1 Warranties and Consumer Protection....... 25

3.2 Solar Standards and Codes ............ 26

3.3 Licensing of Solar Installers . . . . . . . . 28

3.4 Union Involvement ............. 30

3.5 Mandatory Installation........... 31

3.6 Competition in the Solar Industry ....... 33

3.7 Liability of Manufacturer's, Retailers, and

Installers.................. 34

3.8 Patents and Licenses . . . . . . . . . . 35

4. ACCESS TO SUNLIGHT . . . . . . . . . . . . 37

4.1 Concept of "Sun Rights" . . . . . . . . . . . . 40

4.1.1 Analogy with western water law ...... 41

4.1 .2 Solar access permits .......... 42

4.1 .3 Solar access "recordation" ......... 42

4.1 .4 Nuisance law approach .......... 43

4.1 .5 Trespass law approach ......... 43 
4.2 Assuring Solar Access Through Established Land Use Controls . . . . . . . . . . . 44 4.2 .1 Zoning ................ 46 4.2.2 Subdivision regulations ......... 51 4.2.3 Vegetation controls ......... 56

4.3 Other Legal Devices for Protecting Solar Access . . . 59

4.3.1 Solar access easements ......... 60

4.3.2 Restrictive covenants . . . . . . . . . 63

4.3.3 Transfer of development rights ...... 64

4.3.4 Zoning by special-assessment-financed eminent doma in .......... . 65

4.3.5 Site plan review ........... . 65

4.3.6 Environmental impact assessments . . . . . 66

5. FINANCIAL INCENTIVES AND IMPEDIMENTS TO THE USE OF SOLAR TECHNOLOGIES ..................... 68

5.1 Taxation ................ 68

5.1.1 Property tax ............. 68

5.1 .2 Sales and use taxes .......... 70

5.1 .3 Income $\operatorname{tax} . . . . . . . .771$

5.2 Lending Policies and Interest Rates ....... 73

5.2.1 Solar lending policies ........ . 73

5.2 .2 Interest rates on solar loans . . . . . . 79

5.3 Pricing of Competing Fuels........... . 80

5.4 Government Procurement Policies ..... . . . . 81

5.5 Insuring Against System Damage and Owner Liability ........... . . . 82

6. THE PUBLIC UTILITY-SOLAR USER INTERFACE . . . . . . . 84

6.1 Utility Rates .............. 84

6.1.1 Rate schedules that discourage solar use ... 85

6.1.2 Rate schedules that encourage solar use ... . 86

6.2 Utility Service Policies............. 99

6.3 Utility "Buy-Back" of Solar-Generated

Electricity .............. . 91

6.4 Provision of Solar Equipment by Utilities . . . . . 9?

7. SUMMARY AND DISCUSSION OF IMPLEMENTATION OPTIONS $\ldots . .97$

7.1 Major Issues Revisited . . . . . . . . . . . . . 97

7.2 Major Actors . . . . . . . . . . . . . . . 99

7.3 Implementation Options for Government.s Sepking to
Further Solar Commercialization . . . . . 99

7.3.1 Local government ................ 100

7.3 .2 State government ......... 101

7.3 .3 Federa1 government ......... 104

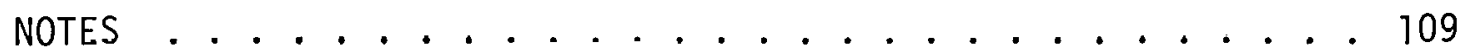

BIBLIOGRAPHY . . . . . . . . . . . . 127 


\title{
REVIEW OF LEGAL AND INSTITUTIONAL ISSUES IN THE USE OF DECENTRALIZED SOLAR ENERGY SYSTEMS
}

\author{
Martin Schweitzer
}

\begin{abstract}
This report examines the legal and institutional issues involved in the use of decentralized solar energy systems for the purpose of advising government planners and policymakers, the solar industry, solar researchers, and prospective solar users of present and potential impediments and incentives to solar commercialization. This information was gathered primarily through a comprehensive literature review, with supplementary data provided through interviews with representatives of organizations active in the solar field.

Five major issue areas were identified in the course of this study: (1) prohibitions on the use of solar equipment, (2) regulation of the production and placement of solar systems, (3) access to sunlight, (4) financial incentives and impediments to the use of solar technologies, and (5) the public utility-solar user interface. Each can be important in its impacts on the incidence of solar usage.

The major actors involved with the issues identified above represent both the private and public sectors. Important private sector participants include solar manufacturers and installers, labor unions, lending institutions, utility companies, solar users themselves, and other community property owners. In the public sector, local, state, and federal governments are all capable of acting in ways that can influence the sular commercialization effort.

Implementation options are available for all levels of government seeking to take an active role in addressing the previously mentioned legal and institutional issues. The appropriate actions will vary from federal to state to local governments, but each level can be important in removing existing barriers and creating new incentives for solar use.
\end{abstract}




\section{THIS PAGE}

\section{WAS INTENTIONALLY LEFT BLANK}




\section{ACKNOWLEDGEMENTS}

The author wishes to thank the following persons for their special contributions. Ben Bronfman and Jesse Tatum, both colleagues at Oak Ridge National Laboratory, offered guidance in the selection of materials reviewed during this study as did Peter Pollock and Barbara Euser of the Solar Energy Research Institute. The information available through the existing literature was supplemented by interviews with a number of individuals involved in the solar energy field who graciously shared their knowledge with the author. Invaluable assistance, both in locating and compiling printed materials and in interviewing primary sources, was provided by Elaine Llewellyn here at ORNL. Within the Laboratory, review and commentary on the draft report were provided by Jesse Tatum, Marc Strohlein, Ben Bronfman, Linda Berry, Elizabeth Peelle, Lois Martin, Sam Carnes, and Carey Rosemarin. Outside reviewers included Clara Miller, who helped conduct a community-based solar technology assessment in the Southern Tier Central Region of New York State; Janet Patton, who is active in a similar venture in Richmond, Kentucky; and the members of the review team engaged in reviewing ORNL's entire Decentralized Solar. Energy Technology Assessment Program. Finally, special thanks are due Ruth Friar, who typed the manuscript and provided ongoing support and encouragement, and to Lynn Elrod, who moved everything along to publication. 


\section{INTRODUCTION}

Man's use of solar energy is not a new phenomenon. Twenty-five hundred years ago, Greek and Roman architects were designing houses to maximize heat gain in winter and minimize it in summer; in fact, solar design principles served as the basis for an entire ancient Greek city, 01 ynthus, which housed 30,000 residents in "passive" solar structures. 1 Perhaps a better known example of early solar design is the native American cliff dwellings at Mesa Verde, Colorado, which utilized the orientation, overhang, and thermal mass of the cliffs to moderate daily and seasonal temperature variations and achieve a comfortable year-round living environment. It is assumed that earlier cave dwellers also took account of similar factors when choosing shelter. ${ }^{2}$ Closer to the present, the early decades of this century saw the use of solar systems to produce domestic hot water in southern California and Florida. Thousands of solar water heaters were installed in California between 1895 and 1930,3 and many thousands more were placed in southern Florida during the 1930s and 40s. ${ }^{4}$ While solar applications are far from new, it is still a fact that the use of solar energy on a national scale to meet a significant portion of U.S. energy dellidid is just beginning. It is cxpected that the widespread use of solar technologies in this country will be accompanied by a unique set of legal and institutional issues, and those issues will be the focus of this report.

As the title indicates, this report deals with decentralized solar energy systems. A solar system is hereby defined as a set of components which derives usable energy directly from solar radiation. The various technologies which fit this description include the heating and cooling of buildings with "active" and "passive" systems, solar domestic water heating, swimming-pool heating, the production of industrial process heat, and the generation of electricity through photovoltaic cells and solar thermal conversion. The reader who desires additional information on the technical workings of these systems is referred to the Solar Energy Research Institute's (SERI) Annual Review of Solar Energy for 1977 (complete reference in Bibliography). Issues associated with systems that utilize 
indirect forms of the sun's energy such as wind, hydropower, and biomass, involving significantly different technologies, do not fall within the scope of this study.

A decentralized system is defined here as one which is on or adjacent to the structure it supplies with energy. This means that issues unique to district heating, where thermal energy is collected at a central location and distributed to a group of buildings for space or water heating, ${ }^{5}$ will not be addressed. Solar total energy systems (STES), which produce electricity through thermal conversion and also utilize the waste heat generated in the process, ${ }^{6}$ will likewise be excluded where they provide energy for more than a single structure. The reasons for limiting this study to issues associated with on-site solar applications follow.

Currently, the vast majority of solar energy applications are for swimming-pool heating, domestic hot water, and space heating. ${ }^{7}$ According to a spokesman for the Solar Energy Industries Association, nearly all of the above systems now in place serve single structures, ${ }^{8}$ an observation which is borne out by officials with DOE/HUD's Solar Demonstration Project. ${ }^{9,10}$ The conventional systems being replaced by solar technologies are overwhelmingly used on-site, and it is likely that this pattern will continue for some time to come. Finally, there is little information available on the legal issues associated with the use of shared solar energy systems, probably because of the limited experience in this area. For all these reasons, on-site systems were chosen as the focus of this study. Single-structure solar total energy systems, currently in the experimental stage, were not. examined because of a lack of ovailable material. However, it is suggested that attention he given in future studies to the issues involved with using district heating and STES systeilis.

of all recent solar installations, roughly four-fifths were in the residential sector, and most of the remainder were for commercial use, with only minimal industrial and agricultural applications.11 The solar literature reflects this state of affairs, and little information is available on the issues associated with solar industrial process heat. For the above reasons, this report will look most closely at the legal 
and institutional issues arising from residential and commercial solar applications.

\subsection{Purpose of this Study}

This study was undertaken as part of Oak Ridge National Laboratory's Decentralized Solar Energy Technology Assessment Program (TAP) sponsored by the Office of Solar, Geothermal, Electric, and Storage Systems, Department of Energy. ${ }^{12}$ Its purpose is to furnish an overview of the major institutional and legal issues associated with the use of decentralized solar energy systems. The intended audience consists of the principals involved in the TAP's community-based solar technology assessments and local planners and administrators attempting to gain a fuller understanding of the solar field. Others who may find this work of interest include members of the solar industry, potential solar users, and energy policymakers at the state and federal levels. Unlike some, this report is not written primarily for those readers already conversant with the workings of the various solar technologies or the intricacies of our legal system, nor does it give exhaustive coverage to one or a few important questions to the exclusion of other major issues; rather, it is designed to provide an understanding of the broad range of nontechnical solar issues and the means available to deal with them for those individuals and organizations most likely to be involved in this field. It is hoped that this information will help the reader, when confronted with the issues described herein, to choose appropriate actions toward the continued development of solar energy.

\subsection{Research Methodology}

Information for this report was gathered primarily through a comprehensive review of the current. literature on solar legal and institutional issues. In addition, several interviews were conducted with representatives of organizations active in the solar field. Five major issues emerged as most important in this area, each of which will be described briefly in the following section. 


\subsection{Major Issues}

Taken together, the five issues presented here offer an overview of the major legal and institutional concerns in the emerging solar energy field.

\subsubsection{Prohibitions on the use of solar equipment}

Public statutes and private agreements that regulate building characteristics and land use can also have the cffect, generally uninlended, of restricting the usc of solar energy sysleims. These rēstrictions can apply to systems that are part of new construction as well as those that are retrofitted to existing structures. The following may all be inadvertently applied in such a way as to prohibit the use of solar structures and equipment.

Public statutes. Zoning is a widely used regulatory device, exercised under the police power of the state, that controls various factors relevant to the use of land and buildings within communities. Regulated features include building height and bulk, the proportion of a lot that may be occupied, setback and sideyard dimensions, and the permitted uses of primary and accessory structures. 13 The way in which these laws are written may prohibit the use of solar devices, as is the case, for example, where setback requirements preclude the placement of a free-standing solar collector, and height restrictions will not allow the addition of solar panels on a building's rnof. Modification of existing stintutes or the design of new ones can do much to alleviate these prnhlems.

Ordinances that control building appearance can also result in the prohibition of solar energy systems. Such statutes frequently establish an architectural review board that must approve all new construction and additions within the community. The use of nonconforming building materials or designs are often not allowed under this kind of regulation, a fact which bodes 111 for solar collector panels placed on roofs or in yards. 14 As with zoning ordinances, changes in aesthetic controls can eliminate problems that may otherwise exist for prospective solar users. 
A final type of public statute that can discourage the use of solar energy is the building code, which establishes minimum requirements for new construction and additions to existing structures. ${ }^{15}$ Existing codes often specify particular materials for roofs (where many solar collectors are likely to be located) as well as for heating and ventilating systems. While these requirements may be circumvented by proving to building officials that the solar equipment performs as well as the component it replaces, this can be a costly and time-consuming process for the developer. ${ }^{16}$ The development of nationally recognized standards, testing procedures, and certification programs would represent a giant step toward the elimination of this barrier to solar usage. ${ }^{17}$

Private agreements. Under this category, the device with the most potential for restricting solar usage is the restrictive covenant applied on a neighborhood scale. These mutually binding restrictions are often drafted at the time an area is developed and are included in the new owner's individual property deed. The purpose is generally to improve the desirability of the development by such means as specifying acceptable styles of architecture for future additions or forbidding the placement of mechanical equipment on roofs. ${ }^{18}$ It is clear that measures like the above can have the effect of outlawing the placement of solar equipment even though that was not the original intent. Restrictive covenants that forbid solar usage can be prevented in future developments, but the prospect of voiding existing restrictions is much less promising.

\subsubsection{Regulation of production and placement of solar equipment}

This issue is actually an amalgam of subissues dealing with the process whereby solar systems are made, installed, and used. Each component will be briefly explained in the following paragraphs.

Warranties and consumer protection. At present, broad warranties on system performance are not offered solar consumers, although some manufacturers do offer limited warranties on workmanship and materials. This lack of strong consumer protection measures, which may inhibit product acceptance, is seen by some observers as a normal characteristic 
of an undeveloped market. 19 The ideas of industry-backed warranty insurance programs, 20 comprehensive service contracts, 21 and product certification 22 are all being explored as ways to improvc consumer confidence and industry accountability.

Solar standards and codes. A building standard is defined as "a specific requirement or instruction for the design, manufacture, installation, and use of a building component, system, or material that will provide an acceptable level of performance under in-use conditions." 23 "Prescriptive" standards sperify the exact material characteristics and methods of construction required, while "performance" standards require only that a desired functional outcome be achieved.24 Building codes combine a variety of standards in a legally binding document. governing new construction and renovation. Many observers feel that the development of standards and codes governing solar energy components and systems is crucial to large-scale commercialization. Not only can this effort lead to increased solar acceptance by potential consumers and financiers, 25 but the incorporation of solar standards into existing codes should greatly simplify the process of receiving a building permit from local officials for the use of solar equipment. ${ }^{26}$ currently, a great deal of activity is evident in this area with federal, state, and local governments; industry; professional and standards-writing organizations; and the major model-building code groups involved. 27

Licensing of solar installers. As the use of solar energy systems increases, so will the urgency of establishing who should be allowed to install the associated equipment. In many jurisdictions the varinus construction crafts, such as electricians and plumbers, must be licencer hy the state or local government in order to practice their specific trade. It is expected that many states and locales will also require solar installations to be performed by licensed craftsmen. ${ }^{28}$ Establishing the appropriate licensing criteria is very important, therefore, since they will determine not only who can perform solar installations but, to some extent, the quality of that work. It is expected that there will be some controversy over whether solar work should be performed by existing trades with their current training or whether a special license is needed; 
if a special solar installer's license is created, it must then be decided what combination of skills and training will be required of a craftsman seeking this certification.

Union involvement. That a number of different craft unions are actively involved in building construction has significance for the future of solar energy use. Because the skills necessary for solar installation do not fall neatly within the purview of a single craft, interunion conflicts may arise. If it turns out that solar installers are to be considered a new craft, there may be disputes over which union will represent them. If, on the other hand, it is decided that solar installations can be done by established craftsmen, disagreements may arise over which craftsmen these will be, with different unions each claiming that their members are the appropriate ones to perform the necessary work. ${ }^{29}$ 0ther issues involve possible union resistance to new technologies and a potential struggle over whether solar installations should be performed by union workers at all.

Mandatory installation. One way to encourage the use of solar energy systems is to make their use mandatory. While this tactic has been rarely used, there are examples of state and local efforts in this direction. ${ }^{30}$

Competition. Assuring free and open competition in the solar industry is a current matter of concern. The possibility exists that the manufacture of necessary equipment will come to be dominated by a few large firms, to the detriment of small companies and the consumer alike. ${ }^{31}$ Concern has also been expressed that large petroleum companies and utilities may try to "take over" the solar market. ${ }^{32}$ The careful application of antitrust law as well as the channeling of funds to small solar businesses ${ }^{33}$ have both been suggested as ways of assuring that the solar industry remains freely competitive.

Liability of manufacturers, retailers, and installers. If a solar system malfunctions, resulting in personal injury or property damage, or if it fails to perform as promised, legal action may be taken against product manufacturers, retailers, or installers to win compensation. ${ }^{34}$ 
The need to resolve this kind of claim, while not unique to this energy source, is expected to accompany the growth of the solar energy industry.

Patents and licenses. The solar energy field is characterized by a substantial amount of research and development effort aimed at advancing the existing "state of the art." The strong government role in this endeavor raises questions of how patent rights for new inventions should be handled on publicly financed research performed by private companies. It is widely believed that by weakening contractors' patent rights, the incentive to produce innovations will be correspondingly weakened. To address this problem several arrangements are being considered, including the granting to inventors of limited-term exclusive licenses for their product and the awarding of prize money for important advances. ${ }^{35}$

\subsubsection{Access to sunlight}

Once a solar energy system is in place, its productive use is dependent on its receiving sunlight. Protecting the solar system's access to that suniight is therefore a very important issue and one which has received much attention in recent years. Solar access may be assured through the acquisition of "sun rightș," by using established land use controls to prevent shading of solar equipment and structures, and through recourse to a variety of other leqal deviçes. A short description of each of these methods follows.

The concept of "sun rights." Quite simply, this involves granting a current or potential solar user a right to receive and continue receiving the sunlight that falls on his or her solar energy system. Because the sun is never directly overhead anywhere within the continental United States, sun rights necessarily involve the neighbor or neighbors over whose land sunlight must pass to get to one's own. The concept of a right to light has a long history, as exemplified by the centuries-old English common-law doctrine of "ancient lights," which allows continued access to light falling across a neighbor's land once that access has been enjoyed for a certain specified length of time (currently 27 years). 36 Today, there is no such common-law right in the United States, but a number of other methods have been proposed for securing the right to light. 
One way of assuring the right to light is through using what a recent study by the Environmental Law Institute (ELI) calls "accidents of time." Under this category, there are several possible approaches. One such approach allows sun rights to be acquired through having used the sun's energy for a specified length of time, as under the English doctrine of ancient lights. A related method grants the right to light to anyone who productively uses the sun's energy before his neighbor blocks it. This approach has been used by the state of New Mexico, which in 1977 enacted a solar rights act based on the prior appropriation doctrine common to western water 1aw. ${ }^{37}$

Another way to assure sun rights is through the issuance of 1 icenses or permits to prospective solar users, guaranteeing them against being shaded by future land uses on neighboring property. Such a permit could only be issued, however, after the appropriate government body weighs the public benefits of conserving conventional fuels on the one hand against the costs of possibly restricting development on the other and finds the proposed solar use justified. ${ }^{38}$

A similar method of protecting solar access is through solar collector "recordation," originally suggested in the previously mentioned ELI study. Once more, the public benefits of solar usage will be weighed on a case-hy-rase hasis against the costs of any rostrictions imposed on the development of nearby property. However, instead of issuing a 1 icense or permit to the solar user, the existence of solar equipment or structures will be recorded in the public records, with the result that a specified amount of solar access is thereby assured the solar user from that point forward. 39

Another method of protecting the right to sunlight is through nuisance law. A private nuisance interferes with an individual's right to use his or her own land, while a public nuisance interferes with common public right.s. Rnth have been proposed as ways of protccting jolar access, 40 and a few laws declaring that shadows on solar devices are public nuisances have alrcady been enacted. 41

A final possibility for protecting sun rights is through the use of trespass law. Under this approach, shadows cast on solar structures and 
equipment could be defined as illegal trespass, but the chance of this actually being used is slight. 42

Assuring solar access through established land use controls. Rather than protecting solar access by establishing the "right" of an individual solar. system to receive unobstructed sunlight, the approaches presented here focus on the specific restrictions on neighboring property necessary to ensure that access. A variety of regulatory devices are available that spell out allowable characteristics and configurations of structures, open space, and/or vegetation, often on an area-wide basis. Each can be used to protect solar access when properly constructed and applied. Zoning, subdivision regulations, and vegetation controls all fall within this category, and each is discussed briefly below.

As described in Sect. 1.3.1, zoning ordinances control such things as building height and bulk, setback from property lines, and permitted land uses. It is not hard to see that by drafting the ordinance with solar access in mind, shadows cast by new structures can be kept from impinging on solar systems on neighboring properties. While traditional zoning techniques can be used to protect solar access, 43 a number of observers have suggested modifications to increase the effectiveness of this tool. "Envelope" zoning establishes a three-dimensional area in which developments may occur which vary for different parts of a lot. The exact size and shape of the envelope is based on the position of the sun, and the restrictions imposed can be applied to vegetation as well as structures. 44

The effect of any kind of zoning ordinance on solar access will vary between newly developing and already established areas. Where requlations precede development, solar access can be assured from the start, while in built-up areas, the impact of new zoning ordinances wi11 be more gradual, since they will generally influence only additions and replacements for existing buildings and vegetation.

Subdivision regulations are local ordinances used to regulate the conversion of undeveloped land into building lots. Requirements are established pertaining to site design, street and road characteristics, the provision of public utilities, and the dedication of land for open 
space. These regulations can impact solar access by their effect on the orientation of lots and individual houses where solar energy systems may be located. 45 By calling for the orientation of lots and buildings to allow natural access to sunlight, subdivision regulations can be useful in helping provide solar access for new developments.

Vegetation controls have traditionally been used by communities for a number of different purposes. They can enhance aesthetic quality, separate various 1 and uses, and control erosion. They can also conserve energy, both by calling for plantings where needed to moderate the effects of wind and sun and, most central to this study, limiting plantings where they would shade solar energy systems. ${ }^{46}$ Regulations can be used to control vegetation on both public and private property and, where designed correctly, can contribute to the provision of good solar access. As with zoning ordinances, the effect of vegetation controls will be much more immediate in new areas than in established areas with existing large trees.

Other legal devices for protecting solar access. In addition to the well-established land use controls discussed above; there are a number of other means available to protect solar access. These include the creation of solar easements, the use of restrictive covenants, the transfer of development rights, zoning by special-assessment-financed eminent domain, site plan review, and environmental impact assessment, all of which will be discussed in greater detail in Sect. 4.3.

\subsubsection{Financial incentives and 1mpediments to the use of solar technologies}

The relatively high first cost of solar energy systems is frequently cited as a barrier to their widespread adoption. However, there are a number of factors other than purchase price that contribute to the total economic picture of solar vs conventional fuel costs. The most important of these are taxation, lending policies and interest rates, the pricing. of competing fuels, government procurement policies, and the particulars of insurance and owner liability. Each of these can have an important influence, positive or negative, on the economics of solar energy use, and each will be discussed briefly below. 
Taxation. Property, sales, and income taxes can all be important in determining the economic attractiveness of buying solar. Property tax assessments that rise with the installation of solar equipment can be a disincentive to the potential solar user, while provisions exempting such systems from taxation, as has been done in several locations, can have the opposite effect. Sales and use tax exemptions will also result in savings for solar consumers, as will income tax deductions and credits for solar purchases. 47

Lending policies and interest rates. Because the front-end costs of solar equipment can be substantial, the availability of financing at reasonable interest rates is very important to the prospective solar buyer. Obtaining adequate financing will be difficult if solar energy systems are underapprassed by lending institutions, ${ }^{48}$ while a more enthusiastic attitude on the part of these organizations can make solar systems more accessible to prospective users. Interest rate subsidies could also go a long way toward improving the economics of solar usage. 49

Pricing of competing fuels. The price of other available energy sources is often cited as an important factor in the consumer decision of whether or not to go solar. ${ }^{50}$ Because conventional fuels are subject to substantial government regulation, changes in those regulations could change their competitive position. It has been suggested that by imposing the full social costs of producing and using conventional fuels on the consumer, fairer pricing in relation to solar should result. ${ }^{51}$

Government procurement policies. Through direct government purchase of solar equipment for public use, the solar industry may be stimulated sufficiently to result in economies of scale in both production and installation. 52 This in turn could result in lower costs for private consumers and a more favorable economic climate for solar use.

Insuring against system damage and owner liability. It is likely that solar energy systems will have to be insured both against damage which may befall them and against injury which they may inflict upon other property or persons. ${ }^{53}$ The availability and costs of this insurance will affect the attractiveness of the solar option as perceived by potential users. 


\subsubsection{Public utility-solar user interface}

Over $75 \%$ of U.S. electrical generating capacity is the property of privately owned power companies that are regulated by state public utility commissions (PUCS). Public regulation is considered necessary because utilities are, by nature of their generation and distribution arrangements, "natural monopolies."54 The policies of the utilities and the commissions that regulate them can have a powerful impact on the attractiveness of solar usage to the consumer as well as on the viability of the utilities themselves. Rate schedules and service policies for solar users receiving "backup" power from the utilities, arrangements for utility companies to

"buy back" excess electricity from solar customers, and policies governing the utilities' provision of solar equipment are all considered important, and each will be discussed briefly in the following paragraphs.

Utility rates. Since most solar energy systems require backup power for those times when the sun is not shining and stored energy has been depleted, the rates charged by public utilities for that service will directly impact total costs. Of the numerous different pricing schemes that have been developed, it is anticipated that some will have a beneficial effect on solar users and some will be detrimental. In the beneficial category are time-of-day pricing, lifeline rates, flat rates, inverted rates, and interruptible service rates; on the other hand, declining block rates, preferred rates for all-electric buildings, standby charges, and demand charges are all seen as being detrimental to solar users. 55

Utility service policies. This is another area where solar users with utility backup power will be impacted by decisions made by the utilities and PUCS. If public utilities are allowed to refuse to service structures using solar as their primary energy source, the chilling effect on potential solar users could be major. At this point, however, it appears that this drastic action will not be taken. 56

Utility "buy-back" of solar-generated electricity. Where a solar electric generating system produces more electricity than can be used by the owner at any given time, arrangements can be made for a local utility 
company to "buy back" the excess power. This arrangement can be beneficial to both the solar user and the utility and requires only that two major conditions be met: arrangements must be worked out for the installation of the special equipment that allows solar-generated electricity to be fed safely into the grid, and mutually acceptable buy-back prices will have to be established. ${ }^{57}$ There has already been some experimentation with utility "buy-back" schemes, and government interest has been expressed at both the state and federal levels. The importance of refining arrangements in this area is expected to increase proportionally to the incidence of use of decentralized solar electric generating devices.

Provision of solar equipment by utilities. It has been suggested that public utilities could become involved in selling, leasing, or financing on-site solar systems for their customers. Not surprisingly, strong arguments have been advanced both for and against this idea. It has been suggested that utility involvement in the solar field will further the development of this energy source ${ }^{58}$ and, alternatively, that the most likely effect will be a detrimental one to small solar businesses, consumers, and solar development in general. ${ }^{59}$ Despite the lack of agreement, the force of these arguments indicates that this is an area with great potential impact on the future use of solar energy.

\subsection{Plan of the Report}

Most of the remainder of this report will be devoted to an elaboration of the issues described in Sects. 1.3.1 through 1.3.5. Each of the major issues will be discussed individually, with Chap. 2 devoted to prohibitions on the use of solar technologies, Chap. 3 treating the regulation of production and placement of solar equipment, Chap. 4 covering access to sunlight, Chap. 5 describing financial incentives and impediments to solar use, and Chap. 6 looking at the interface between public utilities and the solar user. Examples of relevant public and private actions will be given in each subject area, and the roles available to federal, state, and local governments will be examined. Chapter 7 will conclude with a brief summary of the major legal and institutional issues 
in the use of solar energy systems and a discussion of implementation options available to governments at each level seeking to encourage solar usage. 


\section{PROHIBITIONS ON THE USE OF SOLAR TECHNOLOGIES}

While the need to increase the use of solar energy in this country is gaining greater recognition, a variety of public statutes and legally binding private agreements that act to inhibit or forbid solar applications continue to be used. Provisions of zoning ordinances, aesthetic controls, and building codes, enacted to protect the public health, safety, and welfare, can have the side effect of making the use of solar technoloqies difficult or illegal. Restrictive covenants, drafted in the interest of assuring the quality of particular developments, can likewise serve to outlaw solar. Although the prohibition of solar energy systems is generally an unintended consequence of these laws and agreements, the barriers created for the prospective user are nonetheless real and can affect both new construction and retrofitted solar applications.

\subsection{Public Statutes}

The following public statutes can have the effect of prohibiting the use of solar technologies; they can also be modified to allow solar usage. Both possibilities will be discussed below.

\section{ż.1.l Luniny}

As described in Sect. 1.3.1, zoning is a regulatory device which controls various factors pertaining to the use of land and buildings in communities. It is exercised under the police power which allows the state to enact and enforce laws in the interest of the public health, safety, and general welfare. Zoning ordinances are traditionally drafted and executed by local governments, which derive their powers to do so through a grant of power from the state. This power is generally transferred through state "enabling legislation," which allows local governments to act within established substantive and procedural 1imits;60 less frequently, locales are empowered to act through state-approved "home rule" provisions. 61

Local zoning ordinances typically specify allowable building heights, lot coverage, use of primary and auxiliary structures, distances of 
buildings from property lines, and the distance structures can project into yards. Regulations applying to each of these areas can have the effect of inhibiting solar use. Where a proposed rooftop solar collector would extend past allowable building heights as established by the zoning ordinance, its placement would not be permitted. Where a free-standing system located in a yard would push the total lot area covered past the legal limits, the solar system would once more be prohibited. A rooftop solar collector may also be excluded if it is classified as an unacceptable use, and a detached system may be seen as a prohibited auxiliary use. Restrictions on the distance a structure may project into required yard space could have the effect of banning certain components of some solar systems such as reflectors. ${ }^{62}$ Finally, specified setbacks may not provide sufficient room for free-standing collectors, particularly in retrofit situations where the primary structure is already in place.

Some of the problems described here can be avoided in new construction where the height, bulk, and location of all necessary structures and equipment can be designed to conform to existing zoning provisions. However, other features of the zoning ordinance, such as yard projection or use restrictions, preclude solar usage even when system size and location are carefully planned in advance. Where a local zoning ordinance is found to restrict solar usage in any of the above, or similar, ways, modifications are possible to make solar systems allowable. Examples of possible zoning ordinance revisions follow.

Height restrictions that may prevent the placement of solar energy systems can be addressed by exempting solar equipment from these provisions. Precedent for such a maneuver exists in that chimneys, TV antennae, cupolas, and other similar devices are routinely exempted from height limits. In Protecting Solar Access for Residential Development, the American Planning Association (APA) recommends adding "solar energy collectors and equipment used for the mounting or operation of such collectors" to the list of exempt protrusions. 63

Similarly, solar energy systems could be exempted from lot coverage requirements as is frequently the case with porches and like structures. Iin the work referenced above, the APA suggests suitable language for 
this: "A portion of a principal or accessory building, or any terrace, balcony, breezeway, porch or portions thereof, or any solar collection device or related apparatus, not included as floor area of a building, by definition shall not be included in computing lot coverage."64

To assure that a solar energy system is considered an allowable use, a specific statement to that effect can be included in the zoning ordinance. In a recent study, the city of Colorado Springs, Colorado, considered a model zoning ordinance with the following provision:

Use Permitted - The use of solar energy collectors for the purpose of providing energy for heating and/or cooling is a permitted use within all zones, whether as a part of a struc- . ture or incidental to a group of structures in the nearby vicinity. 65

Such an amendment would serve to make explicit the acceptability of solar energy use within the various zones of a community.

Finally, solar energy systems could be exempted from yard projec$\operatorname{tion}^{66}$ and setback requirements, or, short of full exemption, the restrictions imposed could be modified to reflect the expected characteristics of solar equipment for new and retrofitted buildings.

There are several possible roles for state and local governments in the enactment of the kinds of zoning provisions presented above. The most common action to date consists of state passage of enabling legislation allowing local authorities to adopt various regulations encouraging ' solar usage; Connecticut and Minnesota are two states with recently passed laws exemplifying this option. ${ }^{67}$ States may also develop model zoning provisions which are available to local governments for voluntary adoption. Another possibility is for states to mandate that locales must adopt provisions to their zoning ordinances that meet certain minimum standards; the state would then monitor local progress and step in if what is enacted or the way it is enforced proved unsatisfactory. The most active state involvement would be provided by a preemptive approach, whereby the state enacts zoning provisions applicable at the local level; under this approach, enforcement could be left as a local responsibility, or this too could be subsumed by the state. ${ }^{68}$ A nonlegislative state role would be for the state to offer financial and technical assistance 
for local governments to develop and implement appropriate solar zoning provisions.

The reader should note that the various state and local roles discussed above are not unique to the case in point, which is the use of zoning for the purpose of allowing solar use. The same options are available for dealing with the adoption of aesthetic controls, building codes, and a host of other laws for a broad range of purposes. The reader should also note that any law exercised under police power is only valid for the purpose of promoting the public health, safety, and welfare. For this reason, it is considered good practice for the adopting body to include a statement of the public purpose of solar energy in any ordinance promoting its use. 69

In addition to the state and local roles discussed above, the federal government can also be involved.in the modification of zoning ordinances in order to allow solar energy use. The federal government could mandate that the states adopt certain types of provisions meeting certain minimum standards, similar to their initiative under the Federal Water Pollution Control Act Amendments of 1972. They could also adopt preemptive legislation under the commerce or national defense powers, forcing the statcs and their local governments to act in specified ways, but this is likely to be very controversial politically. Alternatively, much influence can be exerted on state and local governments through conditions placed on the granting of federal funds. At present, this kind of involvement seems most likely. Participation in a variety of federal assistance programs could be made contingent on the adoption of specific regulations, 70 in this case zoning provisions allowing solar use. Also, the location of federally owned or operated facilities could be made dependent on the enactment of the same kinds of provisions. ${ }^{71}$ Once more, the reader should note that the same options discussed here could be applied to the adoption of a number of other regulatory devices for many different purposes. 


\subsubsection{Aesthetic controls}

Some communities exercise control over the style and appearance of all new buildings and the additions to existing structures. This is often accomplished through the establishment of an architectural review board that judges the aesthetic compatibility of additions to the existing community. ${ }^{72}$ Because solar systems frequently differ in appearance from existing structures, their placement on buildings or in yards may be rejected by community boards as conflicting with current standards. This can present a problem for systems that are proposed as part of new construction and especially for retrofits where the structure or yard receiving the unit was not designed to minimize aesthetic impacts. $\dot{A}$ case in point is the board of architecture in Coral Gables, Florida, which requires that solar collectors not be visible from public streets for aesthetic reasons. Where a building's south-facing roof surface also happens to front on a street, the prospective solar user must try to find an alternative location for his solar collectors or forego installation. 73 Aesthetic controls can be modified, however, to allow the use of solar systems.

One very straightforward way to prevent aesthetic considerations from prohihiting the use of snlar energy in a rommunity is ton simply exempt solar systems from the authority of the review board. Short of this, compromise measures are possible that would recognize the public purpose of using solar devices that differ in appearance from prevailing styles, while imposing reasonable restrictions on the solar user to minimize incompatibilities through system placement and screening. As with other building and land use regulations, aesthetic controls have traditionally been exercised by local units of government, and local action on this issue is a distinct possibility. However, state governments may exert influence in any of the various ways outiined in Sect. 2.1.1. The California Solar Rights Act of 1978 is an example of preemptive state action; in this bill, local governments are forbidden from enacting ordinances that prohibit or restrict the use of solar systems. ${ }^{74}$ Federal action in this area is less likely, but the options available are the same as discussed in Sect. 2.1.1. 


\subsubsection{Building codes}

The building code is a legal document, exercised under police power, that sets minimum requirements for new construction and improvements to existing buildings. ${ }^{75}$ It is widely used in this country, and that use has traditionally been considered a local prerogative, with states delegating the power to enact and enforce building codes through enabling acts. Most building codes are not developed at the local level, however; roughly two-thirds of all jurisdictions with populations exceeding 5000 base their codes on one of three widely used model codes. Many other locales with "original" codes borrow freely from the models. ${ }^{76}$

The major model codes are: the Basic Building Code written by the Building Officials and Code Administrators International, the Uniform Building Code of the International Conference of Building Officials, and the Standard Building Code of the Southern Building Code Congress. ${ }^{77}$ Although many local governments have adopted one of these three models, there is still much variation in codes between jurisdictions because of local amendments and the failure of locales to consistently adopt periodic updates issued by the model groups. ${ }^{78}$

Currently, the major model building codes and most local codes do not contain standards pertaining specifically to the testing and performance of solar energy systems. ${ }^{79}$ Some observers feel that for this reason existing codes will have little bearing on solar use. ${ }^{80}$ 0thers, including the author, disagree.

When a prospective solar user applies for a building permit to construct a new building or retrofit an existing one, a lack of code provisions does not release the local code administrator from his responsibility to determine that any work done does not endanger the public health, safety, and welfare. Since most codes do not cover solar equipment explicitly, if a building permit is to be issued, the building official will have to be convinced that the equipment in question is as good as that specified in the code. 81 And since many solar collectors will be located on rooftops, the solar system may have to meet performance standards for roofing materials as well as for heating and ventilating systems. ${ }^{82}$ The process of attempting to prove on a case-by-case 
basis that solar systems are the equal of those they are replacing could prove to be costiy and time-consuming for the prospective user, and there is no guarantee as to outcome.

An alternative to the current situation would be the establishment of nationally recognized standards and testing procedures for solar systems along with a certification program whereby solar manufacturers could show that their equipment meets those standards. Incorporation of the standards into building codes by state and local governments and their recognition of certification as proof of compliance could eliminate the difficulty and uncertainty that currently face prospective solar users and the building departments that must judge their systems. While local or state codes and certification programs would also expedite solar system.approval, the use of nationally recognized standards saves effort at lower levels of government and avoids the fragmentation of solar markets that can result from the existence of divergent codes from one locale or state to another. 83 A brief description of some recent national code writing efforts follows.

In 1976 the International Association of Plumbing and Mechanical Officials adopted a model solar code which has been characterized as a noble, but flawed, effort. ${ }^{84}$ In March 1979 the first draft of a federally sponsored "model solar document" was completed by the Council of American Building Officials with the assistance of the National Council of States on Building Codes and Standards. After several reviews and revisions, it is expected that this document will emerge in final form around the end of 1979 and may have its provisions adopted by the major model code organizations. 85 In the meantime, several solar testing and performance standards exist which could be adopted on an interim basis by interested states and locales. These standards will be discussed further in Sect. 3.2.

The preceding discussion shows lhat certain characteistics of existing zoning ordinances, aesthetic controls, and building codes can all serve to inhibit or actually ban the placement and use of solar energy systems. It is important, therefore, that local statutes be examined and any components found to have such effects be modified. Without this action, any other steps taken to promote solar usage are likely to be fruitless. 


\subsection{Private Agreements}

In addition to the public statutes described above, legally binding private agreements can also restrict the placement and use of solar energy systems. As pointed out in Sect. 1.3.1, the restrictive covenant applied on a neighborhood scale is the type of private agreement most likely to have this effect. Deed restrictions drafted at the time an area is developed bind all property owners so encumbered to the conditions therein. ${ }^{86}$ While the exclusion of solar energy devices is generally not an intended purpose of these covenants, that may still be the ultimate outcome of their enforcement.

Specifically, problems may arise with restrictive covenants specifying primary and auxiliary land uses, architectural style and materials, 87 building heights, and setbacks. ${ }^{88}$ The ways in which these requirements act to restrict solar usage are the same as when similar requirements are included in zoning or aesthetic control ordinances, discussed earlier in Sects. 2.1.1 and 2.1.2.

A prospective solar user who finds his desire to install a solar energy system frustrated by existing covenants has two basic options; he can ignore the covenant and install the system anyway, or he can attempt to secure a change in the dyreement. The first option is dangerous because if neighbors complain, the courts are likely to uphold valid covenants. The second option offers more hope but can be exceedingly difficult because either all affected property owners or the established development association must be persuaded to approve a change. ${ }^{89}$ Outside of these private actions, however, there are several options open to state and local governments which may prove more effective in preventing private deed restrictions from banning solar use.

To prevent future problems from arising, loca $7^{90}$ and state governments cail declare new covenants restrlcting solar use void and unenforceable. ${ }^{91}$ This is an important first step toward increasing solar usage. It has also been suggested that state governments declare all such existing agreements void retroactively. The California Solar Rights Act of 1978 contains such a provision, but there is some doubt as to whether 
or not California and other states which may follow their lead are constitutionally empowered to act thus. ${ }^{92}$ The resolution of this question will be very important in determining whether solar rétrofits will be allowed in areas restricted by existing covenants. 


\section{REGULATION OF PRODUCTION AND PLACEMENT OF SOLAR EQUIPMENT}

There are a host of issues involved with how solar systems are made, installed, and used, all of which are important in determining the success of the solar commercialization effort. These include the characteristics of warranties; the development of standards and codes; the licensing of solar installers; union involvement; mandatory installation; questions of competition; the liability of manufacturers, retailers, and installers; and the issuance of patents and licenses.

\subsection{Warranties and Consumer Protection}

Warranties and other consumer protection devices have the effect of limiting potential risks to the consumer and may, therefore, result in a strengthening of buyer confidence and expansion of the potential market for solar equipment. Those solar warranties offered in today's market, however, are partial in scope, favoring 1 imited coverage of workmanship and materials over a broad-based guarantee of overall product quality. While this situation may be characteristic of newly developing technologies in general, it has been suggested that a kind of circularity is operating here which acts to keep the solar industry from growing more rapidly. Because manufacturers have only limited experience with their products, broad warranties cannot be prudently offered; however, until such protection is offered, consumers will resist buying, with the result that manufacturers will have trouble gathering the empirical data and capital reserves necessary to allow them to issue those warranties. ${ }^{3}$ The general dearth of product certification programs may also be a retardant to more rapid commercialization. 94 To combat these conditions, action can be taken by state and federal governments and by the solar industry itself; examples of these are discussed below.

A plan for an industry-backed warranty insurance program has been suggested by the SolarCal Council in California. Under this plan, participating manufacturers and installers would pay a small amount of their earnings in return for the assurance that claims against their 
warranties will be honored. 95 This allows the solar businessman to offer broad warranties to consumers without the risk of financial ruin in case of equipment failure. To protect the program itself, however, all participating solar manufacturers should be required to submit their equipment for testing so that only well-designed and constructed materials are covered.

State governments can contribute to consumer protection through the establishment of solar equipment certification programs. Both Florida and California have programs whereby solar collectors are tested in accordance with referenced standards by independent laboratories, and the information is made available to prospective consumers. In both states, participation is voluntary but will soon be mandatory in Florida and may be tied to receiving the state income tax credit for solar installations in California. Other states have more limited programs whereby solar equipment must be approved by a specified agency in order to be eligible for certain financial incentives. ${ }^{96}$ Certification programs are tied closely to the development of testing and performance standards for solar equipment, which will be discussed more fully in Sect. 3.2.

It has been suggested that the federal government may be able to encourage solar development by underwriting comprehensive service contracts for maintenance and repair. Like the development of broad warranties, such a policy may inspire consumer confidence and expand the solar market, but it could also encourage the use of substandard equipment and be very costly if measures are not taken to assure the quality of all included sys tems. 97

\subsection{Solar Standards and Codes}

The development of standards covering solar components and systems is very important for several reasons. Standards provide guidelines for solar manufacturers in their efforts to design and build acceptable equipment. They can also serve as the basis for certification programs whereby consumers and financiers are advised which products meet certain established levels of quality. Finally, solar standards can be incorporated into building codes so that code administrators can readily 
determine system acceptability and prospective users can avoid the difficulties involved in acquiring a building permit described in Sect. 2.1.3. The establishment of solar standards for this last purpose is particularly important, since most local jurisdictions have no solar provisions in their building codes.

In recent years the need for standards to facilitate large-scale solar commercialization has been widely recognized, and a number of standards-writing efforts have been launched. At the local level, several local governments in states with high solar use have written their own code provisions covering solar equipment. A recent survey conducted by the Florida Solar Energy Center revealed that approximately a dozen locales in that state have some sort of solar provisions, however rough, in their building codes. 98

A small number of states have also addressed the issue of solar standards and codes. California, Connecticut, Florida, Minnesota, and New Mexico all have enacted public statutes charging specified agents of the state with developing standards for solar systems. 99 In Florida, several local governments use the standards thus developed as the basis for judging the acceptability of proposed solar installations. 100 In addition to their standards legislation, Florida and California have also addressed the issue of solar building codes. Florida requires Lhal dll new single-family residences be built with plumbing that facilitates the future installation of solar water heating equipment, California has enabled local governments to require new buildings to be built so as to permit future solar use, and Nevada's statewide energy conservation code includes design and construction allowances for solar system installations. 101 The reader should note that while few states have acted in this area, all have the power to control building construction and are free to pursue a wide range of options ranging from simple enabling legislation to preemptive statutes establishing statewide solar codes.

In recent years, there has been a fair amount of federal involvement in solar standards writing. This includes the development of intermediate minimum property standards (MPS) for solar domestic hot-water and space heating systems as a supplement to existing FHA standards, the writing of 
interim performance criteria for solar heating and cooling systems for use by HUD in the solar residential demonstration program, and sponsorship of the recently drafted "model solar document" discussed in sect. 2.1.3.102 The possibility exists for an expanded federal role through the enactment of a national solar building code, but, as of now, no preemptive action has been taken in this area.

Various industry, professional, standards-writing, and model-code organizations have also been working on solar standards in recent years. The American Society of Heating, Refrigerating, and Air Conditioning Engineers published standards on the testing of solar collectors and storage devices in July 1977, and the Solar Energy Industries Association just prepared a rating standard for certifying collectors based on this work. The Sheet Metal and Air Conditioning Contractors National Association published standards for solar installation in March 1977, and work has been done by the Air Conditioning and Refrigeration Institute Foundation and the Solar Energy Research and Education Foundation to identify laboratories equipped to test solar collectors and to develop a plan for collector certification. The American Society for Testing and Materials, the American National Standards Institute, and a number of other organizations have also been involved in solar standards development. 103

Despite all this effort - and the above list is not comprehensive much work remains to be done in the development of solar standards that will turther the commercialization effort. A number of those working in the solar field have stressed the need to be careful that emerging standards do not ignore passive solar in favor of active systems, that prescriptive standards are not developed at the expense of performance standards, and that the current "state of the art" is not locked into law by a premature or overly restrictive national code. 104

\subsection{Licensing of Solar Installers}

As the use of solar energy systems grows in this country, so does the necessity to decide who should install those systems. Two questions must be asked here: Who is legally entitled to install solar equipment? 
Who is qualified to do this work? It is the opinion of some observers that the answer to the first question is not always the same as the answer to the second. Efforts by various government and private agencies, however, are being undertaken in an attempt to improve the current situation.

The earlier discussion of codes pointed out that building permits are normally required for both new construction and for additions to existing structures. Solar units installed in new buildings will thus fall under this permit requirement as will retrofitted solar units in many jurisdictions. In order to issue a permit, the local code administrator must review and approve the plans for the prospective solar installation; it is also common for the credentials of the person doing the installing to be reviewed. In many areas, professional contractors must be licensed by the state or local jurisdiction to do the work in question, while owner-builders are not subject to this constraint. In Orange County, California, 105 and in Dade County, Florida, 106 two areas where many solar units have been installed, licensed plumbers and swimming-pool contractors have been responsible for most of the work. In these jurisdictions and probably in many others, the installation of solar hot-water systems and swimming-pool heaters is not seen as significantly different from traditional plumbing or swimming-pool work; therefore, licensed contractors in these areas are legally entitled to perform the work in question. In other places, more than one licensed craftsman will be required to do the job, as in Memphis, Tennessee, where plumbing, electrical, and construction contractors are all involved in domestic hot-water installations. 107

There are those who maintain that by limiting solar installations to contractors licensed in established crafts, the best possible job is not always assured. In Florida, licensed contractors can get a permit to do solar installations with no prior training or cxperience in this field, 108 while in California a "Solar Installer" license is available as a supplement to existing licenses with no examination or other proof of skill required. 109 The creation of a separate solar installer classification with testing and/or experience required for licensing could 
possibly result in a class of installers more highly qualified to perform this work. On the other hand, advocates of the established crafts maintain that not only is there nothing involved in solar installation that a licensed craftsman in a related trade cannot do, but that the extensive skills held by these individuals better enable them to deal with any difficult or unusual problems that may arise.

In Florida, the Dade, Broward, and Palm Beach County trade licensing boards are trying to decide what, if anything, should be done to change present training and licensing procedures for solar installers. 110 Current practices here as well as in California would seem to preclude specially trained solar installers from doing contract work if they are not also licensed in a related craft. At the same time, a newly formed group called the Contractors National Bureau for Solar Certification is trying to devclop a testing and certification program for installers.lil The question of licensing is one that can be expected to increase in importance in the coming years as the demand for high-quality solar installations continues to grow.

\subsection{Unioñ Involvement}

A closely related issue to the one discussed above cuncerns lhe involvcment of labor unions in the installatinn nf cnlar energy systems. It has been suggested that labor unions may resist the diffusion of solar technologies to protect the interests of their members. Earlier union efforts to combat the use of labor-saving plastic pipe are often cited as an example of what may occur in the solar field, but the analogy does not fit well; solar usage does not seem to constitute an immediate threat to existing jobs. 112

A more real possibility is that differenl uniuris will find themselves in conflict with each other over what share of the emerging solar job market each will take. If solar installation becomes established as a separate trade, disputes may arise over which of the existing craft unions will represent these solar workers. If, on the other hand, no such new craft emerges, there may be conflict over which existing union will do solar work.113 Because solar installations represent a kind of 
hybrid task that can involve elements of plumbing, roofing, electrical wiring, and sheet-metal installation, the delegation of work assignments may not be easy. The sheet-metal workers and the plumbers, currently the two unions most heavily involved in solar energy, have reached a provisional agreement for cooperation in solar installations, but it is too early to say that the possibility of future interunion disputes no longer exists. 114

Another possible conflict is between the various interested unions taken as a whole and those builders and contractors who would prefer to use nonunion labor for solar installations. Again, it is too early to say whether this will emerge as a serious issue in the years ahead.

Labor disputes that result in a strike, or the threat of a strike, will be handled by the federal government, under the National Labor Relations Act of 1947 (Taft-Hartley Act). The National Labor Relations Board created by this act has the power to arbitrate a settlement if, for instance, a conflict over work assignments leads to a strike. To settle such problems before they get to that point, it has been suggested that the federal government could create a Solar Energy Labor Board to develop appropriate regulations in this area. State governments could also pass legislation aimed at settling problems prior to a strike, although federal power would be preemptory should a work stoppage occur. 115

\subsection{Mandalury Installation}

It is hard to imagine a more direct way for governments to encourage solar use than to simply mandate its use in all buildings. Such action could be unpopular where the costs of solar systems exceed those of the conventional systems which they replace. Even where solar systems prove less expensive on a life-cycle cost basis, the additional front-end costs may be protested by builders and home owners alike. Nevertheless, several legal commentators believe that legislation mandating solar use for new construction is likely to be upheld by the courts; an existing precedent is the building code, which routinely specifies acceptable heating, cooling, and hot-water equipment, the costs of which are often substantial. 
Existing building codes enabling legislation will have to be examined, however, and possibly amended, to make sure that the power to regulate energy usage is included therein. Where the need to conserve conventional energy resources can then be proven and exemptions are allowed for special hardship cases, it is expected that measures requiring use in new buildings witl be upheld.113

Mandatory solar retrofits to existing structures can also be required, but it is less certain that this would pass judicial review. The economic costs involved in replacing heating, hot-water, and/or other systems with solar ones could be substantial and may be widely contested, despite the fact that precedent does exist for requiring costly improvements to existing buildings. In the case of solar, physical characteristics of the house or lot such as unfavorable orientation or standing trees may preclude the use of these systems. Nonetheless, it is possible that an ordinance mandating solar retrofit would be upheld providing it allowed exemptions where physical or other factors make solar use uneconomic and where the systems being replaced are amortized over a reasonable period. 116

As of now, there are no examples of government action mandating solar retrofit, but there are cases of solar energy systems, or allowances for their use, being required in new construction. In December 1978, San Diego County, California, enacted an ordinance requiring the installation of solar hot-water heaters in all new homes. County officials claim that, in addition to saving conventional fuel, the life-cycle costs of a solar system will also be less over a 20-year period. The regulation, which will take effect on 0ctober 1, 1979, in areas not served by natural gas and on October 1, 1y8u, èverywhere èlsè, hás beèn contested by the local building industry because it will increase the first costs of construction.117 If, as is expected, the ordinance survives any resulting court challenges, it may serve as an example for similar actions in other locales.

A 1974 Florida state law making plumbing that facilitates the future use of solar water heaters mandatory for a 11 new construction has already been cited. 118 While this does not mandate the present use of solar, it 
does illustrate the power of the state to act preemptively in this area. A properly written law requiring solar devices in all new construction should not exceed the state's constitutional authority, but it would probably be less acceptable politically than an enabling act or model statute that allows local governments to pass the necessary provisions.

While it is also possible for the federal government to pass preemptive legislation in this area, such action is unlikely due to the expected resistance of state and local governments. An alternative that has been suggested is for the use of solar energy to be made mandatory in federally assisted housing through appropriate modifications to the FHA MPS. It has been estimated that such an action could affect up to $20 \%$ of al1 new housing in the United States. 119

\subsection{Competition in the Solar Industry}

As the market continues to grow, it is feared by some observers that the active competition which now exists among the various firms involved in solar development, production, and marketing may diminish. This, in turn, could result in a lessening of product innovation and quality and an increase in prices, which would hurt the solar consumer and may ultimately discourage solar use. Several specific anticompetitive possibilities are discussed below, followed by some suggested actions to remedy them.

One way in which competition in the solar field could be undermined is if the production of solar equipment comes to be dominated by one or a smal1 number of firms. For this reason it is important for close attention to be paid to any proposed mergers in this area. 120 Another possibility is that large energy corporations or electric utilities may attempt to gain control of the solar industry, not just for the purpose of assuring profits in this area, but also to protect investments in competing energy sources. ${ }^{121}$ Finally, standards and code provisions that are overly restrictive can also be anticompetitive if they act to "limit product innovation or fix prices. 122

An effective tool for combating anticompetitive actions is the assiduous application of antitrust law before one or a few companies 
gain dominance in the solar field. Existing federal antitrust provisions can be utilized, and state governments can also have a hand in assuring - competition; currently, 43 states have antitrust offices, and there is a trend toward increasing state involvement in this area. Anticompetitive actions on the part of publicly regulated utilities can be prevented through firm controls exercised by existing regulatory agencies. 123

A final way to assure competition in the solar industry is through the extension of government aid to small solar businesses. At the federal level, funds can be made available through the Small Business Administration's solar loan program, while the states can also help small companies in securing adequate financing. 124

\subsection{Liability of Manufacturers, Retailers, and Inslallers}

As solar energy gains wider use, cases are likely to arise where systems fail to perform as promised or where there is malfunction with resultant property damage or personal injury. When this happens, established tort laws dealing with product liability will be used to determine whether, and to what extent, solar manufacturers, retailers, and installers are responsible for restitution. Three legal theories may apply in this area: strict liability, negligence, and breach of implied warranty. 125

The strict-liability approach holds that, provided a product is expected to reach the consumer in basically the same condition as when it left the seller, the seller is liable for any physical harm caused by an unreasonably dangerous defect in the product. A manufacturer, retailer, or installer can also be held accountable for damages if negligence can be proven. This involves showing that the defendant failed to exercise as much care as would a "reasonable person" under the same circumstances. Both of these legal approaches offer compensation for bodily and property damage and may, therefore, afford some security to the potential solar consumer; at the same time, the solar businessmen who are potentially liable may be influenced to exercise "reasonable" care in the manufacture, sale, and installation of their products. 126 
In contrast to the protection offered by the two legal theories discussed above, it may be possible to collect compensation for economic harm resulting from a solar system not performing as expected by claiming breach of implied warranty. This would be important in the case of a solar system that injured no one but failed to provide the heat, hot water, or electricity for which it was purchased. An implied warranty means that the seller has implicitly warranted the product in question for the ordinary purposes for which it is used. ${ }^{127}$ The collection of damages through this approach is not assured, however, and does not promise the kind of protection, or consumer confidence, that would be provided by the express warranties discussed in Sect. 3.1.

\subsection{Patents and Licenses}

Because of the active government role in financing solar research and development, the content of federal patent policy is important; private companies doing publicly funded work on solar energy are vitally interested in the nature of their rights to any patentable new inventions which may result from their efforts. In general, it is the policy of the federal government to take title to all patents for inventions made under government contract, granting the inventor only a revocable, nonexclusive license to his product. The option does exist, however, to extend greater rights to the researcher if doing so would be in the country's best interests. Past experience indicates that the right to practice the inventor's background patents, patented inventions upon which the new work builds, may also be taken by the government under certain circumstances. 128

In the area of solar research, as elsewhere, a federal policy that optimizes the incentive of inventors by strengthening their patent rights can also result in monopolistic practices and a sluggish dissemination of new products and practices. 129 On the other hand, by following the policy of granting only nonexclusive rights to inventors, market concentration is avoided but innovation may be slowed because of the hesitancy of some researchers to participate in the government program. 
A discussion follows of several possible ways in which federally funded innovation can be increased without encouraging monopoly.

The granting to researchers of limited-term exclusive licenses for their inventions has been suggested as a way to strengthen the incentive to innovate without unduly weakening competition. The length of time which licenses remain exclusive, could vary depending on such factors as the size of the firm responsible for the invention and the vigor of their effort in developing it. ${ }^{130}$ The former criterion could be used to aid small solar husinesses, while the latter could assure that now inventions will be developed as quickly as possible. Since basic federal patent policy allows necessary exceptions to the general rule of granting nonexclusive licenses to inventions, the method described above does not represent a significant departure from current practice.

The award of prize money for important solar advances is another way in which the incentive of researchers can be increased. This method has the advantage of allowing no monopolistic rights, however short-lived, to inventors. On the other hand, the determination of appropriate prize amounts may be difficult, and the costs to the government could be substantial. 131

On the matter of government rights to background patents, it has been observed that firms with extensive patent portfolios would be reluctant to conduct government-funded research if, by doing so, they risk losing exclusive rights to their prior inventions. For this reason, an effective patent policy may require assuring researchers that back. ground patents will only be taken in extreme cases, where no other reasonable alternative exists for allowing the use of the new invention. ${ }^{132}$ 


\section{ACCESS TO SUNLIGHT}

Solar energy systems must receive sunlight to function. While simple to understand, this condition is not always as simply met, and therein lies a potential problem for the solar user.

Nowhere in the continental United States, at any time of the year, is the sun directly overhead, which means that a solar system is dependent for its operation on sunshine which must travel over neighboring properties. The placement and characteristics of structures and vegetation on these nearby properties, then, can become very important to the solar user, since the "wrong" configuration can result in his system being shaded. While a property owner can tailor his own land uses to avoid casting shadows on his solar system, he does not normally have direct control over how his neighbors use their land. To address this, a number of ways have been suggested by which a solar user's "access to sunlight" can be protected through the imposition of various restrictions on how neighboring parcels may be utilized.

The concept of "sun rights" can be used to assure a solar user that he will receive the sunlight necessary for the operation of his solar system. Quite simply, this means that a "right" to receive sunshine can be granted a particular property owner, with the result that neighboring property owners are not allowed to build structures or plant vegetation in such a way as to shade his system. Another way to protect solar access is through established devices such as zoning ordinances, subdivision regulations, and vegetation controls which establish specific requirements concerning how land can be used. Toward the end of protecting access to sunlight on an area-wide basis, these devices can spell out allowable configurations of open space, structures, and vegetation. Finally, there are a number of other legal devices available for the purpose of protecting solar access. These include the establishment of easements and restrictive covenants to prevent solar systems from being shaded as well as the use of more novel controls such as the transfer of development rights (TDR) and zoning by special-assessmentfinanced eminent domain (ZSAFED). 
The solar access issue has received a lot of attention in recent years for several reasons. The purchase and installation of a solar system represent a substantial investment, the utility of which can be seriously diminished or even destroyed if sunlight is blocked. Also, this is an area where protecting the interests of the solar user can directly affect the property rights of his neighbors, raising questions of whether the public benefit resulting from solar's displacement of conventional fuels justifies the potential hardships arising from the restriction of other land owners' development opportunities. Lastiy, it has been suggested that the necessity to protect solar access on a community-wide basis may result in alterations to traditional land use patterns, a source of concern to some observers.

Protecting solar access is an issue of importance, both where solar systems are included in new construction and where they are added to existing buildings or lots in previously developed areas. However, the difficulties associated with assuring sunlight in older areas are expected to be more formidable than in new ones. This is because in new developments, the positions of buildings and vegetation, the size and orientation of lots, and the placement of open spaces can all be designed with the purpose of furthering solar use, while in older areas all the above factors are already fixed. While the focus in new areas, then, is likely to be on finding optimum solar access devices to guide growth, older neighborhoods are likely to require tools to protect whatever solar access exists and to appropriately channel any redevelopment and in-filling.

There are a number of criteria by which the value of solar provisions can be judged, only one of which is how well shadows from neighboring land uses are kept off solar collectors. The Environmental Law Institute (ELI) has suggested a number of additional attributes, including clear and fair allocation of costs and benefits, compatibility with other policies and laws and with the physical environment, protection of future - as well as present - access, and reasonable flexibility. 133 All of these should be considered important in choosing solar access controls. 
As in other areas, actions taken to protect solar access can involve federal, state, and local governments in a number of different roles. Local governments have traditionally enacted and enforced laws governing land use, and it is expected that increasing involvement with solar access will be seen at this level. A number of observers have suggested that this is as it should be, since local governments are most familiar with land use and other environmental and political factors in their areas. According to this view, state or federal involvement, at least at first, may best be limited to the supply of technical and financial assistance as counties and municipalities seek controls that are best suited to their individual needs. 134

State governments, as suggested in Sect. 2.1.1, have several possible roles they may play. They might provide support of the type just mentioned, or they may pass enabling legislation giving local jurisdictions the power to adopt certain kinds of access provisions. The development of model regulations for voluntary local adoption is also a possibility. Finally, a more active state role can be assumed through the passage of mandating legislation, where locales are required to pass solar access controls meeting certain minimum requirements, or through preemptive statutes where local jurisdictions are bound by a statewide act. Under these last options, the enforcement function can be kept in local hands or it can be assumed by the state. ${ }^{135}$ It is expected that most states will not preempt the traditional power of local governments to act in this area unless it appears that locales are unwilling or unable to act, or it is felt that the need for solar access laws constitutes an emergency situation.

A number of legal commentators have argued that the federal government could, if it so chose, pass preemptive legislation dealing with solar access protection. Short of this, a law could be drafted mandating certain actions by the states. It is widely agreed, however, that this type of action is unlikely, since the area of land use control has traditionally been one of state-enabled local control. The extension of technical and financial assistance is a much more likely alternative, and this would probably be well received by the benefited parties. ${ }^{136}$ 
The attachment of various conditions to the receipt of these funds could be used to assure that actions.necessary to protect solar access are taken at the appropriate level.

Each of the possible methods for protecting solar access - the "sun-rights" approach, the use of established land use controls, and the use of other legal mechanisms - will be discussed in some detail below. The various devices available in each category will be presented, as will examples of their application and the roles played by the various levels of government.

\subsection{Concept of "Sun Rights"}

The protection of solar access through the granting of "sun rights" has a long and venerable history. Twenty-five hundred.years ago, when the ancient Greeks and Romans made extensive use of "passive" solar structures, Roman law forbade construction that blocked an existing structure's sunlight. ${ }^{37}$ In English common law, the doctrine of "ancient lights" has for centuries recognized a land owner's right to light coming in over neighboring lands, provided it has been received unobstructed for a certain length of time; currently, this period is 27 years. ${ }^{38}$ In Japan, sun rights have also long been recognized, and this state of affairs continues to the present. A 1972 Supreme Court case in that country reaffirmed solar access as a protectable interest and awarded damages to a home owner whose light had been blocked by an addition to a neighboring residence. ${ }^{139}$ In this country, however, the right to light has not fared so well.

Over the years, courts in the United States have repeatedly denied the existence of a common-law right to light. Such findings are consistent with public policy that has traditionally favored the full development of property, a goal which could be jeopardized by prohibitions on structures which shade their neighbors. ${ }^{140}$ The most famous case repudiating the notion of common-law sun rights in this country was Fontainebleau Hotel Corporation vs Forty-Five Twenty-Five, Inc. In 1959 a Florida Court of Appeals held that the Fontainebleau could not be stopped from adding a new wing to their hotel, even though it 
would shade the neighboring Eden Roc Hotel's swimming pool. The court held that, without a specific contractual or statutory obligation, a landowner does not have a legal right to light or air crossing the property of another. ${ }^{141}$ In recent years, however, there has been a resurgence of interest in the sun-rights concept, and a number of modern approaches to this ancient concept have been suggested.

\subsubsection{Analogy with western water law}

It has been suggested that sun rights could be allocated in the same manner as are water rights in the western United States, through the prior appropriation doctrine. Basically, this holds that "priority in time has the better right" and, applied to solar energy, would mean that once a property owner has established a beneficial solar use, his sunlight cannot be blocked by structures or plantings on a neighboring parcel. ${ }^{142}$ In effect, this grants an instant access right to a solar user upon the erection of a solar system and makes neighboring landowners responsible for limiting their development to the extent necessary. to protect that access.

In 1977, New Mexico passed a statewide Solar Rights Act based on the prior appropriation doctrine. ${ }^{143}$ While it does effectively protect a solar user's right to light once his system is in place, the law has been widely criticized for a number of shortcomings inherent in this kind of approach. Perhaps the most serious problem is that the costs and benefits engendered by solar usage are not fairly distributed. The installation of a small solar energy system on one piece of property can severely restrict, or even deny completely, development on neighboring parcels. Because the end result can be a radically different treatment

- of basically similar properties, resulting in benefits for some and extreme hardships for others, the law is likely to be challenged on constitutional grounds as violating "equal protection" and "due process" provisions. Other problems with this "first-come first-served" approach are that it encourages rapid action over advance planning, offers no protection for other types of development that may be restricted by the obligation to protect sun rights, and provides no future protection for potential solar users. ${ }^{144}$ 


\subsubsection{Solar access permits}

An approach to sun rights that avoids some of the worst faults described above is the issuance of permits or licenses granting solar users the right to light on a case-by-case basis; a law establishing such a procedure was recently considered by the state of Massachusetts.145

Solar access permits could be modeled after conventional building permits or special zoning permits and would prevent structures or vegetation on neighboring properties from casting shadows on a licensed solar system. 146 It has been suggested that a permit could be issued only after a review process in which the positive impacts associated with solar use in the case at hand are balanced against the negative effects of any restrictions on neighboring development which may occur; 147 this would assure a more equitable distribution of costs and benefits than under the prior appropriation approach and would explicitly recognize the community's interest in both the promotion of solar energy and the encouragement of other thoughtful land uses. A major weakness of the permit system is that future solar access is not protected; unitil a prospective solar user applies for an access permit, he has no guarantee that the sunlight currently falling on his property will not be blocked by subsequent construction or plantings by neighboring landowners.

\subsubsection{Solar access "recordation"}

"Recordation" is a method of protecting solar access originated by the ELI, which is similar to the permit approach described above. In order to establish a right to light, a prospective solar user applies to the local authorities to have the existence of his solar system entered in the public record. If granted, this "recordation" assures the user a specified amount of solar access. The decision on whether or not to record the solar system will he based on a balancing of the competing interests involved, recognizing the importance of solar use while avoiding excessive restrictions on neighboring development. The ELI has recommended that each case be judged within the context of a city-wide solar access plan which recognizes that different areas within a community have different suitabilities for solar usage. 
A major drawback to this option is that an unwieldy number of hearings may be required to allocate solar access for an entire community. ${ }^{148}$

\subsubsection{Nuisance Iaw approach}

The use of both private and public nuisance law has been suggested for protecting solar access. Under the private nuisance approach, a solar user would have to prove that shadows cast on his solar system by neighboring land uses interfere with the use and enjoyment of his property and constitute an abridgement of a legally protected right. The interference with property use may not be hard to establish, but it would be very difficult to prove that a legal right to sunlight exists, since the courts in this country have consistently denied the existence of a common-law right to light. 149 Because of this, there appears to be more promise for the assurance of solar access through legislative action, establishing shadows on collectors as a public nuisance.

An example of the latter approach is provided by California's recently passed Solar Shade Control Act. This statute declares shadows cast upon solar collectors by newly planted vegetation located on neighboring properties to be a public nuisance. While this particular law is careful to specify height and setback requirements to which solar systems must comply in order to be protected, as well as limiting the hours of the day during which that protection is extended, 150 there is no guarantee that other ordinances using the public nuisance approach will do likewise. This raises the possibility of sun-rights laws that can unfairly restrict development on some properties to the advantage of solar systems on others. Another shortcoming of using nuisance law is that no protection is offered a prospective solar user until his system has been put in place. 151

\subsubsection{Trespass law approach}

It has been suggested that trespass law may be used to assure a solar user the right to sunlight. A trespass consists of "an invasion of a landowner's exclusive possession of property," a condition which some may say exists when a shadow from neighboring structures or 
vegetation is allowed to fall on a solar energy system. It is highly unlikely that the courts would uphold such a contention, however; past cases have found that light cast on another's land is not a trespass, and shadow, which is the absence of light, seems one step further removed from constituting an invasion. Another option is for legislative action making trespass law applicable to shadows cast on solar systems. ${ }^{152}$ In general, however, little serious attention has been given to the use of trespass law as a means of protecting solar access; it offers no clear advantages over other sun-rights approaches and is open to criticism as being basically inappropriate for this purpose.

A number of modern approaches to the establishment and protection of a right to sunlight have been discussed above. All of these allocate the right to light on a case-by-case basis as the placement of a solar system necessitates it; this means that prospective solar users are not assured of future solar access, and hasty development to guarantee that access may be encouraged. Some approaches, such as the one based on western water law, can place severe restrictions on the use of neighboring properties without explicit consideration of who will receive the accompanying costs and what the effects will be on community development in general; nuisance law and trespass approaches can also share this shortcoming. Solar access permit and recordation techniques, on the other hand, can be designed to include considerations of how costs and benefits will be allocated, but the more carefully potential impacts are considered, the greater the burden placed on the governmental body responsible for deciding which applicants will be granted access. The use of traditional land use regulations to protect solar access on an area-wide basis has been suggested as a way of avoiding some of the difficulties mentioned here. Zoning, subdivision regulations, and vegetation controls can all be designed to regulate development that shades solar systems, and each will be treated below.

\subsection{Assuring Solar Access Through Established Land Use Controls}

Before a community enacts specific land use controls for the purpose of protecting solar access, it is advisable that it first take the following steps: 
1. Gather information on existing and projected solar use, existing solar access, and the provisions of relevant land use regulations within the community.

2. Decide on appropriate levels of solar access to be protected; the major options here are rooftop protection, south-wall protection (which provides the opportunity for many "passive" solar designs), south-lot protection (covering the sough wall and parts of the lot adjacent to $i t)$, and detached collector protection. Starting with rooftop protection, which assures the least amount of solar access, each succeeding approach offers more access but also necessitates greater restrictions on nearby development.

3. Consider how potential solar goals fit in with other community goals and accepted development policies.

4. Draft appropriate goals and policies for the protection of solar access. It has been suggested that, for communities with a comprehensive plan, the logical place for these goals and policies is within that document. 153

Simply stated, a comprehensive plan is "an official public document adopted by a local government as a policy guide to decisions about the physical development of the community."154 Because the physical pattern of the community is a crucial factor in determining the availability of solar access, it is important that the plan include specific policies addressing this issue. Official solar goals and policies can serve as a guide for the development of land use control provisions to protect the desired amount of solar access within the community. The inclusion of a solar element in the comprehensive plan will also provide a strong legal rationale for these regulatory devices if they are ever challenged in court, since the legitimacy of such measures is greatly enhanced if they can be shown to be in accord with a community plan. 155

It has been suggested that to further assure the validity of land use controls designed to protect solar access, the comprehensive plan should include a statement of purpose in which it is convincingly explained why the promotion of solar energy use is in the public interest. Communities that do not have a comprehensive plan are still likely to 
benefit from drafting resolutions on solar energy and adopting solar access policies prior to the adoption of the kinds of land use controls discussed below. 156

\subsubsection{Zoning}

Because it regulates a number of factors relating to land use, including the height and setback of buildings, the zoning ordinance can be a powerful tool in shaping the physical layout of a community and the pattern of light and shadow within it. "Improperly" designed zoning laws can allow buildings to be constructed in such close proximity or to such heights that neighboring landowners interfere with each other's solar access. On the other hand, a statute developed with an eye toward optimizing the usable sunlight received by each individual property owner can create a situation where the opportunities to utilize solar energy systems are greatly enhanced. Following is a brief description of how various zoning techniques can be applied to achieve this end.

Traditional zoning. A number of ways have been suggested in which the factors commonly covered by the traditional zoning ordinance can be manipulated to protect the community interest in solar access. One way to limit the amount of shade cast on neighboring properties is to set appropriate height limits for buildings. This can be done through reducing the heights allowed in existing zoning ordinances. ${ }^{157}$ It may also be possible merely through redefining how height is calculated, since this is often figured as the distance from the ground to a point midway between the eaves and the actual peak of the roof. A final way to more strictly control building height is to limit the sometimes extensive list of exemptions, such as domes, chimneys, antennae, water tanks, and air-conditioning units, currently allowed under many zoning laws. 158

Shadows cast on potential solar sites can also be limited through the manipulation of setback and sideyard requirements. Where streets run from east to west, road frontage requirements can be reduced to encourage deeper lots along the north-south axis. A corresponding decrease of required sideyard setbacks can permit buildings to be sited 
with the long dimension running from east to west. The result is a structure with a long south-facing wall located in a yard that is significantly deeper from north to south than would otherwise be the case. This allows a solar. system to be set back sufficiently from its south property line to avoid being shaded by any obstructions on neighboring lots. By increasing required front and rear setbacks, builders can be forced to take advantage of this opportunity and build in the optimum (from a solar perspective) location. Access can also be improved by allowing zero setbacks along the north property line, which maximizes the distance between the primary structure and any obstructions on neighboring lots to its south. ${ }^{159}$

A final way in which traditional zoning techniques can be used to protect solar access is to lower allowable land use densities. ${ }^{160}$ The judicious use of height and setback requirements, however, as discussed above, may make this action unnecessary.

The use of traditional zoning techniques provides a relatively simple and effective method of protecting present and future solar access. through the use of a well-established regulatory device. Access provisions for the zoning ordinance can be developed that balance desired levels of prulecliun ayainst other community development goals. Because an area-wide approach is used, equal protection is likely to be provided, but court challenges may still arise if the new regulations significantly restrict other development rights. Finally, it must be remembered that zoning classifications are subject. t.n change hy legislative action, raising the possibility that solar access protection conveyed by a zoning ordinance could be removed at a later date.

Envelope zoning. Envelope zoning, also known as bulk plane zoning, is an old concept that has great promise for a modern purpose, namely, the protection of solar access on an area-wide basis. Very simply, erivelope zoning refers to the practice of defining the buildable area of a lot in three-dimensional terms. This envelope can be a simple square or rectangle, allowing development to a uniform height over the entire lot, or it can be a more complex geometric shape, with taller structures allowed on some parts of the property than on others. For 
the purpose of protecting solar access, an envelope could allow greater development on the south end of a lot than on the north, so as to protect adjacent properties from shading without unduly limiting a property owner's options to build. This offers a flexible tool whereby the restrictions placed on a landowner are directly related to how the development of his property affects the sunlight available to his neighbors. An added advantage of the solar envelope is that it can cover vegetation as well as buildings, providing a solar user protection from shadow regardless of the source. ${ }^{161}$ Because it is likely that, in many areas, trees will pose a greater threat to solar access than will buildings, the ease with which bulk plane zoning can address this is especially important.

Envelope zoning shares the strengths of traditional zoning while enjoying a greater flexibility which allows the achievement of desired levels of solar access protection with less potential interference with neighboring development. The development of effective envelopes, however, can require considerably more local data gathering and design work than are generally entailed in the traditional zoning approach.

For those readers with a greater interest in the envelope zoning technique, a more detailed discussion is presented in Solar Mocese Law: Protecting Access to Sunlight for Solar Energy Systems, by the Environmental Law Institute, and Protecting Solar Access for Residential Development - A Guidebook for Planning Officials, by the American Planning Association.

Negotiated zoning techniques. There are a number of zoning techniques in use where the exact configuration of allowable building and open spaces in a development is arrived at through a negotiation process between the builder and the community. The placement of "floating zones" is determined through such a negotiation process as are the exact siting requirements for planned unit developments (PUDs) and mixed use developments (MXDs). It has been suggested that the flexibility offered by such zoning approaches is well suited for protecting solar access while at the same time assuring that this does not impose undue restrictions on other kinds of development. 162 As solar usage increases, the use of 
PUDs and MXDs will retain their original advantages, but a reliance on floating solar zones could give an unplanned flavor to solar access decisions, making this approach less desirable. A thorough treatment of all these negotiated techniques is offered in the American Planning Association's solar guidebook, referenced earlier.

Performance zoning. A final zoning technique that can be used to protect solar access is based on the concept of the performance standard discussed earlier for building codes. Instead of prescribing heights or setbacks that must be adhered to within a particular zone, this approach sets a maximum amount of shadow that structures or vegetation on one lot can cast on another. 163 While the requirements imposed by other zoning methods can be designed with a particular level of performance in mind, performance zoning makes this level explicit but leaves it to the property owner to determine how his development opportunities will be affected by the necessity of meeting this goal. Because required heights and setbacks are not specified, establishing compliance may be more difficult than under other zoning techniques.

As with other land use controls, the enactment and enforcement of zoning ordinances have traditionally been under local control. To date, little has been done at this level to modify zoning provisions toward the end of protecting solar access; it is likely, however, that as solar usage increases, the perceived need for local statutes to assure access will grow correspondingly. Technical and financial assistance from the federal and state governments could greatly facilitate the local planning effort that will be required for the design and adoption of solar zoning provisions.

While a wide range of options is open to state governments in this area, their primary involvement so far has been through the enactment of enahling legislation empowering local governments to include solar access considerations in their zoning laws. Among the states that have acted in this fashion are Connecticut, Minnesota, and Oregon, 164 and it is expected that more will join their ranks in the near future. While it has been posited that the courts would probably uphold the right of local governments to protect solar access under their existing police 
powers, it is still considered advisable for the states to make this authority explicit, as those mentioned above have done.

Like the states, the federal government could act to protect solar access in any one of several ways, but their involvement to date has been minimal. As mentioned earlier, technical and financial assistance from this quarter to encourage local enactment and enforcement of solar zoning provisions is likely to be well received.

It has been hypothesized that the widespread use of solar energy systems wi11 be accompanied by worsening urban spraw1 as the growing need for solar access necessitates greater distances between buildings. Closer study, however, suggests that this fear may be ungrounded. One energy-conscious architect has suggested that south-wall access can be achieved at densities of slightly over eight dwelling units per acre for single-family detached residences, much greater than the current norm, and ten per acre for attached row houses at $40^{\circ}$ north latitude. 165 Where only rooftop access is desired, much higher densities are achievable, provided that building heights are kept fairly uniform throughout the area. ${ }^{166}$

While the overall lot size will not have to increase, the precise configuration of buildings and vegetation may have to be altered in order to accommodate solar use. In many areas, building heights will not have to vary significantly from current practices, ${ }^{167}$ but the shape of lots, required setbacks, and the location of large trees may all necessitate some variation. Buildings are likely to be significantly further from neighboring structures and vegetation on the north and south than from those on the east and west. To achieve this, lots could be laid out on a grid pattern with narrow east-west dimensions and deep north-south ones, 168 but more innovative urban design is also possible, with public rights-of-way and open spaces used as buffers between solar systems and other development. 169 Traditional setbacks are likely to be modified, and the common practice of siting structures parallel to roadways may be abandoned in favor of siting explicitly to optimize solar orientation. 170

Zoning is a well-established land use control that can be applied in a number of different ways to protect solar access. Its utility has 
been recognized for new developments, where access can be protected from the start, as well as in established areas, where existing access can be saved and gradual changes begun that will eventually improve current conditions. The technique of envelope zoning, in particular, was recently endorsed by the ELI; in their previously mentioned study emphasizing solar access for existing developments, the ELI called solar envelopes "the best presently available legal device for protecting solar access for entire cities and neighborhoods."171 Envelope zoning can likewise be important in new areas, but in that situation other effective tools for encouraging solar use are also available. One such device will be discussed in the following section.

\subsubsection{Subdivision regulations}

Subdivision regulations are local ordinances which set requirements pertaining to how raw land is converted into building lots; typically, these regulations control the layout of streets, lots, and buildings and the dedication of open space, all of which are important in determining the level of solar access that will be available in new developments. The direction in which a building is oriented is generally determined by how its lot is oriented, which, in turn, is based on the layout of area streets; 172 the location of open spaces can serve as a buffer between solar systems and neighboring obstructions. Through the careful design of regulatory provisions covering the above factors, new developments can be required to assure sufficient unobstructed sunlight for rooftop, south wall, or any other desired level of solar access protection. To reduce the risk of legal challenges to such locally enacted regulations, it would be prudent for state governments to first pass enabling legislation explicitly empowering local governments to act in this manner.

Provisions governing street layout and design. Many local subdivision regulations have provisions requiring that new streets line up with existing streets outside the new development, or that streets follow area topography; but the actual direction in which they must run is generally not specified. For the purpose of assuring solar access, however, 
the exact orientation of streets is vital. In both low- and higher-density residential areas, optimum solar access is achieved where buildings are located along east-west. streets. For this reason, subdivision regulations that aim to assure solar access should require that all new streets, where practicable, be laid out along the east-west axis. Such a plan has been proposed by the community of Contra Costa, California, in their recently issued guidelines for energy conservation in new developments. 173

The east-west orientation is considered optimum because, in most developments, lots are laid out with their short dimension parallel to the street and their long dimension at right angles to it. On east-west streets, then, lots will be deepest from north to south, which allows the best building orientation when conventional siting practices are followed. In neighborhoods of detached single-family residences, the long dimension of houses generally runs along the short lot line, parallel to the street. East-west streets thus mean east-west houses, with one long wall facing south for the optimum south-wall axis. In more densely developed areas, where row houses or other attached dwellings are common, the long dimension of buildings generally runs parallel to the long lot line, but each unit still has its own narrow street frontage. In this situation, east-west streets mean that the longest walls of multifamily dwellings run from north to south, but each individual unit will still have one short south-oriented wall for potential solar energy use.174 In addition to dealing with the orientation of streets, subdivision regulations can also address the required width of streets and rightsof-way. It has been suggested that streets could be widened to increase the distance between structures and improve solar access. This possible benefit, however, must be weighed against the negative effects which more pavement could mean in terms of increased runoff and higher summer air temperatures. At the same time, proposals to narrow streets for the above reasons must be carefully examined for any possible negative impacts on neighborhood solar access. 175

Lot line angles and frontage requirements. In most areas, as mentioned earlier, lots are created with their short dimension parallel to the roadway and their long dimension perpendicular to it. Since 
typical subdivision regulations require side lot lines to be at right angles to the street, east-west roadways will automatically mean lots that are deepest from north to south, providing optimum sites for buildings which follow lot lines. Where streets do not run east-west, however, lots which are set at right angles to them will no longer provide the best possible solar orientation. To address this, it has been suggested that requirements for perpendicular lot lines, be dropped. to allow greater flexibility when streets are not oriented "properly." Another possibility is for provisions requiring that the longest dimension of a lot run from north to south, regardless of street layout. ${ }^{176}$ Both suggestions could be effective in creating lots that afford good solar building sites.

The discussion on zoning pointed out that minimum lot frontage requirements may have to be reduced on east-west streets to allow deeper lots from north to south. Subdivision regulations generally include the same provisions on this as does the zoning ordinance, and it is suggested that, where necessary, they be modified in the same fashion. 177 Subdivision ordinances could also require developers to take account of solar access when planting vegetation in new developments. 178

Building setback requirements. Local subdivision regulations generally require that a building be sited on its lot parallel to the property lines, according to certain specified front, side, and rear setback distances. The effect of this is to make the orientation of buildings dependent on the orientation of lots and streets. Where these are not optimum for the protection of solar access, flexible setback requirements can allow buildings to be sited other than squarely on the 1ot. Because setback provisions often follow those established in the zoning ordinance, it will be necessary to make similar changes in that document as we11.179

Provisions for dedication of open space. Subdivision regulations generally include provisions requiring developers to dedicate open space for parks, playgrounds, and schools. The amount of land necessary for these purposes is commonly specified, but the exact location is usually left to the developer's discretion. Because open space acts as a buffer 
between neighboring properties, separating one from the shadows cast by the other, locational requirements for this dedicated land can be an important component of regulations designed to protect solar access. ${ }^{180}$ Specifically, solar access buffer space can be required between taller buildings and shorter ones where the shorter structures would otherwise be shaded. In other cases, open-space corridors could be required to run through developments to provide an undeveloped "safe space" between neighbors. Finally, the amount of open space to be dedicated could be increased if this were found necessary for the desired level of solar access protection.

In addition to dedicating open space for public purposes, dcvelopers are alsó frequently required to dedicate easements for purposes such as the placement of utility lines or public rights-of-way. An easement conveys to one party a limited right to use the property of another without owning it. In the case of solar access protection, "negativc" easements could be drafted which forbid a "burdened" property owner from using a designated piece of land so as to shade adjoining parcels. It has been suggested that subdivision regulations require the dedication of such solar easements throughout a new development. Individual property owners would then be bound by restrictions in their deeds designed to keep them from casting a shadow on their neighbors. $181 \mathrm{~A}$ turther discussion of solar access easements will be found in Scct. 4.3.1.

Another possible approach to protecting access with subdivision regulations is to use performance standards to require optimum solar orientation. These standards could apply to the orientation of lots, as is the case in Sacramento County, California, wherc subdivision review standards specify that the long axis of a lot must be oriented to within $22.5^{\circ}$ of true north. Performance standards could also apply directly to buildings, requiring that a certain percentage of all structures be sited within a specified number of degrees of the optimum solar orientation for that area. As mentioned earlier, this means that the long axis of single-family detached structures will run roughly from east to wesl, while town houses and other attached dwellings will have their long axis running north-south. While the use of performance standards, because of their directness, could be very effective in 
achieving desired solar orientation in new developments, it is expected that the administrative burden placed on local officials to determine compliance would be greater than with the traditional prescriptive approach. 182

As with zoning ordinances, the enactment and enforcement of subdivision regulations are generally considered a local responsibility. Several examples of local efforts to use these regulations to protect solar access were cited above, and the possibility is great for future actions in this direction by other counties and municipalities. At the state level, Connecticut, Minnesota, and Oregon have adopted enabling legislation giving local governments the power to amend their subdivision ordinances for the purpose of assuring access, 183 and California recently took preemptive action requiring locales to deny approval to new developments that do not provide for the future use of passive solar systems. 184 To date, federal involvement in this area has been minor, but technical and financial assistance to develop needed controls may be forthcoming.

In general, the land use pattern likely to result from developers following subdivision regulations designed to protect solar access is similar to that projected earlier in the discussion on zoning. Structures will be significantly further from each other on the north-south axis than from east to west. Most development is likely to take place along east-west streets, which will serve both to orient buildings optimally and to buffer them from neighboring obstructions. The accepted shape of lots may change, with the possibility of fewer rectangles and more narrow, deeper lots. Building siting may also change, with a greater emphas is un solar orientation and less on following lot lines or facing the street. Finally, the use of open spaces as solar buffers may be expected to appear, both in the form of parks located between areas built to different heights and in linear greenbelts running throughout neighborhoods. The use of solar access easements could also result in more open space along property lines, with large trees set back further than illay now be common. As mentioned earlier, allowing for solar access. should not necessitate lower-density development; neither should aesthetics nor design flexibility have to be sacrificed. 
The subdivision ordinance emerges from the preceding discussion as a potentially effective tool for protecting solar access in newly developing or redeveloping areas. Not only can it require streets, lots, and structures to be oriented so as to allow the use of active solar energy systems, but it can encourage the pervasive use of passive solar building design as well. The regulations which achieve this goal are not expected to significantly interfere with a landowner's right to develop his property, and it is expected that solar access protection can be achieved in harmony with other community development goals. Once an area has been developed, all lots will be assured comparable levels of solar access and, where solar easements are written into deed restrictions, all will he equally burdened. Finally, by setting a fixed pattern of streets, lots, and buildings, a fair amount of certainty concerning future sular access is provided. A drawback to the use of subdivision regulations, however, is that they no longer apply once a develupment is completed and sold. This means that, without other public statutes or deed restrictions, existing levels of solar access can be partially eroded by future additions to structures and private plantings. ${ }^{185}$

\subsubsection{Vegetation controls}

I radlliumaliy, laws controlling vegetalion have becn enacted for several purposes. These include the assurance of aesthetic quality in a community, the buffering of various land uses from each other, the enhancement of property values, the achievement of environmental benefits such as erosion control, and, musl recently, cnergy concervation through the moderation of wind and sun. Another possible applicalion of vegetation controls is to limit shadows cast on solar enérgy syslemis. ${ }^{18 \mathrm{~h}}$ Since the worst shading problell is causcd by trees, as npposed to smaller flora, this section will focus on tree control ordinarices and how they can be adapted to protect solar access.

Tree controls can be roughly divided into two broad categorics: those that regulate the planling and maintenance of trees on public property and those that cover trees on private land. In this latter category, there are regulations that pertain to the preservation of 
trees on developing land and regulations controlling the characteristics of new plantings. These provisions can either stand alone in a separate document or be included in another land use control such as the zoning ordinance. 187 As with the use of any regulatory device to protect access, it is recommended that the existing statement of purpose be modified to include solar goals and that state enabling. legislation be examined and changed if necessary to support access objectives. It is also important that communities carefully choose the appropriate level of access to be protected by balancing the importance of solar use against other local goals that could be affected by actions in this area.

Controlling trees on public lands. Laws that regulate the placement and maintenance of trees along roads and in other public areas are generally referred to as "street tree ordinances" and enjoy widespread use. Such ordinances will either prescribe specific planting standards within the body of the document or will reference a master street tree plan which maps out the planting arrangement of designated species for the entire-community. In either case, the varieties of trees allowed can be conditioned on how their physical attributes affect solar access. Such characteristics as height, canopy size, and the time of year that old leaves fall and new ones grow are all important in determining how much shade a tree will cast and can be taken into account in compiling tree lists. 188

The location of trees is also very important in determining the amount of solar access that will be available, and this too can be controlled by local ordinanccs. Where standards are prescribed in the body of the document, guidelines for choosing "proper" location in terms of solar access can be inserted. These can be quite generat, declaring that solar access should be taken into account in tree siting decisions, or they can be more specific, requiring measures such as the planting of shorter trees on the north side of streets than on the south. Street tree plans offer more control than the most specific guidelines, however, because they actualiy site trees on a street-by-street basis. The use of tree plans allows optimum locations to be chosen for specific species with the aim of protecting desired levels of access, and, for 
this reason, the American Planning Association recommended this approach in its recent solar access guidebook. ${ }^{189}$

Finally, most tree ordinances specify conditions under which trees can be removed. This is considered an extreme action and is generally only justified by extreme circumstances such as when trees are seriously diseased or they pose a threat to the public safety. It has been suggested that interference with solar energy systems could be added as a justification for tree removal. Since such an action could be unpopular, provisions to require the trimming of trees that obstruct solar access should be considered as a more politically acceptable alternative. 190

Controlling trees on private property. Reyulations covering the preservation of existing trees during the development process are used by many communities. Generally, these establish conditions which must be met before trees over a certain minimum size can be cut. It has been suggested that solar access be added to existing considerations, removing the obligation to preserve trees that would obstruct solar systems.191

Another type of tree control is that which regulates new plantings on private property. Buffer strips are sometimes required between incompatible land uses, and these may include minimum allowable heights. For the purpose of solar access protection, amendments can be drafted that add maximum height limits as well. Some locales also have ordinances which require the planting of trees in new developments, but these are much less common than the measures discussed previously. Where they do exist, guidelines could be included that make clear the community's interest in solar access protection and how this can be achieved.1.92

While the controls described above can be used to protect solar access at the time an area is developed, they do not. rnver plantings that may occur after a new development is approved.193 Measures are also needed, therefore, that offer protection from trees planted after project approval. A deed restriction that forbids property owners from planting trees in such a manner that shading of neighbors occurs is one method that has been suggested to protect future solar access. This approach will be discussed further in Sect. 4.3.2. Various zoning techniques, such as envelope and performance zoning, can also be used 
to control shadows from vegetation, as can a number of "sun-right" approaches discussed earlier. Finally, the use of "tree permits" has been proposed as a possible way of limiting shadows cast by trees on solar systems. Under this plan, an individual would have to apply for a permit before planting a tree on his property; approval would be granted only if the size and location of the tree do not pose a potential threat to the solar access of neighboring landowners. While this could be very effective in protecting access, it is likely to be considered an infringement on accepted property rights and could also be difficult to administer. 194

While measures to control future plantings can be used to prevent existing levels of solar access in established areas from being further eroded, they do not address the problem of shading caused by vegetation currently in place. While it may be possible to require old trees to conform to new standards within a set period of time, this is likely to meet with considerable resistance from those whose trees are set for extensive pruning or removal.

In many areas it is expected that trees will present a larger threat to solar access than will buildings. Vegetation controls can be modified in order to address that threat, and it is likely that shadows cast by trees on public lands can be reduced through the use of properly designed street tree ordinances. Success is anticipated here because laws controlling public trees are well established and do not restrict the rights of individual owners to use their property. Gaining support for measures that control private plantings may be more difficult, however, particularly where future plantings are addressed and in areas where extensive trimming or removal of existing trees may be desired.

\subsection{Other Legal Devices for Protecting Solar Access}

In addition to the various "sun-right" approaches and the established land use controls discussed in Sects. 4.1 and 4.2 , there are a number of other legal devices that can be used to protect solar users' access to sunlight. As stated in the Introduction, these include the use of easements, restrictive covenants, TDR, ZSAFED, site plan review, and 
environmental impact assessments. There is a great deal of variety among the above approaches. Some involve the use of public statutes, while others protect solar access through private agreements. At the same time, some necessitate no private or public outlay of funds, while others call for cash payments as compensation to "burdened" landowners for restrictions placed on their development rights. Each approach will be discussed below.

\subsubsection{Solar access easements}

An easement conveys upon its holder certain specified rights in respect to the property of another. $\Lambda$ "positive" easement allows the holder of that easement, called the "benefitted" party, to use the property in question, called the "burdened" property, in certain specified ways, as for the placement of utility lines. A "negative" easement, on the other hand, forbids the "burdened" property owner from using his land in certain ways. A solar easement would fall into this latter category, restricting the placement of buildings or vegetation on the burdened property that would shade a benefitted party's solar system. ${ }^{195}$

Easements are generally purchased through the payment of a fee by the benefitted party to the burdened party, and the terms of the agreement are recorded with a public agency such as the registrar of deeds; easements can also be acquired by local governments through their power of eminent domain. Currently, easements for light and air are legal in most states, but to guarantee that solar access easements are binding and can be transferred to subsequent property owners, it is recommended that states pass legislation expressly establishing the legality of this kind of agreement. 196

Privately negotiated easements. It has been suggested that solar access easements negotiated between private parties include the following elements: the exact description of the burdened property; the terms of the grant, including the conditions under which it will be terminated; the means for compensating the benefitted party for any future interference with his solar system; and provisions for compensating the burdened party for any costs involved in maintaining the easement.197 
For a more detailed discussion of solar easement design, the reader is referred to Solar Law, Present and Future, with Proposed Forms, by Sandy F. Kraemer, and the American Planning Association's previously referenced solar access guidebook.

The privately negotiated solar easement has a number of strengths as a solar access protection device. Because it is voluntary and provides compensation to property owners whose development opportunities are limited, the easement is likely to be politically acceptable. In addition, no public expenditure or government "red tape" is involved, the exact terms of the agreement can be fitted to the individual situation at hand, and solar access can be protected in new developments as well as in established areas. On the negative side this is a potentially expensive approach where all the costs of access protection are borne by the solar user, despite the fact that the increased use of renewable energy sources is widely seen as being in the public interest. Finally, obtaining solar easements can be difficult, especially where a number of different property owners are involved, and enforcement can pose significant problems. 198

Publicly acquired easements. Another approach to the use of solar access easements is to have local governments acquire them through their power of eminent domain. Under this method, property owners within a community would be required to grant solar easements in return for monetary compensation. Because any land condemned in this fashion must be put to a public use, it is considered advisable for the state to pass legislation authorizing this activity and declaring that the protection of solar access is in the public interest. Once the needed solar easements are acquired, they can be transferred to the benefitted property owners, and those parties could then be assessed the costs of acquisition; another option would be for the community as a whole to absorb the associated costs. ${ }^{199}$ An alternative to public purchase of solar easements is to amend local subdivision regulations to require that easements be dedicated during the development process, as discussed in Sect. 4.2.2. 
The use of solar access easements acquired through local powers of eminent domain can afford protection to solar users in both newly developing and established areas. However, as with privately negotiated easements, a substantial expense could be entailed. There is also the danger of legal challanges to the public condemnation of land to protect individually owned solar energy systems.

To date, the states have taken a more active role in promoting the use of privately negotiated solar easements than they have with any other access protection device. Primarily, this involvement has been in the form of the enactment of laws providing for the creation, conveyance, and recordation of voluntary easements. As of early 1979, a dozen states had passed such laws, 200 and it is likely that more will do the same. At the local level, ordinances have been developed for the cities of Santa Clara, California, and Colorado Springs, Colorado, which affirm the right to create solar easements between individual property owners. ${ }^{201}$

Because of the active state role it is unlikely that local governments will significantly increase their involvement in this particular area, but the future may find more local initiative in the area of publicly acquired solar easements.

The major effect which solar access easements will have on community land use is that concerned with improvements to property, particularly the planting of trees, which are likely to be set back further from property lines and may be shorter than in areas not using this device.

The privately negotiated easement is a flexible tool that can be used by individual property owners to protect solar access and that has received much attention at the state level. It can be used in both new and established areas, offering a permanence not provided by amendable land use controls, but it can also be very expensive for solar users and present difficulties in creation and enforcement. Publicly acquired easements present a way by which local governments can assist solar users in obtaining access protection, but, again, the costs are much greater than with those approaches based on police power, discussed earlier. 


\subsubsection{Restrictive covenants}

As mentioned earlier, restrictive covenants are often drafted at the time an area is developed to impose limitations on the allowable uses of property for the purpose of improving the new development's desirability. These covenants are normally incorporated into the deeds of individual landowners and are legally binding for them and all subsequent owners. It has been. widely suggested that. this device could be easily adapted to the protection of solar access on a neighborhood scale. ${ }^{202}$

Quite simply, solar access covenants would limit the allowable height and location of vegetation and structures on individual lots so as to prevent their casting shadows on neighboring solar systems. These restrictions could be drafted by a developer and incorporated into each deed at the time lots are sold in a new subdivision or industrial park; in this way, solar access would be ensured throughout the entire development. If developers do not voluntarily choose to impose the necessary restrictions for access protection, it has been suggested that state or local governments could require the appropriate covenants as a condition of project approval. Finally, on a smaller scale, a group of property owners could draft their nwn mutually binding solar access covenants, but getting widespread approval of such agreements may be difficult. 203

There is much to recommend the use of restrictive covenants to protect access. They offer a method whereby access can be assured throughout entire developments. The restrictions imposed upon private development opportunities are imposed equally on all property owners, as are the benefits of solar access. Because growth is not expected to be unreasonably limited, access protection should be compatible with other community goals. Finally, solar access is reserved for prospective future users as well as present ones.

The major weakness of this approach is that it is of little bene$f i t$ in established areas where structures and vegetation are already in place. The usefulness of covenants is also diminished where growth takes place on a piecemeal basis with many different developers; under these circumstances, there is much less opportunity to include uniform deed restrictions throughout an entire area. Lastly, the enforcement of 
restrictive covenants can sometimes be a costly and time-consuming process. 204

The use of restrictive covenants is expected to have much the same effect on community land use patterns as will the utilizing of solar easements, discussed in Sect. 4.3.1. The height of trees and buildings may be limited, and development will tend to be set back further from property lines.

To sum up; the restrictive covenant can be a very effective tool for protecting solar access in new. developments, even though enforcement may raise some problems. This view is shared by a number of observers, one of whom recently called the use of well-prepared solar covenants "the most effective method of providing sunlight to new residential developments." 205

\subsubsection{Transfer of development rights}

The transfer of development rights (TDR) is a method of controlling land use whereby property is broken down into two separate components: the physical land itself and the right to develop it. If the public interest demands that a piece of land be limited to less than the fuli growth allowed by $l a w$ in that zone, as in historic preservation districts, the "development rights" lost by such restrictions call be transferred to another tract of land, increasing the intensity of development ailowed on that parcel. Allowing the sale of these development rights is an attempt to compensate landowners for any losses caused by the restrictions imposed on their property, without necessitating direct government payment. Currently, the TDR concept is still very new and largely untried; if TDR does become a viable land use control, however, it could conceivably be used to compensate property owners for development opportunities lost due to the need to protect solar access for neighboring properties. 206 With TDR, the density of development may decrease in areas of high solar usage and increase correspondingly somewhere else; this shift may not be necessary, however, since good solar access is achievable in many areas at higher land use intensities than are currently the norm. 
While TDR must be recognized as a possible way to protect solar access, it is too early to know how widely it will be used and with what degree of success. The administration of any TDR scheme is likely to be complex, with methods needed to allocate, transfer, and arrange compensation for development rights. In answer to that need, the ELI has recommended that states pass enabling legislation authorizing local experiments with TDR. ${ }^{207}$

\subsubsection{Zoning by special-assessment-financed eminent domain}

Zoning by ZSAFED is a rarely used land use control that may have. some applicability for protecting solar access. Basically, this allows a majority of the landowners in an area to restrict various land uses in their district by purchasing the rights to develop in those "undesirable" ways; the funds to pay for this will be raised by an assessment of all benefitted property owners. For the purpose of solar access protection, states could authorize the formation of solar ZSAFED districts where the majority favors this. Land uses that block sunlight to solar users would then be forbidden, and the owners of the restricted properties would be compensated for their 10ss. As with TDR, the ELI recommends state legislation allowing local experimentation in this area, 208

\subsubsection{Site plan review}

Site plan review is the process whereby a detailed plan of a proposed development, generally in map form, is reviewed by a local governing body in order to determine the project's acceptability. This mechanism is widely used in the enforcement of subdivision regulations and zoning provisions covering PUD; in recent years, site plan review has been used to evaluate other types of development as we11.209

It has been suggested that solar access considerations could easily be incorporated into the site plan review process, with the result that approval of a proposed new development would be made contingent on its protecting a specified level of access for prospective solar users. Compliance with this general requirement, or a set of criteria designed to implement it, would be determined from information submitted concerning 
the physical layout of the proposed development and the environmental characteristics of the specific site on which it is to be built. The strength of this approach is that it assures the protection of desired levels of solar access in new development through detailed site-specific review. The major drawback is that a great deal of additional time and expertise may be required of local officials for successful implementation. 210

\subsubsection{Environmental impact assessments}

At the federal level; as well as in some states and locales, the preparation of an environmental impact assessment is a prerequisite for government approval of certain kinds of activities that could have a significant effect on the human environment. While the federal requirements apply only to public actions, some states and locales extend their coverage to various private projects as well, such as the development of new residential, commercial, or industrlal areas. The impact that the project at hand is expected to have on the immediate environment, and often on the community as a whole, must be examined before construction may begin. The integration of solar considerations into the assessment process should be difficult and has been suggested as one more way in which access can be addressed. 211

Specifically, it has been proposed that several basic solar questions be addressed within the environmental impact assessment. These are: (1) Will the proposed project shade neighboring properties and, if so, to what extent? (2) Within the project itself, what level of solar access will be provided and will this be sufficient for projected needs? (3) If solar access is provided, will any negative environmental impacts be incurred in the process? ${ }^{212}$ The answers to these questions will provide important information about solar access for the project in question but will not, in and of themselves, guarantee that access will be provided.

While the consideration of solar access impacts could increase the overall value of the environmental impact assessment in those jurisdictions where it is required, it does not seem that this method is the best 
available for protecting access. As it stands, the impact assessment process can point out potential problems, but it does not expressly forbid actions that block solar access nor does it set specific standards for the approval or denial of proposed projects. 
5. FINANCIAL INCENTIVES AND IMPEDIMENTS TO THE USE OF SOLAR TECHNOLOGIES

Cost is a very important factor in determining the attractiveness of solar energy systems to prospective buyers. It is important to note, however, that much more is involved here than the purchase.price of solar equipment. The actual cost to the consumer will be strongly influenced by tax rates, by interest rates and the willingness of lending institutions to make solar loans, by the price of competing fuels, by government policies toward the direct purchase of solar devices, and by the availability and cost of insurance covering system damage and owner liability for injury to others caused by faulty solar systems. Each of these topics will be discussed separately in the following sections.

\subsection{Taxation}

Government policy toward the taxation of solar users can be an important factor in determing the economic viability of this energy source. Property tax, sales and use taxes, and income tax rates can all affect the ultimate cost of solar systems, and all can be modified to reduce those costs.

\subsubsection{Property tax}

Property taxes are generally levied by local governments based on the assessed value of real properties within individual juristictions While state governments do not normally share in the revenues collected, they do exert a great deal of influence over local actions in this area. Among other things, the states commonly certify local asseșors, define. which types of property are subject. to taxation and which are exempt, and provide guidelines for the assessment of those properties that are taxable. In contrast, the federal government has traditionally been excluded from the property tax arena. 213

Because the capital cost of a solar energy system is generally greater than for a "conventional" system, it is considered likely that the assessed value of the solar system will also be greater, resulting 
in a heavier property tax burden for the solar user. To remove this disincentive to solar use, it has been widely suggested that any additional value added by the installation of solar equipment be exempted from the property tax. Such an action has been defended as encouraging increased solar usage without reducing existing tax revenues. However, there may be legal problems involved with this because most states have "uniformity clauses" in their tax laws or their constitutions which hold that all similarly situated properties. must be taxed at the same rate.214

In some states, constitutional amendments will be necessary in order to exempt solar systems from the property tax. Voters in Florida, Texas, and Georgia have all recently approved amendments allowing such exemptions. 215 In most states, however, solar property tax exemptions can be instituted through legislative action. One available option is for state legislatures to simply declare solar equipment exempt from the property tax. Such actions have been taken for other public interest items such as pollution control devices, fallout shelters, and homesteads for disabled veterans. ${ }^{216}$ Another possible approach stems from the fact that, in many states, properties are classified according to their use and character, with different tax rates applied to different classifications; since the same rates apply to all properties within a given classification, the uniform treatment of "similarly situated" properties is upheld. Under these circumstances, solar systems could be given preferential tax treatment by placing them in a separate class from structures utilizing conventional energy sources. Finally, solar systems cuuld be exempted from property taxes by legislative action defining them as personal, rather than real, property. 217

It has been postulated that the widespread use of property tax exemptions could increase solar usage over what it would otherwise be, particularly in the area of single-family, owner-occupied residences. 218 Toward that end, there has been a great deal of activity in this area, mainly at the state level. As of January 1979, 28 states had passed laws offering property tax exemptions for solar energy systems, making this the most widely used solar financial incentive to date. In all but two of the 28 states, the solar exemption applies to commercial and 
industrial structures as well as to residences. Some states automatically exempt solar systems, while others require the owner to apply. Finally, close to two-thirds of the states have established time limits governing when systems must be installed to qualify for the exemption and/or for how long the exemption witl last.219

At the federal level, several possible strategies have been suggested whereby states and locales can be encouraged to grant property tax incentives to solar users. Federal funds could be used to pay state and local governments the additional revenues that would have been generated by solar installations without the existence of a tax break; another approach would be to deny specified forms of federal aid to states that do not enact the desired measures. 220

As the above discussion shows, exempting solar equipment from the property tax is a widely used method of encouraging solar use. It is suggested that, at a minimum, tax exemption measures should include a clear definition of what constitutes a solar energy system, should specify how backup energy systems will be assessed, and should explain how solar access easements will be assessed and taxed.22l

\section{1 .2 Sales and use taxes}

Sales and use taxes are levied by state and local governments on goods sold, transported, or stored inside their jurisdictions. 222 Because such taxes add to the purchase price of solar equipment, it has been suggested that this equipment should be exempted from them, thereby lowering front-end costs and increasing the attractiveness of solar to the consumer. 223 Unlike the property tax, the sales tax is yerrerally not subject to "uniformity clauses," and this simplifies the process of adapting it to the purpose of providing incentives to solar users. 224

Of a 11 levels of government, the states have taken the most active role in providing sales and use tax exemptions for solar users, just as they have done with the property tax. The amount of activity here, however, is much less than in the previously discussed area. As of early 1979, only eight states had passed legislation exempting solar equipment from sales and use taxes. Residential systems are covered in all eight 
states, while commercial systems are covered in seven and industrial in six. Three of the states have set definite expiration dates for this incentive, while the remaining four have left it open. 225 As with the property tax, the federal government can encourage action by states and

locales by reimbursing them for lost revenues or by denying federal aid to jurisdictions that do not adopt the desired measures.

A number of observers have predicted that the impact of sales and use tax exemptions on the solar commercialization effort is likely to be minor, 226 especially compared with measures such as property and income tax incentives.227 However, the sales tax exemption does make a contribution, thought sight, to reducing the front-end costs of solar systems and may, according to one author, give a "psychological lift to manufacturers and potential users of solar devices."228

\subsubsection{Income tax}

The modification of income tax rates is one more method by which incentives can be provided for the use of solar energy systems. The provision of solar credits, deductions, and accelerated depreciation and amortization schedules have all been suggested as ways in which solar usage can be encouraged. Such measures could further the solar commercialization effort, but the cost in lost revenues to the federal and state governments is likely to be relatively large. 229

The provision of solar credits is the most widely used type of income tax incentive to date. Under this approach, a certain proportion of the cost of solar equipment is subtracted from the consumer's total tax bil1. Because the credit is received in the same year that the solar purchase is made, many observers see this method as helping to relieve the burden of high front-end costs which may discourage potential buyers.230 The amount of the tax credit is determined independent of the taxpayer's income and can be made available to residential, commercial, and industrial solar users. 231

At the federal level, the recently passed Energy Tax Act of 1978 (PL 95-618) provides a tax credit for residential solar users and an investment credit for commerce and industry. The residential tax credit, which w11l expire at the end of 1985, applies to active solar systems 
and nonstructural components of passive systems; a credit of $30 \%$ is allowed on the first $\$ 2000$ of the solar purchase and $20 \%$ on the next $\$ 8000$, for a maximum of $\$ 2200$. For commercial and industrial users, an investment credit of $10 \%$ is allowed on expenditures for solar equipment, ending on December 31, 1982.232 The size of the investment credit has been surrounded by controversy, since many observers both inside and outside of government had originally expected it would be $20 \%$, as opposed to the $10 \%$ that can now be claimed for investments on most solar technologies. 233

Sular income tax incentives have been passed in 16 states; in 12 uf these, tax credits of varying amounts are provided for solar users. Most of these state tax credits are aimed primarily at residential structures and may actualiy exclude commercial and industrial buildings. The amount of the credit offered varies widely from state to state, ranging from $10 \%$ of the cost of installation in Alaska, with a maximum credit of $\$ 200$, to $55 \%$ of solar costs in California, with a maximum of $\$ 3000$. Many. of the states offering credits have limited the length of time during which those credits can be claimed; for all types of income tax incentive programs, the average termination date is 1983.234

While not as popular as the tax credit, solar income tax deductions are nffered in five states. Under Lhis appruach, a specified proportion of a solar system's purchase price can be subtracted from the buyer's total gross income for the purpose of figuring his tax obligation. The exact amount that can be deducted varies from state to state. 235

In addition to tax credits and deductions, some states allow accelerated depreciation or amortization scheduies to be used by owners of solar equipment. Under this approach, the cost of the solar system can be depreciated or amortized more rapidly than would otherwise be allowed, with a resulting decrease in the owner's tax obligation. As of early 1979, provisions of this kind had been adopted in four states.236

Income tax incentives of various kinds are enjoying substantial usage at both the federal and state levels; of the available options, the tax credit is the most popular. It has been suggested that the use of such incentives could significantly increase the use of solar energy 
in this country ${ }^{237}$ but that any tax incentive offered should specify a termination date to avoid the problem of governments being saddled with tax programs that have outlived their usefulness. ${ }^{238}$

\subsection{Lending Policies and Interest Rates}

It is generally acknowledged that the initial costs of solar energy systems are often high relative to the cost of conventional systems. Because the required capital investment for solar equipment can be significant, the availability of financing and the terms at which it is available are important factors in determining this energy source's economic feasibility. If loans are hard to obtain, if large down payments are required, or if interest rates are unattractive to potential buyers, solar commercialization may be significantly impeded. The following sections will examine solar lending policies and interest rates and will discuss several methods that have been suggested for making capital more readily available at more attractive terms for prospective solar users.

\subsubsection{Solar lending policies}

The availability of financing for prospective solar buyers is strongly influenced by events in the primary and secondary mortgage markets and by public and private loan insurance programs. Primary mortgage lenders are those who deal directly with the borrower, providing the funds needed for new construction and retrofit installations; the policies established toward solar loans by this sector, therefore, can have an important impact on the availability of funds for solar purchases. The secondary mortgage market consists of those agencies and institutions that purchase mortgages from primary lenders. These secondary market entities play an important role by providing a steady supply of capital to primary lenders, who, in turn, pass it on to the building industry. The policies at this secondary level toward the purchase of solar mortgages will also be important in determining the rates at which funds are made available to prospective solar buyers. Finally, the guidelines established by loan insurance programs can have a significant effect on 
the availability of financing for solar energy systems. The willingness of these insurors to underwrite loans on solar energy systems as well as the maximum loan size and the proprotion of total system costs which will be covered will in turn impact the solar loan decisions of primary lending installations. 239

Primary mortgage market. Nearly all primary mortgage loans for new residential construction are made by commercial banks, life insurance companies, mortgage bankers, or "thrift institutions" such as savings and loan associations and mutual savings banks. Of the four, thrift institutions are the single most important force in today's market, doing a greater volume of business than any of the others. 240 The policies of these institutions toward making solar loans will be largely determined by two major factors: government regulations and the attitudes of the lenders themselves toward this energy technology.

of particular importance in the regulatory field are the provisions of the Home Owner's Loan Act of 1933, which restricts the amount of money that can be lent by federally chartered savings and loan companies; such companies hold approximately three-fifths of all savings and loan assets and are therefore very important potential solar lenders. Quite simply, the Home Owner's Loan Act limits the number of loans over a certain specified amount, currently $\$ 60,000$, that can be made by regulated institutions. Because solar equipment is usually relatively expensive and would raise the price of a typical residential structure, these restrictions on the allowable size of loans can mean that prospective buyers will have to settle for financing that covers less of their total costs when choosing the solar option. Potential solar consumers who cannot afford the additional down payment will therefore be priced out of the market, to the detriment of the solar commercialization effort. ${ }^{241}$

The attitudes toward solar energy held by lending institutions will also have an important influence on the size of loans that will be made for solar equipment and, indeed, on whether or not such loans will be made at all. Lenders are vitally concerned about the impact of solar systems on property values and on the technical performance of those systems. Recent surveys indicate that solar systems are considered by 
many lenders to be "overimprovements," the costs of which are not reflected by a corresponding increase in the market value of solarequipped structures. Until this perception is disproved, most lending institutions are likely to exclude some or all solar system costs from the amount they will lend for a solar-equipped structure. Due to this undervaluation, the down payment required on solar buildings will be greater than for conventional ones. Although it is not expected that lending institutions will flatly refuse to extend solar loans, the extra initial costs involved in getting such a loan are still likely to discourage prospective solar users. 242

While it is true that many primary lending institutions will be hesitant to make solar loans at high loan-to-cost ratios until the market value of the technologies involved is proven, it is likely that at least some solar buyers will be able to obtain adequate financing from a limited number of "lead banks" that are willing to take extra risks in this area. As the name implies, "lead banks" are those which break new ground to provide an example for other financial institutions to follow. Examples of lead activities are the San Diego Federal Bank's solar loan program, which offers loans on solar water heaters at a low down payment, and the Florida Federal Savings and Loan Association's water heater loans, which require a set payment of $\$ 25$ per month regardless of the total loan amount. ${ }^{243}$ It is expected that thrift institutions that are lending for their own account are more likely to lead the way in solar financing than are mortgage companies and any others that rely on the salabllity of their loans on the secondary market. 244

Another important factor in determining the availability of solar financing is the set of criteria used by lending institutions to judge the credit worthiness of prospective borrowers. A widely used formula is that monthly housing costs should not exceed $25 \%$ of the owner's income; these housing costs are figured by summing principal, interest, tax, and insurance payments, while excluding energy costs. Not only does this practice ignore the fact that solar users save substantially on utility bills, leaving them greater assets with which to repay a loan, 
but it also raises the required income of a solar borrower proportionate to the added first cost of his solar system. 245 This inequity can be addressed by adding energy expenditures to the formula for figuring housing costs and adjusting the percentage of one's income that can be spent on loan repayment; it has also been suggested that housing costs should be figured on a life-cycle rather than a first-cost basis. ${ }^{246}$

Secondary mortgage market. As mentioned earlier, the workings of the secondary mortgage market can influence the behavior of primary lenders toward prospective borrowers. The major actors in the secondary market are the Government National Mortgage Association (GNMA), which is federally owned and operated, and the Federal National Mortgage Association (FNMA) and the Federal Home Loan Mortgage Corporation (FHLMC), which are privately owned but federally regulated and supported; in addition to these three, there are many smaller institutional investors involved in the market. In general, these secondary entities assume a conservative attitude toward atypical structures or unproven technologies and therefore may refuse to purchase solar mortgages, particularly where the amount loaned is high in proportion to the total combined costs of structure and solar equipment. Because of this, primary lenders who count on selling mortgages on the secondary market may refrain from making solar loans, or may make them purposely small in order to așsure their future salability. ${ }^{247}$

Loan insurance. Loan insurance programs protect private lending institutions against possible losses from borrower default and, by so doing, can encourage the extension of credit to prospective buyers. The government-sponsored Federal Housing Administration (FHA), Veteran's Administration, and Farmer's Home Administration programs are the best known examples of these, although a number of private mortgage insurors have also sprung up in recent years. ${ }^{248}$ The willingness of these actors to insure mortgages on solar structures can be an important factor in determining the reaction of primary lenders to solar loan requests. Limits on the size of insurable loans, such as the FHA ceiling of $\$ 60,000,249$ can exclude solar structures because of the extra front-end costs normally associated with the use of this energy source. The 
manner in which solar sys.tems are appraised by loan insurors can also be very important. 250 If a conservative approach is taken and it is assumed that the added costs of solar will not necessarily result in a proportionate increase in market value, the amount of insurance offered will be less than for an identically priced conventional structure. This in turn can influence the amount that private lenders will be willing to offer, resulting in the necessity of a higher down payment by the solar consumer.

At the federal level a number of possible actions have been suggested to increase the availability of funding for solar installations. The loan practices of the primary mortgage market can be addressed directly by modifying the provisions of the Home Owner's Loan Act of 1933, discussed earlier, to ease restrictions on the making of solar loans over $\$ 60,000$. This upper limit could be raised specifically for solar structures, or new limits could be established for all buildings in terms of life-cycle costing, which takes into account continuing expenditures for fuel and maintenance as well as front-end costs. ${ }^{251}$ Another plan receiving widespread attention is the establishment of a federally funded Solar Energy Development Bank. The proposed bank, now being considered by Congress, would provide long-term, low-interest loans for residential and commercial solar users. 252 It may also be possible to successfully exert federal influence on private lenders to make solar loans at higher loan-to-cost ratios than those currently offered.

In the secondäry mortgage market, the policies of the GNMA, FNMA, and FHLMC could be adapted to give preferential treatment to mortgages on solar structures; ${ }^{253}$ the resulting ease in selling solar mortgages should act as an incentive to primary lenders to make this type of loan.

Finally, federal mortgage insurance programs such as FHA could modify their guidelines to allow larger loans and higher loan-to-cost ratios for solar structures. Under the recently passed National Energy Act, the limits on federal mortgage insurance have been increased $20 \%$ for buildings with solar equipment. 254

As of early 1979, eight state governments had passed state legislation aimed at increasing the availability of financing for prospective 
solar users. Most of these laws provide for funds to be made available through state agencies, while a few attempt to facilitate the extension of private financing. There is a great deal of variety among the different approaches, with some states offering loans at reduced interest rates or for extended time periods, while others adhere to prevailing market terms. Some states allow loans to be made to the general public; others have special target groups such as veterans, disaster victims, or low-income families. Nearly all programs, however, are aimed at residential energy users. 255 Several states also require life-cycle costing to be used in determining the most cost-effective design for government buildings. 256 Lastly, it has been suggested that state governments could develop their own loan insurance or guarantee programs, either independently or in concert with similar federal efforts, to encourage primary lenders to extend financing to solar buyers. ${ }^{257}$

Obtaining a loan to retrofit an existing structure with solar equipment can involve a different set of problems than those encountered in financing a new solar building. Because the structure to be retrofitted is generally financed by an existing mortgage, finding suitable financing is not at all the same process as that discussed above. A second mortgage to cover just the cost of the new solar equipment is often unattainable because federally chartered savings and loan associations and many state-chartered institutions are allowed to make only first liens on residential properties. Personal installment or home owner's improvement loans are generally available, but these involve substantially higher interest rates. Other options available to potential solar buyers include refinancing the entire property, generally at a higher interest rate than under the original mortgagc, or getting a "wraparound" mortgage, which consisls of a new loan "wrapped around" an existing mortgage. 258

Several of the states discussed earlier with legislation covering solar financing have specifically addressed the solar retrofit issue. Tennessee, for example, has empowered its Housing Development Agency to make solar loans to low- and moderate-income persons, with repayment schedules designed to reflect energy savings. At the federal level, 
the National Energy Act authorizes the GNMA to purchase energy conservation home improvement loans made by primary lenders to low- and moderate-income families. 259

\subsubsection{Interest rates on solar loans}

While there has been some speculation to the contrary, it is unlikely that the interest charged on solar loans, particularly in the residential sector, will 'differ significantly from interest rates for conventional structures. 260 Because the initial costs of purchasing a solar building are likely to be greater, however, paying off a solar loan, even at present interest rates, can represent a heavy burden for the prospective buyer. Also, the cost-effectiveness of solar energy systems relative to conventional fuel sources will vary markedly depending on interest rates, since nearly all the costs of solar energy are capital costs.261 For these reasons, the use of interest rate subsidies has been advocated by a number of observers as a means of improving the attractiveness of solar to the prospective user.

A major federal effort in this area has been the preparation of legislation for a Solar [nergy Development Bänk, menliumed edr.lier. The solar bank bill before Congress would allow the extension of 30-year loans at $3 \%$ interest for both residential and commercial structures. 262 At the state level, a number of recently passed laws providing for solar loans make financing available at lower than normal interest rates. By far the most attractive terms are offered by California, which loans money at $2 \%$ annual interest to disaster victims making solar improvements to damaged property. Other states with low-interest solar loans include Alaska, where funds are available at a maximum interest rate of $8 \%$, and Montana, where public utilities are allowed to extend credit at a maximum charge of $7 \% .263$ The impact of such measures on the rate of snlar utilization could be substantial. A recent study conducted by H. C. Petersen at Utah State University projected that the availability of financing at an annual interest rate of $7 \%$ would be almost as effective in stimulating solar commercialization as a property tax exemption on solar equipment or a $25 \%$ income tax credit; dropping the interest rate 
to $2 \%$, according to these findings, would result in a much more dramatic jump in solar usage, far outstripping the impact of either of the previously mentioned options. 264

\subsection{Pricing of Competing Fuels}

The economic feasibility of using solar energy in any given location is strongly influenced by the cost of conventional fuels in that area. Where cheap natural gas is available, for example, solar systems will genérally be less desirable by comparison than in thuse reyiuns where only higher-priced electricity can be obtained. 265 It has been frequently pointed out that the price of the various competing fuels, so important in determining the attractiveness of solar energy, is determined to a large degree by government policy. The wellhead regulation of natural gas sold in interstate markets and price controls on oil, which keep the cost of these fuels below true replacement value; the provision of tax subsidies and credits for energy producers; utility rate structures that allow the higher costs of electricity from new power plants to be averaged out over the entire rate base; and reduced-premium insurance programs for nuclear power plants have all been cited as examples of government programs that allow conventional fuels to remain artifically cheap. It has been further maintained that the cost of these energy resources is reduced still more because producers are not held responsible for all associated social and environmental costs, removing the necessity for these to be fully reflected in the ultimate selling price. 266

In light of the above discussion, it is clear that the competitive position of solar energy could be improved by eliminating existing controls, subsidies, and pricing policies that keep the cost of conventional fuels below their true replacement value or that externalize any social costs involved with their production and use. Because high relative costs are considered a serious drawback to the widespread use of solar, actions such as the above are potentially powerful tools for furthering the solar commercialization effort. 


\subsection{Government Procurement Policies}

The direct government purchase of solar equipment for use in public buildings is a much discussed option for stimulating the solar market. Solar energy systems could be incorporated into new structures or retrofitted into existing ones with, potentially, a number of beneficial effects. The injection of substantial amounts of new money into the solar market could stimulate the development of new technologies and encourage additional investment by manufacturers while increasing consumer acceptance and providing a "laboratory" to study any technical or institutional problems that may accompany increased solar use. Finally, and most salient for this discussion on financial incentives, large government procurements could result in economies of scale in the production and installation of solar equipment, bringing lower costs for future consumers. 267

Solar procurement programs are possible at all levels of government. The recently passed National Energy Conservation Policy Act (PL 95-619) authorizes the federal government to spend up to $\$ 100$ million over a two-year period to provide federal buildings with solar equipment for the purpose of demonstrating solar heating and cooling technologies. The same act encourages the ongoing use of solar energy by mandating the use of life-cycle costing to judge the cost-effectiveness of new federal structures; existing structures will also be examined and retrofitted where necessary to assıure minimum life-cycle costs. 268 state governments could also use public buildings for solar demonstration purposes and require the use of life-cycle costing for judging new construction and searching out possibilities for solar retrofit. In addition, both the federal and state governments could provide technical and financial assistance to county and municipal governments for the planning and development of solar projects at the loral leve1.269 Even without such aid, however, it would be possible for local governments to encourage the use of solar energy in public buildings through measures similar to those discussed above.

Because of the tremendous purchasing power that exists in the public sector, it is possible that a government procurement policy of sufficient 
size to engender economies of scale in the production and installation of solar equipment could be mounted. The resulting reductions in the price of solar systems could stimulate more solar use, while the cost of the procurement program itself would be spread over the entire taxpaying public. Other advantages of this approach are that much of the administrative machinery to run it already exists within various government agencies and that the initial investment would be at least partly reimbursed through continued savings in fuel costs. Disadvantages include the fact that the required investment could be extremely large and that, as with many other government procurement programs, this one may be characterized by large expenses and overruns resulting in the creation of an industry with artificially high costs. 270

\subsection{Insuring Against System Damage and Owner Liability}

It is generally acknowledged that the possibility exists of damage befalling a working solar energy system or of that system somehow malfunctioning and causing property damage or personal injury. To defend against these eventualities, it is expected that the owners of solar structures will seek to purchase insurance, just as the owners of conventional structures do. The availability and cost of this insurance can affect the attractiveness of the solar option to the prospective user.

It has been suggested that private insurance companies may be reluctant to insure solar structures against damage because of uncertainties concerning the reliability of solar equipment and a lack of actuarial data on the system durability and the effect of special risks such as vandalism. Even if insurance is available, its price is likely to be higher than for a conventional structure because the replacement cost of a solar building is likely to be higher. If private companies prove unwilling to meet the future need in this area, the federal government could step in and insure solar buildings directly or reinsure private insurance policies as is now done in certain inner-city neighborhoods. ${ }^{271}$ 
In addition to providing protection in case of damage to the solar system itself, a solar insurance policy will also have to cover owner liability arising from any property damage or personal injury to others which may be caused by that system. Those potential dangers most frequently mentioned are associated with broken glass and leaking chemicals from damaged collectors and glare from collector surfaces that may temporarily blind automobile drivers and cause accidents. Again the major problem is the lack of data on the risks involved. As of now, solar systems are not expressly excluded from the standard home owner's contract, but until more information on solar performance is available, the insurance industry may be inclined to charge higher premiums or require the owner to assume more risk than is normally the case. 272

To sum up, it is expected that insurance will be available for solar users, either through private companies or government programs, but the cost of this protection is still uncertain. Insurance costs that are substantially higher than for conventional structures could act as a disincentive to potential solar users, but this condition is not expected to arise unless state insurance departments determine that solar structures are substantially riskier than other buildings and should bear the full cust of that extra risk. ${ }^{273}$ 


\section{THE PUBLIC UTILITY-SOLAR USER INTERFACE}

The policies developed by public utilities and the commissions that regulate them toward solar energy use can have-an important impact on the success of ongoing solar commercialization efforts. At the same time, the change in energy consumption patterns engendered by increased solar usage can profoundly affect the viability of the utilities themselves. Rate structures and service policies for solar users with utilitysupplied "backup" power, arrangements for individual solar users to sell surplus power back to the utilities, and utility programs to provide their customers with solar equipment are all important to solar users and utilities alike. Each will be discussed in more detail below.

\subsection{Utility Rates}

Because sunshine is available only on an intermittent basis, solar energy users generally require a backup source of power often supplied by public utilities through the electric power grid. While solar users are understandably interested in obtaining this backup power at the lowest possible rates, the utilities that supply it are concerned with preventing any monetary losses that may accompany increased solar usage. A central issue here is the utility's "load factor" and how the necessity of providing backup power for solar users will affect it. ${ }^{274}$

The load factor is derived by dividing average demand by peak demand and is a good indicator of how efficientiy, and profitably, a power company's generating facilities are utilized. 275 The fear of many utilities is that an increase in solar usage will lower existing load factors by causing a decline in average energy use without appreciably affecting peak demand. 276 This is likely to occur, it is arqued, because solar users will cut their overall power consumption but could still need $100 \%$ backup during extended periods of cloudy weather. The result is that expensive peak generating capacity will have to be maintained, and possibly expanded, while revenues will drop due to the decline in total consumption. Many solar advocates, on the other hand, feel that load factors may improve with stepped-up solar use because peak demand 
could drop even more than average demand does. The explanation for this is that energy storage is an integral component of most solar systems, allowing solar users to draw their backup energy during those hours when demand is rowest. 277

The differing projections given above concerning solar's effect on load factors can be used to justify a variety of utility pricing schemes that directly affect the costs paid for backup power by solar users. Some of these, such as demand charges, declining block rates, standby charges, and preferred rates for all-electric dwellings, result in higher charges to solar users 278 and are likely to be favored by those who feel that solar use will be accompanied by declining load factors. 0thers, such as time-of-day pricing, lifeline rates, flat rates, inverted rates, and interruptible service rates, can favor solar users ${ }^{279}$ and would more likely be the choice of those who see solar as improving the load factor. The effect of solar use on utility load factors is not the only possible criterion, however, for choosing appropriate pricing schedules. A case could also be made for favoring solar users because saving conventional fuels constitutes a desirable societal goal.280

A brief description of each of the pricing schemes mentioned above and their probable effects on solar users follows.

\subsubsection{Rate schedules that discourage solar use}

Demand charges. Under a demand charge pricing system, the utility customer is assessed according to the maximum power demanded during a specified length of time over the entire billing period. Such a schedule was recently proposed by a Colorado utility, with the demand charge based on maximum kilowatt demand during any 15 min in a given month.281 This charge generally only comprises one component of a customer's bill, with an energy charge also levied on total consumption. The effect of the demand charge, which is supposed to reflect the cost of peak generating capacity, can be very detrimental to solar users, who have to pay a premium for occasional high demand despite overall low consumption. Under the Colorado proposal mentioned earlier, which was initially approved and later rescinded, one observer calculated that a solar system generating $70 \%$ of a structure's heating needs would reduce the total electric 
bill only 15\%.282 The onty possible justification for such an arrangement is if peak solar demand coincides with peak demand for the entire utility, a supposition that is hotly contested by solar advocates.

Declining block rates. The declining block rate is the most common rate schedule for residential consumers and was designed to encourage increased energy consumption. Under its terms a higher fee is charged for the first "block" of power purchased than for subsequent blocks. The kilowatt-hours saved by using a solar system, therefore, will be priced at a lower rate than those initial units which must sti11 be purchased for backup power. According to the author cited earlier in the discussion on demand charges, a utility customer who cuts his consumption by $70 \%$ would save only $35 \%$ on his electric bill under a declining block rate schedule. ${ }^{283}$

Standby charges. Some utilities levy "standby" charges against those users who are not regular customers to compensate for the irregular and unpredictable nature of the demand from this sector. If this rate were applied to solar users, the high minimum monthly standby charge could negate much of the savings that would otherwise result from reduced energy consumption. ${ }^{284}$ A recent proposal by a Washington, D.C., natural gas utility to impose a $\$ 14$ monthly surcharge on customers whose gas consumption drops substantially has met with resistance from energy conservation and solar advocates. 285

Preferred rates for all-electric customers. Lower rates for al1electric structures still exist in many areas as a carry-over from the time when growth was a source of declining costs and, therefore, a benefit to all customers. Despite the fact that solar users may utilize electricity as their only conventional energy source., it. is experted that, in some areas, their reliance on solar power may disqualify them from the cheaper all-electric pricing. If this is the case, such a customer's utility rates will be higher with solar than without it. 286

\subsubsection{Rate schedules that encourage solar use}

Time-of-day pricing. This type of rate schedule has been advocated as being fair to both solar users and the utilities. Under time-of-day 
rates, power consumed during the utility's peak demand periods, generaliy the daytime and early evening, costs more than that used during off-peak hours. This reflects the fact that the utility must pay more to produce power during peak periods and that growth in peak demand can necessitate further capital investment in new generating facilities. Leveling out the demand curve is therefore in the interest of the utility and is also well within the power of the solar user. ${ }^{28.7}$

On sunny days the backup power needed by solar users will be minimal during the utility's peak demand hours. Even during extended periods of cloudiness, however, the fact that energy storage is an integral part of solar systems should allow the purchase of backup power during off-peak hours to save until needed, 288 resulting in lower prices for solar users and encouraging further utilization of this energy source. Despite the initial costs necessary for the purchase and installation of new electric meters, utility companies in 15 states have filed time-of-day rates. ${ }^{289}$

Lifeline rates. Under the "lifeline" system, enacted in a few states, customers are provided a relatively small block of energy at a low, fixed fee. While originally intended to benefit low-income families, these rates can also offer savings to solar users, whose backup requirements fall within the lifeline allotment. ${ }^{290}$

Flat rates. Unlike some previously discussed pricing arrangements, with the flat rate a customer is charged the same price per unit of energy regardless of the amount used or the timing of those purchases. ${ }^{291}$ Each unit saved by using a solar system is therefore worth as much as each unit purchased for backup power, in contrast to the situation described earlier for declining block rates. Public utility commissions (PUCS) in roughly 25 states have adopted policies encouraging the use of flat rates or the flattening of rates that favor large energy users. 292

Inverted rates. Under an inverted rate structure, energy charges increase as usage mounts, in direct constrast to the declining block rate. Because the first units of energy purchased are less expensive than . 
succeeding ones, this pricing scheme promises savings to solar users and other energy-conserving customers who buy only limited amounts of backup power. As of this writing, such a rate structure has been tried in five states and the District of Columbia. ${ }^{293}$

Interruptible service rates. Interruptible service rates, like time-of-day pricing, can help improve utility load factors while. simultaneously providing savings for solar users. Under this pricing plan, lower energy costs are offered to those customers willing to have their service interrupted during extreme peak periods or system emergencies. Since solar users with adequate storage capacity would be able to save energy drawn during nonpcak periods for these occasions, periodic interruptions should not cause them extreme hardship. At the same time, utilities would be able to avoid buying expensive power from neighboring utilities or expanding their own generating capacity. ${ }^{294}$ The interruptible service rate is most commonly available to large industrial customers, although it has also been offered to residential users. In Detroit, approximately 200,000 homes have interruptible service on their water heaters in return for a $35 \%$ discount in price. 295

Special rates for solar users. While dll of the pricing schemes discussed above can directly impact the amount paid by solar users for backup power, these rates also apply to other customers as we11. Special solar rates, on the other hand, treat solar user's as a separate class of customer and make power available at prices designed specificaliy for them. At present, most utilities do not offer special solar backup rates, but companies in nine states have heen experimenting on a sma11 scale with preferential rates for solar users. 296 Solar advocates are still concerned, however, that other utilities may go in the opposite direction and attempt to implement special solar rates that are higher than the standard rate. Any new pricing schedule, however, will be subject to state statutes that prohibit utilities from favoring some customers over others unless there is a reasonable basis for distinguishing among them. A yenerally accepted principle is that rate differences are not unlawfully discriminatory as along as they are based on differences in the cost of providing service to the parties involved; 
relevant factors include the quantity of energy consumed as well as the time, duration, and purpose of that use. 29 ?

While local governments control the activities of municipal utilities, 298 privately owned utilities are regulated by the states in which they are located with some input from the federal government. Within the states, regulatory powers are usually exercised by PUCs, which control utility actions in a number of important ways; these include judging the acceptability of proposed rate schedules, overseeing customer service policies, and deciding on the necessity of capital investments for system improvements and expansion. The federal role, on the other hand, has traditionally been limited to regulating interstate sales of electricity and the siting of major generating facilities. In recent years, there has been greater interest at this level in exercising more control over important utility policies, but it is most likely that the states will retain primary responsibility in this area. 299

Because of their established role in utility regulation, state governments, acting through their PUCs, can do much to increase the attractiveness of solar energy to potential users. Already, PUCs in a number of states have used their influence to move utilities toward the adoption of rate schedules that encourage solar use. As mentioned earlier, commission policies in 25 states encourage the use of flat rates. At the same time, most state commissions have policies discouraging the declining block rate, and a few have encouraged the adoption of lifeline rates. PUCs in 11 states have also ordered individual utility companies to file time-of-day rates. 300

Title I of the Public Utility Regulatory Policies Act of 1978 (PL 95-617) represents a federal action to encourage rate reform that can enhance the savings offered by solar use. The Act establishes a set of nonmandatory rate-making standards for PUCs and nonregulated utilities to consider and, if they choose, to follow. According to these standards, rates should be designed to reflect the cost of service to each customer class, and these rates are to be on a time-ofday and seasonal basis to represent diurnal and annual changes in the 
cost of supplying power. Declining block rates are prohibited unless it can be proven that energy production costs really decline as consumption rises. Industrial and commercial customers must also be offered lowpriced, interruptible service.

Further state and federal studies aimed at uncovering the true costs of serving solar users can provide information useful for the refinement of rate structures in. the interest of equity for all parties. 301

\subsection{Utility Service Policies}

Because most solar energy systems require a backup source of power, the policies established by utilities and PUCs toward the provision of service to solar users can be very important; a utility's refusal to provide backup service to solar systems could have a significant negative impact on the decisions of prospective buyers considering whether or not to go solar. Most observers agree, however, that utilities are not likely to refuse to serve solar users. Such an action could be interpreted as being taken to protect the utility's monopoly position in violation of federal antitrust laws; refusal of service is also likely to constitute a transgression of state laws, which require utilities to furnish "reasonably adequate" services to those demanding it within their jurisdiction. 302 Finally, provisions of the national Public Utility Regulatory Policies Act of 1978 require utility companies to sell backup electricity at "reasonable rates" to customers with electricity-producing solar devices. 303

The major argument made against providing backup power to solar users is that it necessitates the building of expensive new peak generating facilities that would only be used during extended periods of inclement weather. As pointed out earlier, it is not at all clear that the situation described above would occur. Nevertheless, if the concern exists, other measures could be taken to protect the utility's load factor such as allowing backup power to be drawn only during nonpeak periods 304 or instituting time-of-day rates that charge more for peak-period energy. 
While it is considered unlikely that utilities will institute service policies that deny backup power to solar users, the possibility still exists for refusing service to those customers who do not use solar energy. It is argued that such an action would be justified because the use of solar energy saves conventional fuels, and this serves the broad public interest. As a precedent, it has been pointed out that in several states the receipt of natural gas has been conditioned on the implementation of conservation measures such as insulating buildings or curtailing gas usage for decorative lighting. 305 .

\subsection{Utility "Buy-Back" of Solar-Generated Electricity}

In addition to supplying backup power to solar energy users, utility companies can also "buy back" excess power produced by small, decentralized solar electric devices. This arrangement, which is sometimes referred to as "parallel generation," 306 provides financial remuneration to the solar user who at times produces more electricity than he uses, and may encourage the use of solar electric systems; it can also benefit the utility company by supplying it with additional power without the related cost of building additional generating facilities. In order for parallel generation schemes to work successfully, special equipment will have to be provided that allows the solar user to safely feed his excess electricity into the utility grid, and mutually acceptable buy-back prices will have to be reached.

Portland General [lectric Company (PGE) in Portland, Oregon, is one of the first utilities in the country to buy back solar-generated electricity. PGE's solution to the problem of fitting the solar user into the grid is to require the solar customer to install an automatic synchronizer, designed to ensure that solar electricity is not fed into the system while lines are being repaired or maintained; various other relays, seals, and breakers may also be required to assure safe operation. 307 Pacific Gas and Electric Company has also instituted buy-back arrangements which call for the customer to install a synchronizer and other devices for the purpose of protecting his own, as well as the utility's, equipment. ${ }^{308}$ In New York State, the Public Service 
Commission recently ruled that, in cases of parallel generation, solar users can be required to set up the special apparatus necessary to fit into the grid but cannot be forced to assume full responsibility for damages that may result from such a linkage. ${ }^{309}$

In order for parallel generation to work successfully, fair prices will have to be derived for the electricity bought from solar users. While there are utilities, such as PGE, whose buy-back rates are equivalent to their retail prices, 310 it has been suggested that some utilities may be inclined to pay less for the electricity they purchase in this fashion than for that which they sell. It has also been postulated that inadequate rewards may be offered for peak period power because of the erratic nature of the source.3ll Tit.le Ti nf the Public Utility Regulatory Policies Act of 1978, mentioned earlier, addresses the pricing problem by requiring utilities to purchase excess electricity from small power producers and to do so at "reasonable rates," under rules to be set by the Federal Energy Regulatory Commission. The "reasonable rates" prescribed by these rules are not to exceed the incremental cost to the utility of energy from alternative sources. ${ }^{312}$

\subsection{Provision of Solar Equipment by Utilities}

Not only can the utilities supply backup energy to solar users and purchase solar-generated power, they can also help furnish the solar devices utilized by these customers. This section will cover the various optlons for government regulation of utility involvement in the supply of solar equipment, the different ways in which the utilities can make solar systems available to their customers, and the effects which utility involvement in this area could have on the solar commercialization effort.

It has been suggerted that public utilities could be given monopoly rights to provide solar systems to their customers, with this program regulated by state PUCS in the same way that other utility activities are regulated. Under this setup, no other business would be allowed to market competitive systems. Such an arrangement would be extremely controversial, and it is unlikely that PUCs will be convinced of the necessity of creating a monopoly for the distribution of solar equipment. 313 
A more realistic alternative is for the states to regulate utility involvement in the solar market, with the utility's solar enterprises conducted in competition with other solar suppliers. While such an arrangement may be less attractive to a utility company than the regulated monopoly scheme, it is still likely to be appealing because $i t$ assures a safe rate of return and can allow some of the costs of the solar program to be spread among the utility's other regulated activities; this, in turn, can reduce the unit costs of service to the power company's solar customers and improve its competitive position in relation to other solar businesses. Utility critics, however, have objected to this, claiming that the spreading of solar costs among all of a utility's operations amounts to using its monopoly position in the gas or electric field to achieve an unfair advantage in the solar market. An alternative arrangement is for utility companies to set up unregulated affiliates to conduct their solar business in competition with other solar enterprises. 314

A number of observers have pointed out the existence of a variety of potential advantages associated with utility involvement in the supply of solar equipment, whether in the regulated or unregulated modes discussed above. First, utility companies traditionally deal with capital-intensive business ventures and are well equipped to raise large amounts of money for long-term investments at favorable rates. This puts them in a good position to manufacture or purchase and then distribute solar equipment, the high first cost of which is often perceived as a barrier by individual consumers. Another potential benefit of utility involvement is that these entities are in a position to buy solar devices on a large scale, creating a substantial market for solar manufacturers with the possibility of attendant economies of scale. Utilities could also aid in the diffusion of solar technologies because of their well-established sales, distribution, and service networks. ${ }^{315}$ Finally, the perceived strength and permanence of the utility companies could increase the confidence of consumers and builders alike in solar energy systems supplied by this sector. 316 
On the other hand, a number of disadvantages with utility involvement in this area have been identified, leading some observers to suggest that power companies be forbidden from supplying solar equipment to their customers. It has been suggested that the negative impacts of utility involvement in this area could include excessive profit taking and higher prices for consumers; monopolization of the solar field by large power companies to the detriment of small companies and solar users alike; increased costs to a utility's nonsolar customers, who are forced to subsidize the company's solar operations; and a general retardation of solar commercialization efforts due to lack of utility accountability and a basic lack of commitment to solar energy by this sector. 317 Apparently, some of these concerns are shared at the federal level of government, since provisions of the recently passed National Energy Conservation Policy Act (PL 95-619) forbid the public utilities from supplying, installing, or financing "residential energy conservation measures," including solar devices. Exemptions are allowed from this prohibition, however, provided it can be demonstrated to the satisfaction of the secretary of energy that "fair and reasonable prices and rates of interest would be charged and ...such activities would not be inconsistent with the prevention of unfair methods of competition and the prevention of unfair or deceptive acts or practices." 318

It has been suggested that the advantages of utility involvement could be largely realized and the worst of the associated disadvantages avoided by encouraging the supply of solar energy devices by pubtcly owned municipal utilities. According to this view, municipal power companies are more likely than their privately owned counterparts to be responsive to the needs of the public, since they are directly controlled by publicly elected officials and are not driven by the profit motive. ${ }^{19}$ A potential problem exists in that most states have laws prohibiting municipal utilities from spending funds for "private benefit," but, in light of current concern over the shortage of conventional fuels, it should not be hard to justify the provision of solar devices for privately owned structures as being in the public interest. 320 An example of utility involvement in this area can be found in Santa Clara, California, where the city has installed swimming-pool heaters 
in a number of private structures, leasing the equipment to the building owners in return for a monthly fee. 321

Assuming that the two extremes are avoided and the utilities are neither given monopoly rights nor are completely excluded from participating, there are several possible ways in which these companies may become involved in supplying solar equipment. Specifically, it has been suggested that the power companies could sell solar devices to their customers, couid lease such equipment to their customers while maintaining ownership, or could lend their customers the capital necessary to purchase solar systems from another source. It must be pointed out, however, that none of these roles are possible unless a utility is. granted the necessary exemptions from the terms of the National Energy Conservation Policy Act, cited earlier.

If they choose to sell solar devices to their customers, and receive the required permission, utility companies have the option of manufacturing these devices themselves or purchasing them from independent solar manufacturers for resale. It is expected that direct utility involvement in the manufacture of solar equipment could raise more objections on antitrust grounds, 322 but, in either instance, the customer will probably make monthiy installment payments to the utility until the solar equipment is eventually purchased. 323

Should a utility decide to lease solar equipment to its customers, the same options as those discussed above are available to the company for obtaining this, equipment, and lie same perlodic biliing system is likely to be followed. In this case, however, the solar device will permanently remain the property of the utility, and a number of important questions unique to this arrangement will have to be answered, including: Who will pay the property taxes on the solar device? How will insurance costs and liability for possible damages be distributed? Will a contract for solar service between a building owner and a utility be binding on a future owner? How far will the utility's maintenance responsibilities extend? Should a utility pay the customer for the use of the roof or wail on which the system is mounted? Could a customer force the utility to remove such a system? ${ }^{324}$ 
Finally, the utilities could lend their customers money for the purpose of solar equipment from independent retailers. While the utilities are considered capable of providing the large amounts of capital required for this purpose, they may not willingly choose such a role because the profits allowed on loans could be less than their usual rate of return on investment. It has been suggested that the PUCs could overcome any resistance of this kind by ordering the power companies to lend funds for solar purchases, just as they have ordered the installation of expensive pollution abatement devices at power plants. 325 Another option for encouraging utility involvement in this area is to offer financial incentives as in Montana, where uttlilies are allowed to lend money for "energy conservation materials" at $7 \%$ interest while being reimbursed by the state for the difference between this charge and the prevailing interest rate on home improvement loans. 326

There are still widely divergent opinions over what the effects would be of active utility involvement in the supply of solar equipment. As described earlier, there are those who feel that utility provision of solar devices offers many advantages, while others predict that the solar commercialization effort could be seriously hurt if the utilities are allowed to participate in this area. There also seems to be ample room for a middle position that recognizes the potential benefits of utility involvement while being mindful of the dangers. The provisions of the National Energy Conservation Policy Act prohibiting utility involvement in the supply, installation, or financing of solar equipment were enacted in recognition of the possibility that unfair competition or excessive prices could result from an active utility role in solar supply. This does not, however, foreclose completèly the oppurtunlly for the utilities to use their capital assets and organizational strengths in ways that further solar use, as indicated by the'act's previously described exemptions and exceptions. The current situation is one where careful policy decisions must be made by the utilities themselves, state regulatory commissions, and the federal government in order to avoid the potential dangers to solar commercialization arising from utility supply of solar devices without removing the prospective benefits. 


\section{SUMMARY AND DISCUSSION OF IMPLEMENTATION OPTIONS}

As the previous chapters show, the process of achieving widespread utilization of solar energy systems involves more than just perfecting the physical workings of the appropriate technologies. A broad range of legal and institutional issues must also be faced if solar energy is to significantly contribute to our national energy supply. In this concluding chapter, the five major issues presented earlier will be briefly reiterated, along with their potential impacts on the solar commercialization effort. A brief description of the most influential participants in the solar field, from both the public and private sectors, will follow. Finally, implementation options for governments seeking to remove existing impediments and create new incentives for solar use will be discussed.

\subsection{Major Issues Revisited}

Provisions of various public statutes and private agreements, such as zoning ordinances and restrictive covenants, can act to prohibit the use of solar energy systems by prospective users. While generally unintended, the effects are nonetheless real, as where height restrictions preclude the installation of rooftop solar collectors. Unless modified, such restrictions can effectively outlaw the use of solar equipment and are a serious barrier to the widespread use of this energy source.

Regulations that cover the production and placement of solar energy systems have the potential to either help or hinder the solar commercialization effort. Strong product warranties, for example, could encourage consumers to purchase solar equipment, while the lack of same may inhibit market penetration. Similarly, it is widely believed that the development of solar codes and standards can further solar usage, both by encouraging acceptance by consumers and lenders and by simplifying the process of receiving the necessary construction permits from local officials. Other related subissues concern the role of unions, the licensing of solar installers, requirements for mandatory installation of solar equipment, questions of competition in the solar industry, the 
liability of solar businesses for system malfunctions and resulting damages, and government policies concerning patents and licenses.

The importance of protecting the solar user's access to sunlight is obvious; without adequate insolation, his solar system will not function properly. The major approaches to assuring solar access are through the use of "sun rights," established land use controls such as zoning and subdivision regulations, and other legal devices such as easements and deed restrictions. Without adequate access protection, prospective solar users are likely to be reluctant to invest in costly solar equipment, to the detriment of the solar commercialization effort.

In addition to purchase price, a number of other factors affect the economic attractiveness of solar systems; these include tax rates, lending policies and interest charges, the price of competing fuels, government procurement policies, and the cost and availability of insurance. The policies pursued in these areas can either encourage or inhibit further solar use by their impacts on overall system cost.

The final issue covered in this report concerns the interface between solar users and the public utilities. The policies developed by these entities and the public utility commissions that regulate them can have a major impact on the viability of the utilities themselves and on prospective solar buyers deciding whether or not to "go solar." The rates for backup power can be central in determining how much money will be saved by switching from conventional fuels, which, in turn, is very important in influencing the potential solar user's decision. Utility service policies, arrangements for "buying back" excess solar-generated electricity, and utility programs to furnish their customers with solar equipment also affect the attractiveness of the solar option and can all be manipulated to either promote or inhibit further solar use.

While it is tempting to look for a relative order of importance to the issues presented above, any such ordering would be open to question and is likely to contribute little to our working knowledge of this field. For instance, some observers may be inclined to single out financial incentives and impediments to solar use as being of primary importance because these affect the cost of solar systems, which, in turn, is 
considered central to many prospective buyers. However, costs are also directly impacted by the utility-solar user interface as well as by certain elements of the production and placement issue. And even if costs are brought down by diligent attention to one or all of these issues, this would not assure that the necessary solar access will be available to potential users or that existing prohibitions against solar use will be removed. All of the issues presented in this report, therefore, are important in their own right, and none can be ignored if widespread solar use is to become a reality.

\subsection{Major Actors}

As the preceding chapters illustrate, the major solar legal and institutional issues involve participants from both the private and public sectors. The most important private actors include the manufacturers and installers of solar equipment, lending institutions, labor unions, insurance companies, utilities, solar users themselves, and other community property owners. The activities of these groups can be strongly influenced by the programs adopted by local, state, and federal governments. The following section will discuss options for public actions at each of these levels that are available to governments seeking to further encourage the solar commercialization effort.

\subsection{Implementation Options for Governments Seeking to Further Solar Commercialization}

As a review of major solar legal and institutional issues; this study does not attempt the in-depth analysis of the interactive effects generated by specific policies and programs that would be necessary to justify making recommendations for government action. As a result, a variety of implementation options are discussed below without conclusions being drawn as to which ones should be pursued most vigorously. The need does exist, however, for the kind of rigorous examination of alternative solar policies and their impacts that would make possible the development of recommendations in this area. 
A variety of options are available for all levels of government seeking to get involved in the formulation of policies and programs to address the legal and institutional issues identified in this study. The appropriate response will vary among the different government levels, but each is capable of assuming an active role in this important field. Many of the possible actions discussed below are already in use in at least some pioneering jurisdictions.

\subsubsection{Local government}

Because of their traditional role in regulating land use, local governments are particularly well-suited to deal with the solar access and prohibitions on solar use issues, where land use controls can be most important. Communities interested in furthering solar commercialization can adopt goals promoting solar use and calling for desired levels of solar access, tailored to their own local conditions. These goals should be carefully integrated with other local development objectives and appear in the comprehensive plan, where such a document exists. In the same vein, the comprehensive plan can also include a statement of purpose declaring solar energy use to be in the public interest and explaining the reasons for this finding. In locales where no comprehensive plan is in effect, solar goals and a statement of purpose can be adopted independently.

Specific actions open to local governments to remove prohibitions against solar use include modifying zoning ordinances, aesthetic controls, and building codes in the ways suggested in Chap. 2 and prohibiting future restrictive covenants that forbid solar use. To assure that locally desired levels of solar access are protected, counties and municipalities can utilize the various kinds of zoning techniques, subdivision regulations, and vegetation controls described in Chap. 4 . Solar access can also be addressed through the environmental impact assessment process in those communities where an impact statement is a prerequisite for development, and by affirming the right of individual property owners to privately negotiate solar easements; the option of acquiring easements through the public power of eminent domain is also 
available. Because of the depth of local experience with traditional land use controls and local familiarity with community land use, environmental, and political factors, this level of government is well equipped to assume an active role in dealing with the issues discussed here.

The local solar goals that guide actions taken to eliminate prohibitions against solar use and to assure solar access can also serve as a basis for activities in other issue areas. In the regulation of production and placement of solar equipment, for instance, the goal of promoting solar usage could lead to the adoption of solar standards and codes, the development of standards for the licensing of solar installers, and the passage of ordinances mandating solar use under specified conditions. Counties and municipalities can consider all these steps in light of their objectives for solar use and overall community development.

While most actions to overcome existing financial impediments to solar use and create new incentives will be undertaken at the state and federal levels, there are a few actions open to local governments. Options available to counties and municipalities include the use of property and sales tax exemptions, which can be evaluated in light of the projected increases in solar use vs the lost revenues engendered by these programs. The pros and cons of incorporating solar technologies into public buildings for demonstration purposes can also be studied, even where the life-cycle costs are higher than for conventional structures:

While local governments will not be directly involved in the interface between privately owned utilities and solar users, they will have a major role in dealing with a portion of this nation's solar customers through their control of municipal power companies. Those local entities seeking to further solar use can develop programs to sell, lease, or finance solar systems in their service areas.

\subsubsection{State government}

As with local governments, the states can also manifest their active interest in encouraging solar use through the adoption of solar 
development goals and a declaration of the public benefit of solar energy utilization. Specific actions are open to the states in all the issue areas mentioned above, with a greater variety of options than is available to local units of government.

State governments, like locales, can eliminate prohibitions against the use of solar energy systems through the use of properly designed zoning ordinances, aesthetic controls, and building codes as well as by forbidding the use of restrictive covenants that outlaw solar. In addition to being able to tailor such actions to achieve the desired results, state governments also have a number of alternative ways in which they can implement their chosen controls. They can pass enabling legislation makinq explicit the right. of loc.al gnvernments to adopt the needed legislation; they can develop model codes which their locales can adopt at their own choosing or can offer financial and technical assistance to help local governments develop their own measures; they can mandate that local governments adopt legislation meeting certain statespecified minimum standards; and finally, they can act preemptively and adopt regulatory mechanisms that are automatically applicable at the local level. In choosing from among the above options, respect for the traditional local role in developing land use controls and recognition of the intimate local knowledge of workings at the community level could incline the states toward assuming less direct control, while the perception of an energy emergency or a record of conspicuous inaction at the local level could lead to a decision to pass mandatory or preemptive measures.

The approaches open to the states for implementing solar access protection are basically the same as those discussed ahove. Enabling legislation, model ordinances, technical and financial assistance, mandatory acts, or preemptive legislation can be used to encourage local governments to use zoning techniques, subdivision regulations, and vegetation controls that assure current and prospective solar users desired levels of access to sunlight. The state governments can also pass enabling legislation providing for the use of privately negotiated easements, as many have already done, and require solar access considerations to be included in any necessary environmental impact statements. 
Once again, the decision concerning the degree of direct control to be exerted in this area will have to be made by individual state governments in light of local interests and abilities and the perceived urgency of implementing the appropriate regulatory devices.

Many of the subissues involved in the regulation of production and placement of solar equipment are open to intervention by state governments with a policy of promoting solar energy use. Options available to the states include the establishment of solar equipment certification programs, the development and adoption of standards and codes, the creation of appropriate requirements for the licensing of solar installers, the passage of legislation mandating solar use under specified conditions, and the extension of aid to small solar companies in securing needed financing. In those issue areas where local actions are also possible, state governments will have to decide whether or not to wait for locales to take the initiative and how to deal with situations where local programs differ significantly from those favored by the state.

State governments are also capable of addressing the issue of financial incentives and impediments to solar use. Solar equipment can be exempted from property taxes, as has been done in over half of the states. Exemptions can also be extended from sales and use taxes, and a variety of income tax incentives for solar users can likewise be allowed. In evaluating these options the prospective benefits of increased solar use can be weighed against the costs in lost revenues, allowing the economic efficiency of such actions to be compared with other possible state programs. The states can also adopt measures to make financing available to prospective solar users, either through direct loan programs or the encouragement of funding by private lenders. Low-interest loan and state loan insurance programs are two other possibilities. Finally, state governments can further solar use through the direct purchase of solar equipment for public buildings and the extension of financial and technical assistance to-counties and municipalities for similar programs at the local level. Not only can solar demonstration projects be undertaken, but life-cyclying costing can be required for judging the economic efficiency of all new construction and seeking possibilities for solar retrofit. 
Because of their traditional role in this area, the states are in a strong position to regulate the actions of the privately owned utilities in ways that can further solar use. The rates charged for backup power can be designed to maximize monetary savings for solar users while attempting to avoid significantly degrading existing load factors. At present, time-of-day and interruptible service rates seem to hold great promise for all parties, while declining block rates are especially injurious to solar customers. Public utility commissions can make sure that solar users are not denied backup service while examining the possibility of refusing service to nonsolar users. Where solar customers sell power back to a utility company, the states can examine the terms arranged by the utility to make sure that the solar user is not forced to assume unreasonable costs or responsibilities. Finally, where utility involvement in the supply and financing of solar equipment seems advantageous for the solar commercialization effort, power companies could be aided in applying for the exemptions to the National Energy Conservation Policy Act required for this kind of activity.

\subsubsection{Federal government}

Solar usc can bc cncouraged by carefully designed rederal acliulls in all the issue areas previously discussed. Even in areas like land use control or intrastate utility operations, where regulatory authority has traditionally resided with lower levels of government, there is still ample room for a uniquely federal approach to the problems at hand.

There are a number of options open to the federal government for the removal of existing prohibitions on solar use. The promulgation of mandatory or preemptive zoning ordinances, aesthetic rontrols, and building codes could be attempted, although resistance from state and local governments is likely. A less controversial approach is for states and locales to be influenced to adopt the appropriate measures through conditions placed on the granting of federal funds. Model acts, such as a model national solar building code, can also be developed and their adoption by lower government levels encouraged, possibly by using 
the financial leverage just discussed. The federal government could consider all the options presented here and choose a favored approach based on the perceived urgency of the need to promote solar use and the effectiveness of state and local efforts in this area.

The same options discussed above for implementing regulatory devices designed to allow. solar use are also available when the objective is to protect solar access. Appropriate zoning ordinances, subdivision regulations, or vegetation controls can be adopted for local and state governments in a preemptive or mandatory fashion, or the passage of such measures can be encouraged through the astute application of financial aid programs. Again, the choice among the available alternatives can be based on the need for the measures in question and the demonstrated initiative of lower levels of government.

The potential federal role in regulating the production and placeinent of solar equipment is considerable. Consumer protection can be addressed through measures such as government underwriting of comprehensive service contracts for the maintenance and repair of solar equipment. The merits of different levels of federal support for the development of solar standards and codes could also be considered, as could the suggestion of establishing a solar energy labor board to settle prospective disputes in this area. Competition in the solar field can be encouraged by various federal actions, including the careful application of antitrust law and the extension of financial aid to small solar businesses. Finally, the federal government could carefully design policies reydrding the patent rights of firms doing government-sponsored solar research so as to encourage optimum productivity; alternatives to consider include granting inventors limitedterm exclusive licenses to their products, the award of prize money for important advances, and a commitment to taking background patents only in extreme cases.

There are also many ways in which the federal government can deal with financial incentives and impediments to solar use. While property and sales taxes are generally the doma in of state and local governments, the federal government could encourage states and locales to grant tax exemptions to solar users by reimbursing these governments for revenues 
lost through such programs or by denying various forms of federal aid to jurisdictions that do not participate. The federal government could also examine its current income tax incentives and evaluate possible modifications in light of their costs and impacts upon solar use. The availability of funding for solar installations could be addressed by actions such as modifying the Home Owner's Loan Act of 1933 to make loans over $\$ 60,000$ easier to obtain, establishing a solar energy development bank to provide low-interest solar loans, influencing private lenders to make capital available to solar buyers on more favorable terms, modifying the policies of the public and quasi-public secondary mortgage entities to give preferential treatment to solar loans, and modifying federal mortgage insurançe guidelines to allow larger loans at higher loan-to-cost ratios for solar structures. In addition, modifications can be made to the various federal programs that contribute to artificially cheap prices for conventional fuels, in order to increase the attractiveness of the solar option. As at the state and local levels, additional direct procurement of solar equipment can be realized through demonstration programs and the use of life-cycle costing in judging the cost-effectiveness of new construction and solar retrofit. Lastly, government-sponsored property and liability insurance could be provided for solar owners in case this kind of coverage proves difficult to obtain from the private sector.

While the primary responsibility for regulating utility practices traditionally rests with the states, there are possibilities for federal actions to address the interface between the power companies and solar users. Federal funding can further research efforts aimed at uncovering the true costs to utilities of serving solar users. Such information can be used as the basis for new rate structures that can then be offered as a model to utilities and public utility commissions; a federal attempt could also be made to adopt such rates for the states through preemptive or mandatory legislation. The federal government has already passed legislation requiring utility companies to provide backup power to customers with electricity-producing solar devices, the possibility of denying service to nonsolar customers could likewise be studied. 
Federal legislation also requires utilities to "buy back" solar-generated electricity from their customers at "reasonable rates;" future legislation could further define these rates and set limits for the costs and liabilities which solar customers can be required to assume in any buy-back. scheme. A final area of concern, that of utility supply and financing of solar equipment, has already been addressed by the National Energy Conservation Policy Act, which forbids involvement in this area by privately owned power companies. Modifications could be made to this act that would allow a stronger utility role, particularly in the area of financing, while still ensuring against unfair competition and pricing.

In summary, there are a number of important legal and institutional issues in the solar energy field, each of which can be addressed in different ways by the various levels of government. As these issue areas are given increased attention, it is expected that continuing progress will be made in eliminating old barriers and creating new incentives to solar use. 
THIS PAGE

\section{WAS INTENTIONALLY LEFT BLANK}


NOTES

1. "Research Finds Greeks Used Solar Energy," N.Y. Times, Apr. 24, 1979.

2. Ralph Knowles, "Solar Ethics - Urban Form" in Solar Policy for the $80^{\prime} \mathrm{s}$, Proceedings of a conference sponsored by the Environmental Law Institute, Washington, D.C., Sept. 11-12, 1978, pp. 243-44.

3. Solar Cal Council, Toward a Solar Califomia, Sacramento, Calif., February 1979, p. 9.

4. Jerome E. Scott, "The Solar Water Heater Industry in South Florida: History and Projections," Sol. Energy 18(5): 387 (May 1976).

5. Distributed Energy Systems in California's Future, Interim Report, Vol. II, U.S. Department of Energy, Washington, D.C., March 1978, p. 132 .

6. Application of Solar Technology to Today's Energy Needs, Vol. I, U.S. Congress Office..of Technology Assessment, Washington, D.C., June 1978, pp. 125-27.

7. Sheldon H. Butt, "The Solar Future - 1978" in Solar Engineering, March 1978, pp. 16-18.

8. Telephone interview with Sheldon Butt, Solar Energy Industries Association, May 18, 1979.

9. Telephone interview with Ted Kurkouski, DOE Chicago Operations, May 18, 1979.

10. Telephone interview with Dave Moore, HUD, Washington, D.C., May 18, 1979.

11. Solar Collector Manufacturing Activity, July 1977 through June 1978 , U.S. DOE, Energy Information Administration, February 1979, p. 17.

12. Benson H. Bronfman et al., Decentralized Solar Energy Technology Assessment Program: Research PZan, ORNL/TM-6913 (May 1979).

13. Robert M. Leary, "Zoning" in Principzes and Practice of Urban PZanning, William I, Goodman, ed., Tnternational City Manager's Association, Washington, D.C., 1968, p. 403. 
14. William A. Thomas, "Solar Energy and the Law" in Solar Policy for the 80's, Proceedings of a conference sponsored by the Environmental Law Institute, Washington, D.C., Sept. 11 and 12, 1978, p. 47.

15. Richard L. Sanderson, Codes and Code Administration: An Introduction to Building Regulations in the U.S., Building Officials Conference of America, Chicago, 1969, p. 13.

16. Richard L. Robbins, "Law and Solar Energy Systems: Legal Impediments and Inducements to Solar Energy Systems," Sol. Energy 18(5): 375 (1976).

17. A. S. Miller et al., Legal Barriers to Solar Heating and Cooling uS Buizdinuz, Environmental Law Institute, Washingtun, D.C., 1977. p. 63.

18. Donald N. Zillman and Raymond Deeny, "Legal Aspects of Solar Energy Development," Axiz. State Law J. 25(6): 36 (1976).

19. J. P. Eberhard et a1., Early Use of Solar Energy in Buildings: A Study of Barriers and Incentives to the Widespread Use of Solar Herating and Cooling Systems, National Technical Information Service, Springfield, Va., 1976, pp. 156-60.

2n. Sülar Cal, op. cit., notc $3, p, 37$.

21. Eberhard, op. cit., note 19, pp. 156-60.

22. John Ashworth et a1., The Implementation of State Solar Incentives: A Prel-iminary Assessment, Solar Energy Research Institute, Golden, Colo., 1979, pp. 95-96.

23. D. Waksman et a1., Plan for the Development and Implementation of Standards for Solar Heating and Cooling Applications, National Bureau of Standards, Washington, D.C., 1978, p. 5.

24. Portola Institute, The Energy Primer, Fricke-Parks Preșs, Fremont, Calif., 1974, p. 169.

25. "Standards Status," Dimensions/NBS, January 1978, p. 21.

26. Miller, op. cit., note 17, pp. 49-50. 
27. HUD Solar Status, March 1978, pp. 1-4.

28. Telephone interview with Alex Bablot, California State Contractors' Licensing Board, June 26, 1979.

29. Miller, op. cit., note 17, pp. 154-56.

30. "Rule Requiring Solar-Heat Units Seen as Pioneer Effort on Coast," N.Y. Times, Dec. 17, 1978.

31. Richard L. Schmalensee, "Promoting Competition in Tomorrow's Markets for Solar Energy Systems" in The Solar Market: Proceedings of the Symposium on Competition in the Solar Energy Industry, U.S. Government Printing Office, Washington, D.C., 1978, pp. 123-25.

32. Thomas C. Kauper, "Petroleum Companies and Solar Energy: A Real Issue" in The Solar Market: Proceedings of the Symposium on Competition in the Solar Industry, U.S. Government Printing Office, Washington, D.C., 1978, p. 111.

33. Zillman, op. cit., note 18, p. 56.

34. Miller, op. cit., note 17, pp. 172-74.

35. Schmalensee, op. cit., note 31, pp. 129-31.

36. Sandy F. Kraemer, Solar Law, Shepard's Inc., Colorado Springs, Colo., 1978, pp. 130-31.

37. Gail Boyer Hayes, Solar Access Law: Protecting Access to Sunlight for Solar Energy Systems, Environmental Law Institute, Washington, D.C., May 1979, pp. 103-6.

38. A Formm on Solar Access: Proceedings of a Form on Solar Access Held by the New York State Legislative Commission on Energy Systems, National Solar Heating and Cooling Information Center, Washington, D.C., 1977, pp. 25-26.

39. Hayes, op. cit., note 37, pp. 81-82.

40. Hayes, op. cit., note 37, pp. 97-99.

41. Forrum, op. cit., note 38, p. 25. 
42. Hayes, op. cit., note $37, \mathrm{pp} .100-101$.

43. Martin Jaffee and Duncan Erley, Protecting Solar Access for Residential Development: A Guidebook for Planning Officials, U.S. Department of Housing and Urban Development, Washington, D.C., 1979, p. 46.

44. Hayes, op. cit., note 37, pp. 47-50.

45. Jaffee, op. cit., note 43 , pp. 82-88.

46. Jaffee, op. cit., note 43, pp. 99-100.

47. Proceedinge of the Workshop on Sotar Energy and the Law, Feb. 10, 1975, Arlington, Virginia, American Bar Foundation, Chicago, I11., 1975, pp. 11-12.

48. Workshop on Solar Energy and the Law, op. cit., note 47, pp. 12-13.

49. H.' C. P'etersen, The Impact of Tax Incentives and Auxiliary Fuel Prices on the Utilization Rate of Solar Energy Space Conditioning, National Technical Information Service, Springfield, Va., 1976, p. 79 ,

50. Arthur D. Little, Inc., Residential Solar Heating and Cooling Constraints arld Incentives. A Review of the Literature, U.S. Department of Housing and Urban Development, Washington, D.C., 1976, pp. 26-27.

51. William A. Thomas et. a1., Overcoming Legal Uncertainties about use of Solar Energy Systems, American Bar Foundation, Chicagu, I11., 1978 , p. 14.

52. Interim Policy Options for Commercialization of Solar Heating and Cooling Systems, U.S. Energy Research and Development Administration, Washington, D.C., 1977, pp. 8 and 9.

53. Workshop on Solar Energy and the Law, op. cit., note 47, p.13.

54. Miller, op. cit., note 17, p. 87.

55. Miller, op. cit., note 17, pp. 94-97. 
56. Miller, op. cit., note 17, pp. 92-93.

57. Written communication from Bruce Landrey, Portland General Electric Co., May 18, 1979.

58. Applications of Solar Technology, op. cit., note 6, pp. 148-50.

59. Ken Bossong, "The Case Against Private Utility Involvement in Solar Insulation Programs," Solar Age, January 1978, pp. 23-26.

60. Leary, op. cit., note 13, p. 404.

61. Thomas, op. cit., note 51, p. 52.

62. Jaffee, op. cit., note 43, pp. 46-50.

63. Jaffee, op. cit., note 43, p. 48.

64. Jaffee, op. cit., note 43, pp. 49-50.

65. Jaffee, op. cit., note 43, p. 48.

66. Jaffee, op. cit., note 43, p. 49.

67. National Solar Heating and Cooling Information Center, State Solar Legislation, U.S. Government Printing Office, Washington, D.C., July 1978, p. 10.

68. Hayes, op. cit., note 37, pp. 126-27.

69. Thomas, op. cit., note 51, pp. 49 and 52-53.

70. Thomas, op. cit., note 51, pp. 12 and 15-16.

71. "Solar Rights: Protecting Access to Sunlight" in Solar Policy for the $80^{\prime} s$, Proceedings of a conference sponsored by the Environmental Law Institute, Washington, D.C., Sept. 11-12, 1978, p. 314.

72. Thomas, op. cit., note 14, p. 47.

73. Interview with Mr. Kozak, building official for Coral Gables, Fla., June 22, 1979.

74. Peter Pollock, The Implementation of State Solar Incentives: Land-Uee Planning to Ensure Solar Access, Solar Energy Research Institute, Golden, Colo., March 1979, pp. 20-21. 
75. Sanderson, op. cit., note 15, p. 13.

76. Sanderson, op. cit., note 15, pp. 37-41.

77. Sanderson, op. cit., note 15, pp. 37-41.

78. Advisory Commission on Intergovernmental Relations, Building Codes: A Program for Intergovermmental Reform, U.S. Government Printing Office, Washington, D.C., 1966, p. 71.

79. Interview with Joe Greenberg. Natinnal Rureau of Standards, Center for Building Techmulugy, June 12, 1979.

80. Arthur D. Little, op. cit., note 50, p. 47.

81. Miller, op. cit., note 17, pp. 49-50.

82. Robbins, op. cit., note 16, p. 375.

83. Miller, op. cit., note 17, p. 63.

84. Mi1ler, op. cit., note 17, p. 68.

85. Greenberg, op. cit., note 79 .

86. Z111man, op. cit., note 18, p. 36 .

87. Jaffee, op. cit., note 43, p. 118.

88. Kramer, op. cit., note 36, p. 64.

89. Ziliman, op. cit., note 18, pp. 36-38.

90. Kramer, op. cit., note 36, p. 64 .

91. Pollock, op. cit., note 74, p. 7.

92. Pollock, op. cit., note 74 , pp. 20-21.

93. Eberhard, op. rit., note 19, pp. 156-60.

94. Ashworth, op. cit., note 22, p. 95.

95. Solar Cal, op. cit., note 3, p. 37.

96. Ashworth, op. cit., note 22, p. 95.

97. Interim Policy Options, op. cit., note 52, p. 49. 
98. Telephone interview with Roy Massena, Technology Transfer Division, Florida Solar Energy Center, June 12, 1979.

99. State Solar Legislation, op. cit., note 67, p. 11 .

100. Massena, op. cit., note 98.

101. State Solar Legislation, op. cit., note 67, p. 11.

102. Waksman, op. cit., note $23, \mathrm{pp} .12-15$.

103. HUD Solar Status, op. cit., note $27, \mathrm{pp} .1-3$.

104. National Bureau of Standards, Solar Building Regulatory Study, Vol. I, National Institute of Building Sciences, Washington, D.C., November 1978, p. 3.

105. Telephone interview with Mr. Rechstein, Orange County, California, Building Department, June 26, 1979.

106. Telephone interview with Herman Dekeller, Dade County, Florida, Building Department, Product Control Office, June 28, 1979.

107. Telephone interview with Doug Wilner, TVA Solar Applications Branch, June 28, 1979.

108: DeKeller, op. cit., note 106.

109. Bablot, op. cit., note 28 .

110. Telephone interview with Peggy Kinchen, Dade County, Florida, Building Department, Contractors' Section, June 28, 1979.

111. Telephone interview with Sheldon Butt, Solar Energy Industries Association, June 28, 1979.

112. Miller, op. cit., note 17, p. 154.

113. Miller, op. cit., note 17, p. 155.

114. Organized Labor and Solar Ener'gy, Solar Energy Research Institute, Golden, Colo., February 1979, p. 11.

115. Milier, op. cit., note 17, p. 124.

116. Miller, op. cit., note 17, pp. 121-23. 
117. "Rule Requiring Solar-Heat Units Seen as Pioneer Effort on Coast," N.Y. Times, Dec. 17, 1978.

118. State Solar Legislation, op. cit., note 67, p. 11.

119. Miller, op. cit., note 17, pp. 124-25.

120. Schmalensee, op. cit., note 31, pp. 123-25.

121. Kauper, op. cit., note 32, p. 111.

122. Joel E. Hoffman, "Antitrust Issues in Setting and Enforcing Product. Standards" ill The Solar Market: Proceedings of the Symposium on Competition in the Solar Industry, U.S. Government Printing Office, Washington. D.C., 1978, p. 61.

123. Interim Policy options, op. cit., note 52, p. 32.

124. Solar Cal, op. cit., note 3, pp. 29-30.

125. Miller, op. cit., note 17, p. 174.

126. Miller, op. cit., note 17, pp. 174-76.

127. Miller, op. cit., note 17, pp. 175-76.

128. Miller, op. cit., note 17, pp. 129-30.

129. Srhmalensee, op. cit., nute 31, p. 129.

130. Schmalensee, op. cit., note 31, pp. 130-31.

131. Schmalensee, op. cit., note 31, pp. 131-32.

132. Schmalensec, op. cit., note 31, pp. 129-30.

133. Hayes, op. cit., note 37 , pp. 29-37.

134. Hayes, op. cit., note 37, p. 125.

135. Hayes, op. cit., note 37, pp. 126-27.

136. Hayes, op. cit., note $37, \mathrm{pp} .128-31$.

137. Kraemer, op. cit., note 36, pp. 130-31.

138. N.Y. Times, op. cit., note 1.

139. Gail Feingold Takagi, "Designs on Sunshine: Solar Access in the United States and Japan," Conn. Law Reu. vol. 10, 1978. 
140. Kraemer, op. cit., note 36, p. 132.

141. Fontainebleau Hotel Corporation vs Forty-Five Twenty-Five, Inc., Florida, 114 So. 2d 357.

142. Forum on Solar Access, op. cit., note 38, p. 24.

143. Solar Rights Act, 1977 New Mexico Laws Chapter 169.

144. Hayes, op. cit., note 37, pp. 103-8.

145. Forum on Solar Access, op. cit., note 38, pp. 25-26.

1.46. Hayes, op. cit., note 37 , pp. 79-81.

147. Forum on Solar Access, op. cit., note 38, pp. 25-26.

148. Hayes, op. cit., note $37, \mathrm{pp} .81-84$.

149. Hayes, op. cit., note 37, p. 98.

150. Solar Shade Control Act, 1978 California Statutes Chapter 1366.

151. Forum on Solar Access, op. cit., note 38, p. 25.

152. Hayes, op. cit., note 37, pp. 100-101.

153. Jaffee, op. cit., note 43, pp. 22-24.

154. Alan Black, "The Comprehensive Plan" in Principles and Practice. of Urban Planning, William I. Goodman, ed., International City Managers' Association, Washington, D.C., 1968, p. 349.

155. Jaffee, op. cit., note 43, p. 22.

156. Jaffee, op. cit., note 43, pp. 42-43.

157. Jaffee, op. cit., note 43, p. 50.

158. Hayes, op. cit., note $37, \mathrm{pp} .42-43$.

159. Jaffee, op. cit., note $43, p, 50$.

160. Hayes, op. cit., note 37, p. 42.

161. Jaffee, op. cit., note 43, pp. 61-68.

162. Jaffee, op. cit., note 43, p. 73.

163. Jaffee, op. cit., note 43, p. 68 . 
164. State Solar Legislation, op. cit., note 67, p. 10.

165. Forum on Solar Access, op. cit., note 38, pp. 6-21.

166. Jaffee, op. cit., note 43, p. 42.

167. Jaffee, op. cit., note 43, pp. 50-51.

168. Forum on Solar Access, op. cit., note 38, p. 19.

169. Jaffee, op. cit., note 43, p. 89.

170. Jaffee, op. cit., note 43, p. 72.

171. Hayes, op. cit., note 37, p. 50.

172. Jaffee, op. cit., note 43, p. 82.

173. Jaffee, op. cit., note 43, pp. 88-90.

174. Jaffee, op. cit., note $43, \mathrm{pp}, 87-88$.

175. Jaffee, op. cit., note 43, p. 93.

176. Jaffee, op. cit., note 43, pp. 90-92.

177. Jaffee, op. cit., note 43, p. 93.

178. Hayes, op. cit., note 37, p. 73.

179. Jaffee, op. sit.., nôt.e 4., p. $4 \%$

180. Jaffee, op. cit., note 43, pp. 93-94.

181. Jaffee, op. cit., note 43, p. 94.

182. Jarfee, un. cil., nule 43, pp. 92-93.

183. State Solar Legislation, op. cit., note 67, p. 10.

184. Peter Pollock, op. cit., note 74, p. 20.

185. Hayes, up. cit., note $3 \overline{7}$, p. 72.

186. Jaffee, op. cit., note 43, p. 99.

187. Jaffee, op. cit., note 43, p. 99.

188. Jaffee, op. cit., note 43, pp. 100-102.

189. Jaffee, op. cit., note 43, pp. 102-103. 
190. Jaffee, op. cit., note 43, p. 103.

191. Jaffee, op. cit., note 43, p. 104.

192. Jaffee, op. cit., note 43, pp. 105-6.

193. Jaffee, op. cit., note 43, p. 106.

194. Jaffee, op. cit., note 43, p. 109.

195. Miller, op. cit., note 17, pp. 13-14.

196. Miller, op. cit., note 17, p. 24.

197. Pollock, op. cit., note 74, p. 8.

198. Miller, op. cit., note 17, pp. 14-15.

199. Miller, op. cit., note 17, pp. 23-24.

200. Stephen B. Johnson, "State Approaches to Solar Legislation: A Survey," Sol. Law Rep. 1(1): 111-15 (May/June 1979).

201. Jaffee, op. cit., note 43, p. 130.

202. Miller, op. cit., note 17, pp. 15-16.

203. Hayes, op. cit., note 37, pp. 111 and 128.

204. Miller, op. c1t., note 17, p. 12.

205. Kraemer, op. cit., note 36, p. 64.

206. Kraemer, op. cit., note 36, pp. 159-63.

207. Hayes, np. rit., note 37, p. 120.

208. Hayes, op. cit., note 37, pp. 120-21.

209. Jaffee, op. cit., note 43, p. 111.

210. Jaffee, op. cit., note 43, pp. 111-15.

211. Hayes, op. cit., note 37, pp. 73-74.

212. Jaffee, op. cit., note 43, p. 116.

213. Miller, op. cit., note 17, pp. 158-59.

214. Miller, op. cit., note 17, pp. 159-60. 
215. Johnson, op. cit., note 198, pp. 58-59.

216. Miller, op. cit., note 17, p. 160.

217. Johnson, op. cit., note 200, p. 59.

218. Petersen, op. cit., note 49, p. 77.

219. Johnson, op. cit., note 200, pp. 68-70.

220. Interim Policy Options, op. cit., note 52, pp. 9-10.

221. Mi17er, op. cit., note 17, p. 163.

222. Johnson, op. cit., note 200, p. 88.

223. Solar tinergy and the Law, op. cit., note 47, p. 11 .

224. Johnson, op. cit., note 200, p. 88.

225. Johnson, op. cit., note 200, pp. 90-91.

226. Petersen, op. cit., note 49, p. 77.

227. Johnson, op. cit., note 200 , p. 88 .

228. Solar Energy and the Law, op. cit., note 47, p. 12.

229. Interim Policy Options, op. cit., note 52, p. 7.

230. Interim Folicy Options, op. cit., note 52, p. 6.

231. Arthur D. Littlc, op. cit., note $42, \mathrm{pj}$. 57-58.

232. Energy Tax Act of 1978 (PL 95-618), Nov. 9, 1978, pp. 3175-79 and 3194-3201.

233. "Investment Tax Credit Shocker - HC Equipment Eligible for only 10\%," Soz. Energy Intezz. Rep. 4(45): 1 (Nov. 6, 1978).

234. Johrison, op. c1t., note $200, \mathrm{pp} .73-80$.

235. Johnson, op. cit., note 200, pp. 74-77.

236. Johnson, op. cit., note 200, pp. 74-77.

237. Petersen, op. c1t., note 49, p. 78.

238. Interim Policy Options, op. cit., note 52, p. 7. 
239. David Barrett et al., Home Mortgage Lending and Solar Energy, U.S. Department of Housing and Urban Development, Washington, D.C., March 1977, pp. 9-10.

240. Barrett, op. cit., note 239, p. 9.

241. Miller, op. cit. note 17, p. 76.

242. Barrett, op. cit., note 239, pp. 11, 14, and 20.

243. "Banking on Solar," People Energy 4(8): 2 (Sept./0ct. 1978).

244. Barrett, op. cit., note 239, p. 21.

245. Barrett, op. cit., note 239, p. 16.

246. Miller, op. cit., note 17, pp. 78-79.

247. Barrett, op. cit., note 239, pp. 10 and 27.

248. Barrett, op. cit., note 239, p. 10.

249. Telephone interview with Phillip Reed, Fidelity Federal Savings and Loan Association, Knoxville, Tenn., Aug. 13, 1979.

250. Barrett, op. cit., note 239, pp. 25-26.

251. Miller, op. cit., note 17, pp. 77 and 79.

252. "Solar Banks May Ease Urban Energy Crunch," APA News, vol. 14, No. 6, June 1979.

253. Arthur D. Little, op. cit., note 50, p. 62.

254. Johnson, op. cit., note 200 , p. 98.

255. Johnson, op. cit., note 200, pp. 92-97.

256. Miller, op. cit., note 17, p. 79.

257. Booz-Allen \& Hamiliton, Inc., The Effectiveness of Solar Energy Incentives at the State and Local Lever, National Technical Information Service, Washington, D.C., March 1976, pp. 1-5.

258. Miller, op. cit., note 17, pp. 81-83.

259. Johnson, op. cit., note 200, pp. 93-98. 
260. Barrett, op. cit., note 239, p. 20.

261. Miller, op. cit., note 17, pp. 81-82.

262. "Solar Bank," op. cit., note 252.

263. Johnson, op. cit., note 200, pp. 93-97.

264. Petersen, op. cit., note 49, pp. 77-79.

265. Arthur D. Little, op. cit., note 50, pp. 26-28.

266. Council on Environmental Quality, Solar Energy. Progress and. Promice, U.S. Government Printing Office, Washington, D.C., April 1978, pp. 36-37.

267. Interim Policy options, op. cit., note 52, pp. 8-9.

268. National Enerğy Conservation Policy Act (PL 95-619), Nov. 9, 1978, pp. 3276-79.

269. Solar Cal., op. cit., note 3, pp. 42-43.

270. Interim Policy Options, op. cit., note 52 , pp. 8-9.

271. Arthur D. Little, op. cit., note 50, pp. 60-61.

272. Miller, op. cit., note 17, pp. 172-77.

273. Miller, op. cit., note 17, p. 177.

274. Petersen, op. cit., note 49, pp. 5-6.

275. Charles Dickson et a1., "Solar Energy and U.S. Public Utilities:

The Impact on Rate Structure and Utilization, "Finergy Policy 5(3): 195 (September 1977).

276. Dickson, op. cit., note 275 , pp. 200-201.

277. Miller, op. cit., note 17, p. 96.

278. Miller, op. cit., note 17, pp. 94-95.

279. Miller, op. cit., note 17, pp. 96-97.

280. Application of Solar Technology, op. cit., note 6, p. 190. 
281. Legal and Institutional Perspectives on Solar Energy in Colorado: A Case Study of Land Use and Energy Decision Making, Environmental Law Institute, Washington, D.C., 1977, p. 76.

282. Miller, op. cit., note 17, pp. 95-96.

283. Miller, op. cit., note 17, pp. 94-95.

284. Miller, op. cit., note 17, pp. 94-95.

285. "Penalizing Conservation," Ponere tine 4(5): 5 (November 1978).

286. Miller, op. cit., note 17, p. 94.

287. Legal and Institutional Perspectives, op. cit., note 281, p. 77.

288. Miller, op. cit., note 17, p. 96.

289. Randali J. Feuerstein, "Utility Rates and Solar Commercialization," Sol. Low Rep. 1(2): 334 (July/August 1979).

290. Miller, op. cit., note 17, p. 96.

291. Miller, op. cit., note 17, p. 96.

292. Feuerstein, op. cit., note 289, p. 327.

293. Feuerstein, op. cit., note 289, p. 328.

294. Feuerstein, op. cit., note 289, p. 334.

295. "Shedding Some Sun on Rate Design," Power Line 4(5): 6 (November 1978).

296. Feuerstein, op. cit., note 289, pp. 336-38.

297. Feuerstein, op. cit., note 289, pp. 351-53.

298. Legal and Institutional Perspectives, op. cit., note 281, p. 78.

299. Miller, op. cit., note 17, pp. 87-88 and 101 .

300. Feuerstein, op. cit., note 289, pp. 326-29 and 334 .

301. Feuerstein, op. cit., note 289, pp. 356-57 and 360-61.

302. Miller, op. cit., note 17, pp. 92-93.

303. Feuerstein, op. cit., note 289, p. 359. 
304. Miller, op. cit., note 17, p. 93.

305. Miller, op. cit., note 17, p. 93.

306. Landrey, op. cit., note 57.

307. Landrey, op. cit., note 57.

308. Pacific Gas and Electric Co., Guidelines for Operating and Protecting Co-Generation and Small Power Projects to be Connected to the PG \& E System, Nov. 3, 1978.

309. "State Clears Way for Upstate Man to Sell Windmill Energy to Utility," N.Y. Times, March 20, 1979.

310. Landray, op. cit., note $b /$.

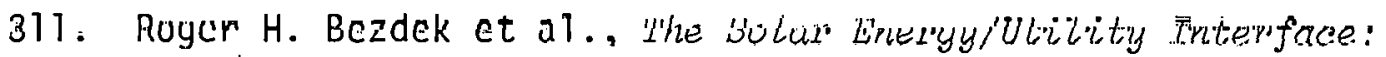
Proceedings of Workshop and Conference, U.S. Department of Energy, Washington, D.C., December 1978, p. 1-19.

312. Feuerstein, op. cit., note 289, p. 359.

313. Miller, op. cit., note 17, p. 105.

314. Miller, op. cit., note 17, pp. 105-6.

315. Miller, op. cit., note 17, pp. 103-4.

316. Application of Solar Technology, op. cit., note 6, p. 14.9.

317. Bossong, op. cit., note 59, pp. 23-27.

318. PL 95-619, op. cit., note 268, pp. 3217-18.

319. Bossong, op. cit., note 59, p. 27.

320. Application of Solar Technology, op. cit., note 6, p. 194,

321. Justin A. Bereny, Survey of the Emerging Solar Energy Industry, Solar Energy Information Services, San Mateo; Calif., 1977, p. 27.9.

322. Application of Solar Technology, op. cit., note 6, p. 192.

323. Bossong, op. cit., note 59, p. 23.

324. Applications of Solar Technology, op. cit., note 6, p. 194. 
325. Miller, op. cit., note 17, pp. 108-9.

326. Feuerstein; op. cit., note 289, pp. 96-97. 
THIS PAGE

\section{WAS INTENTIONALLY LEFT BLANK}


BIBLIOGRAPHY

\section{Books \& Periodicals}

Advisory Commission on Intergovernmental Relations, Building Codes: $A$ Progrom for Intergovernmental Reform. Washington, D.C.: U.S. Government Printing Office, 1966.

Annual Review of Solar Energy. Golden, Colo.: Solar Energy Research Institute, Nov. 1978.

Application of Solar Technology to Today's. Energy Needs, Volume I. Washington, D.C.: U.S. Congress Office of Technology Assessment, June, 1978.

Ashworth, John, et. a1., The Implementation of State Solar Incentives: A Preliminary Assessment. Golden, Colorado: Solar Energy Research Institute, 1979.

"Banking on Solar." People and Energy, 4(8) September/October 1978, 1-3.

Barrett, David, et. a1., Home Mortgage Lending and Solar Energy. Washington, D.C.: U.S. Department of Housing and Urban Development, March, 1977.

Beremy, Justin A., Survey of the Emerging Solar Energy Industry. San Mateo, California: Solar Energy Information Services, 197.

Bezdek, Roger H., et. al., The Solar Energy/Utility Interface: Proceedings of Workshop and Conference. Washington, D.C.: U.S. Department of Energy, December 1978.

Black, Alan, "The Comprehensive Plan" in Principles and Practice of Urburi Flanning, William I. Goldman, ed., Washington, D.C.: International City Managers Association, 1968.

Booz-Allen and Hamilton, Inc., The Effectiveness of Solar Energy Incentives at the State and Local Level. Washington, D.C.: National Technical Informatión Service, March 1976.

Bossong, Kent, "The Casc Against Private Utility Involvement in Solar/Insulation Programs," Solar Age, January 1978, 23-26. 
Bronfman, Benson H., et. a1., Decentralized Solar Energy Technology Assessment Program: Research PLan, ORNL/TM-6913, Oak Ridge National Laboratory, Oak Ridge, Tennessee, May 1979.

Butt, Sheldon H., "The Solar Future - 1978," Solar Engineering, March 1978, 16-18.

Council on Environmental Quality, Solar Energy, Progress and Promise. Washington, D.C.: U.S. Government Printing Office, Apri1 1978.

Dickson, Charles, et. al., "Solar Energy and U.S. Public Utilities: The Impact on Rate Structure and Utilizatiun." tinergy Policy, 5(3) September 1977, 195-201.

Distributed Energy Systems in Califormia's Future, Intorim Report, Volume II. Washington, D.C.: U.S. Department of Energy, March 1978. Eberhard, J. P., et. a1., Early Uses of Solar Entryy in Buildings: A Study of Barriers and Incentives to the Widespread Use of Solar Heating and Cooling Systems. Springfield, Virginia: National Technical Information Service, 1976.

thergy Tax Act of 1978 (PL 95-618). November 9, 1978.

Feuerstein, Rarldạll 1., "Utility Rates dnd Solar Commercialization." Solar Law Reporter, 1(2) July/August 1979, 305-68.

Fontainebleau Hotel Corporation vs. Forty-Five Iwenty-Five, Ine., Florida $114-50,2 d 357$.

A Forim un Solar Access: Proceedings of a Forum on Solar Access He.1.t hy the. New York Dlule Legislative Commission on Energy Systems. Washington, D.C.: National Solar Heating dnd Cooling Information Center, 1977.

Hayes, Gail Boyer, Solar Access Law: Protecting Access to Sunlight for SuZar Energy Systems. Washington, D.C.: Environmental Law Institute, May 1978.

Hoffman, Joel E., "Antitrust Issues in Setting and Enforcing Product Standards" in The Solar Market: Proceedings of the Symposium on Competition in the Solar Industry. Washington, D.C.: U.S. Government Printing Office, 1978. 
HUD Solar Status. March 1978.

Interim Policy Options for Comercialization of Solar Heating and Cooling.

Systems. Washington, D.C.: U.S. Energy Research and Development Administration, 1977.

"Investment Tax Shocker - HC Equipment Eligible for only 10\%." Solar Energy Intelligence Report, 4(45) November 6, 1978, 1.

Jaffee, Martin and Duncan Erley, Protecting Solar Access for Residential Development: A Guidebook for Planning Officials. Washington, D.C.: U.S. Department of Housing and Urban Development, 1979.

Johnson, Stephen B., "State Approaches to Solar Legislation: A Survey," Solar Law Reporter, 1(1) May, June 1979, 55-137.

Kauper, Thomas C., "Petroleum Companies and Solar Energy: A Real Issue." in The Solar Market: Proceedings of the Symposium on Competition in the Solar Industry. Washington, D.C.: U.S. Government Printing Office, 1978.

Knowles, Raply, "Solar Ethics - Urban Form" in Solar Policy for the 80's, Proceedings of a Conference sponsored by the Environmental Law Institute, Washington, D.C., September 11-12, 1978.

Kraemer, Sandy F., Solar. Law. Colorado Springs, Colorado: Shepard's, Inc., 1978.

Leary, Robert M., "Znning" in Principles and Practices of Urban Planning, William I. Goodman, ed., Washington, D.C.: International City Managers' Association, 1968.

Legal and Institutional Perspectives on Solar Energy in Colorado: A Case Study of Land Use and Energy Decision Making. Washington, D.C.: Environmental Law Institute, 1977.

Arthur D. Little, Inc., Residential Solar Heating and Cooling Constrairils and Incentives. A Review of the Literature. Washington, D.C.: U.S. Department of Housing and Urban Development, 1976.

Miller, A. S., et. al., Legal Barriers to Solar Heating and Cooling of Buildings. Washington, D.C.: Environmental Law Institute, 1977. 
National Bureau of Standards, Solar Building Regulatory Study, Volume I. Washington, D.C.: National Institute of Building Sciences, November 1978. National Energy Conservation Policy Act (PL 95-619), November 9, 1978. National Solar Heating and Cooling Information Center, State Solar Legiszation. Washington, D.C.: U.S. Government Printing Office, JuTy 1978.

Organized Labor and Solar Energu. Golden, Colorado: Solar [nergy Research Institute, February 1979.

Pacific Gas \& Eleclric Co., Guidetines for operating and protecting

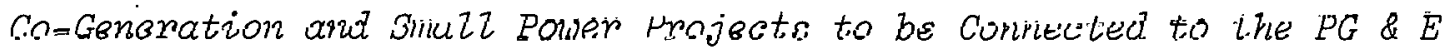
System. November 3, 1978.

"Penalizing Conservation." Fower" Line, 4(5) November 1978, 5.

Petersen, H. C., The Impact of Tax Incentives \& Auxiliary Fuel Prices on the Utilization Rate of Solar Energy Space Conditioning. Springfield, Virginia: National Technical Information Service, 1976.

Pollock. Peter, The Implomentutiur uf State Solar Incentives: Land-Use Planning to Ensure Solar Access, Golden, Colorado: Solar Energy Research Institute, March 1979.

Portola Institute, The Energy Primer. Fremont, California: Fricke-Parks Press, 1974.

Proceedings of the Workshop on Solar Energy and the Law, February 10, 1975, Arlington, Virginia. Chicago, Illinois: American Bar Foundation, 1975.

"Research Finds Greeks Used Solar Energy." N.Y. Times, April 24, 1979.

Robbins, Richard L., "Law \& Solar Energy Systems: Legal Impediments and Inducements to Solar Energy Systems." Solar Energy, 18(5) 1976, 371-79.

"Rule Requiring Solar-Heat Units Seen as Pioneer Effort on Coast." N.Y. Times, December 17, 1978.

Sanderson, Richard L., Codes \& Code Administration: An Introduction to Building Regulations in the U.S. Chicago, Illinois: Building Officials Conference of America, 1969. 
Schmalensee, Richard L., "Promoting Competition in Tomorrow's Markets for Solar Energy Systems" in The Solar Market: Proceedings of the Symposium on Competition in the Solar Energy Industry. Washington, D.C.: U.S. Governmerit Printing Office, 1978.

Scott, Jerome E:, "The Solar Water Heater Industry in South Florida: History and Projections." Solar Energy 18(5) May 1976.

"Shedding Some Sun on Rate Design." Power Line, 4(5) November 1978, 4-6. "Solar Banks May Ease Urban Energy Crunch." APA News, 14(6) June 1979. Solar Cal Council, Toward a Solar California. Sacramento, California: State of California, February 1979.

Solar Collector Manufacturing Activity, July 1977 through June 1978. Washington, D.C.: U.S. DOE, Energy Information Administration, February 1979.

Solar Rights Act. 1977 New Mexico Laws Chapter 169.

"Solar Rights: Protecting Access to Sunlight" in Solar Policy for the $80^{\prime} \mathrm{s}$, Proceedings of a Conference Sponsored by the Environmental Law Institute, Wașhington, D.C., September 11-12, 1978.

Solar Shade Control Act. 1978 California Statutes Chapter 1366.

"Standards Status." Dimensions/NBS, January 1978.

"State Clears Way for Upstate Man to Sell Windmill Energy to Utility." N.Y. Times, March 20, 1979.

Takagi, Gail Feingold. "Designs on Sunshine: Solar Access in the United States and Japan." Connectiout Law Review, Volume 10, 1978.

Thomas, William A., et. a1., Overcoming Legal Uncertainties about the Use of Solar Energy Systems. Chicago, Illinois: American Bar Foundation, 1978.

Thomas, William A., "Solar Energy and the Law" in Solar Policy for the $80^{\prime} \mathrm{s}$, Proceedings of a Conference Sponsored by the Environmental Law Institute, Washington, D.C., September 11-12, 1978. 
Waksman, D., et. a1., Plan for the Development and Implementation of Standards for Solar Heating and Cooling Applications. Washington, D.C.: National Bureau of Standards, 1978.

Zillman, Donal N. and Raymond Deeny, "Legal Aspects of Solar Energy Development," Arizona State Law Journal, 25(6) 1976, 25-58.

\section{Telephone Interviews}

Alex Bablot, California State Contrartors' Licensing Board, June 26, 1979. Shelton Butt, Jolar. Energy Industries Association, May 18 and June 28, 1979.

Herman DeKeller, Dade County, Florida, Building Department, Product Control Office, June 28, 1979.

Joe Greenberg, National Bureau of Standards, Center for Building Technology, June 12, 1979.

Peggy Kinchen, Dade County, Florida, Building Department, Contractors' Section, June 28, 1979.

Mr. Kozak, Building Official for Coral Gables, Florida, June 22, 1979. Ted Kurkuwski, DOE Chicago Operations, May 18, 1979.

Roy Massena, Technology Transfer Division, Florida Solar Energy Center, June 12, 1979.

Dave Monre, HUD, Washington, D.C., May 18, 1979. Mr. Rechstein, Orange County, California, Building Department, June 26, 1979.

Phillip Reed, Fidelity Federal Savings and Loan Association, Knoxville, Tennessee, August 13, 1979. Doug Wilner, TVA Solar Applications Branch, June 28, 1979. 
INTERNAL DISTRIBUTION

1. S. I. Auerbach

2. L. Berry

3. F. D. Boercker

4. W. R. Boyle

5. R. B. Braid

6. H. Braunstein

7. B. H. Bronfman

8. L. M. Bronfman

9. R. L. Carlsmith

10. S. A. Carnes

11. C. V. Chester

12. E. Copenhaver

13. R. M. Davis

14. R. C. DeVault

15. W. Fulkerson

16. J. R. Gracia

17. R. Honea

18. P. W. Hyatt

19. G. E. Kamp

20. S. Kaplan

21. S. V. Kaye
22. A. S. Loebl

23. R. Meyer

24. W. R. Mixon

25. B. Murphy

26. D. C. Parzyck

27. E. Peelle

28. H. Postma

29. C. Rosemarin

30. R. H. Row

31-55. M. Schwejtzer

56-57. J. Sims

58. J. Tatum

59. T. Wilbanks

60. D. Wilkes

61. H. E. Zittel

62-63. Central Research Library

64. Y-12 Technical Ljbrary

65. Laboratory Records

66. Laboratory Records (RC)

67. ORNL Patent Office

\section{EXTERNAL DISTRIBUTION}

68. Office of Assistant Manager, Energy Research and Development, Department of Energy, Oak Ridge Operations Office, Oak Ridge, Tennessee 37830

69-95. Technical Information Center, P. 0. Box 62, 0ak Ridge, Tennessee 37830

96-122. Regional and Urban Studies Distribution List, Energy Division

123. A. Joseph Alarid, P. 0. Box 2770, Santa Fe, New Mexico 87503

124. R. T. Alpaugh, DOE Headquarters, Washington D.C. 20585

125. Austin Planning Department, City Ha11, Austin. Minnesota 55912

126. Lyle Benjamin, Holland Law Center, CGR, UF, Gainesville, Florida 32601

127. Martha Bentley, GEO Library, 301 Bryant Building, Tallahassee, Florida 32301

128. Roger Bezdek, U.S. Department of Energy, Conservation \& Solar Energy Division, 1000 Independence Avenue, N.W. Room 5G-026, Washington, D.C., 20585

129. Kent Bristol, Village of Yellow Springs, 314 Dayton Street, Yellow Springs, Ohio 45387

130. Dr. Allyn R. Brosz, Department of Political Science, Virginia Polytechnic Institute \& State University, Blacksburg, Virginia 24060 
131. Jefferson B. Burch, P. 0. Box 376, Oakland, Florida 32760

132. Loretta R. Buisiere, 301 Bryant Building, Tallahassee, Florida 32304

133. Janie Casey, City of Columbia, P. 0. Box N, 600 E. Broadway, Columbia, Missouri 65205

134. Coon Rapids Planning Department, City Hal1, Coon Rapids, Minnesota 55433

135. P. A. Comella, Office of Standards Development, U.S. Nuclear Regulatory Commission, Washington, D.C. 20555

136. Crookston Planning Department, City Hal1, Crookston, Minnesota 56716

137. Dr. Jon Czarnecki, Senate Minority Programs, Agency Building 4, 17th Floor, Albany, New York 12247

138. Dan W. Deaton, 2626 West Mockingbird Lane, Dallas, Texas 75235

139. Detroit Lakes Planning Department, City Ha11, Detroit Lakes, Minnesota 56501

140. John G. Dullea, City Manager, P. 0. Box 2207, Greenville, South Carolina 29602

141. Pam Elhomey, 61 Perimeter Park, Atlanta, Georgia 30348

142. Gordon A. Enk, The Institute on Man and Science, Rensselaerville, New York 12147

143. Charles Feltus, U.S. DOE, Atlanta Regional nffice, 1655 Peachtree Street, N.E., Atlanta, Georgia 30309

144. James P. Feudner, City of Riverview, 17700 Fort Street, Riverview, Michigan 48192

145. Ive C. Freeman, North Carolina Energy Division, P. 0. Box 25249, Raleigh, North Carolina 27611

146. H. Paul Friesema, Center for Urban Affairs, Northwestern University, Evanston, Illinois 60201

147. Carrol J. Fry, City of Carbondalc, P. 0. Box 3067, G09 [. Co1leyre Street, Carbondale, Illinois 62401

148. Roberto F. Gardner, City of Kettering, 3600 Shroyer Road, Kettering, Ohio 45429

149-159. Mary Wolten Glass, Division of Planning and Technology Transfer, Office of Solar Energy, 600 E. St. N.W., Washington, D.C. 20585

160. Thomas Gunter, Department of Physics, University of North Carolina at Chapel Hill, Phillips Hall, O39A, Chapel Hill, North Carolina 27514

161. Loren Habegger, Building 12, Argonne National Laboratory, Argonne, Ilitinois 60439

162. Francis Hackett, Public Affairs, Pennsylvania Power and Light Company, Two North Ninth Street, Al lentown, Pennsylvania 18101

163. D. L. Hessel, Battelle, Pacific Northwest Laboratories, Battelle Boulevard, P. 0. Box 999, Richland, Washington 99352

164. William W. Hinkley, Environmental Specialist IV, Bureau of Water Management, State of Flnrida, Department of Environmental

Regulation, 2600 Blair Stone Road, Twin Towers Office Building, Tallahassee, Florida 32301 
165. Colleen Kettles, 300 SR 401, Cape Canaveral, Florida 32920

166. Francis P. Koster, 403 Power Building, Chattanooga, Tennessee 37402

167. Salim Kuldanir, 1655 Conn. Avenue, Washington, D.C. 22030

168. Dr. T. R. Lakshmanan, Chairman, Department of Geography, Boston University, 48 Cummington Street, Boston, Massachusetts 02215

169. J. C. Landrum, Director, Research and Development, Department of Natural Resources, Post Office Box 44156, Baton Rouge, Louisiana 70804

170. Donnie Laughlin, Energy Program, National Governors' Association, 444 North Capitol Street, Washington, D.C. 20001

171. Clarie E. Leslie, Science Applications, Inc., 800 Dak Ridge Turnpike, Building C, Suite 100, Oak Ridge, Tennessee 37830

172. Harvey Major, Room 220, 20 Massachusetts Avenue, U.S. D0E/CS, Washington, D.C. 20545

173. W. H. Mashburn, Mechanical Engineering Department, Virginia Tech, Blacksburg, Virginia 24061

174. Gary McGee, Room 105 - Courthouse, Watauga County, Boone, North Carolina 28607

175. Dr. Allan Mazur, Syracuse University, Department of Sociology, 500 University Place, Syracuse, New York 13210

176. C. R. Miles, City of Midland, 202 Ashman Street, Midland, Michigan 48640

177. Clara Miller, 171 E. 90th Street, Apt. 4C, New York, New York 10028

178. Robert Odland, Community \& Consumer Branch, SERI, 1617 Cole Boulevard, Golden, Colorado 80401

179. R. J. Olsen, Charles River Associates, John Hancock Tower, $200 \mathrm{Cl}$ arendon Street, Boston, Massachusetts 02116

180. John Ostrowski, City of Kent, $319 \mathrm{~S}$. Water Street, Kent, Ohio 44240

181. Barbara 0tto, U. S. DOE/Regional Energy Information Center, 2626 W. Mockingbird Lane, P. 0. Box 35228, Dallas, Texas 75235

182. Dr. Janet Patton, Department of Political Science, Eastern Kentucky Universit.y, Richmond, Kentucky 10175

183. John Pelzer, City of Kirksville, Kirksville, Missouri 63501

184. Flora M. Pletson, Energy Library, Resources for the Future, 1755 Massachusetts Avenue, N.W., Washington, D.C. 20036

185. Peter Pollock, SERI, 1617 Cole Blvd. Golden, Colorado, 80401

186. David Pomerance, Northeast Appropriate Technology Network, Inc., P. 0. Box 548, Greenfield, Massachusetts 01301

187. Princeton Planning Department, City Hall, Princeton, Illinois 61356

188-192. James Quinn, U.S. DOE, Strategy and Analysis Branch, 600 E. Street, N.W., Washington, D.C. 20585

193. Bill Rankin, U.S. DOE, Region 4, 1655 Peachtree Street, Atlanta, Georgia 30309

194. Wayne Robertson, Room 615, 270 Washington Street, S.W., Atlanta, Georgia 30334 
195. Kenneth Schafer, Department of Energy, 1000 Independence Avenue, N.W., Room 50025, Washington, D.C. 20585

196. Phillip Scharre, Tennessee Valley Authority, 146 Evans Building, Knoxville, Tennessee 37902

197. John Schuller, U.S. DOE Conservation and Solar Energy Division, 1000 Independence Avenue, Room 5G-026, Washington, D.C. 20585

198. Michael Shapiro, Department of City and Regional Planning, Gund Hal1, Harvard University, Cambridge, Massachusetts 02138

199. John M. Sharp, South Carolina Energy Research Institute, Suite 670, First National Bank Building, Columbia, South Carolina 29201

200. Walter Shouse, Graduate School of Planning, University of Tennessee, $1515 \mathrm{~W}$. Cumberland Avenue, Knoxville, Tennessee 37916

201. Philip Sieber, City of Mankato, 202 E. Jackson Street, Box 3368, Mankato, Minnesota 56001

202. Kent Spriggs, 324 W. College Avenue, Tàllahassee, Floridd 32301

203. Ken Smeltzer, Argonne National Laboratory, 9700 S. Cass Avenue, Argonne, Illinois 60439

204. St. Charles Planning Department \& Research, 200 N. 2nd Street, St. Charles, Missouri 63301

205. St. Joseph Planning Department, St. Joseph, Missourj 64501

206. States Information Center, Council of State Governments, P. 0 . Box 11910, Iron Works Pike, Lexington, Kentucky 40578

207. Marc Strohlein, BDM Corporation, 7915 Jones Branch Drive, McLean, Virginia 22102

208. TVA Law Library, Attention: Mary Frances Cox, 400 Commerce Avenue, E10C65, Knoxville, Tennessee 37902

209. Rubert F. Walker, City of Delaware, Municipal Building, Delaware, Ohio 43015

210. Robert Walle, Deputy Commissioner for Environment, Tennessee Department of Public Hcalth, 349 Cordell Hull Building. Nashville, Tennessee 37219

211. Charles Webb, 512 N. Salisbury Street, 14th Floor, Raleigh, North Carolina 27611

212. Steve Weisman, Southern Tier Central Regional Planning and Development Board, 53 Bridge Street, Corning, New York 14830

213. Jack Wilson, Acting Commissioner, Bureau of Environmental Protection, Department for Natural Resources and Envirumilental Protection, Capital Plaza Tower, 5th Floor, Frankfort, Kentucky 40601

214. F. R. Wyant, EES, \#12, Argonne National Laboratory, 9700 Cass Avenue, Argonne, Illinois 60439 